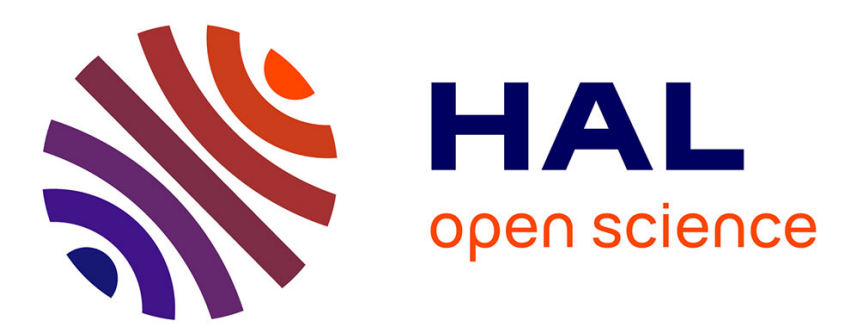

\title{
Effects of four factors on the quality of the male reproductive cycle in pikeperch "Sander lucioperca"
}

Fabrice Teletchea, Martin Pšenička, V. Kaspar, Y. Le Doré, J.N. Gardeur, Otmar Linhart, Pascal Fontaine, . Facultés Universitaires Notre-Dame de La Paix

\section{To cite this version:}

Fabrice Teletchea, Martin Pšenička, V. Kaspar, Y. Le Doré, J.N. Gardeur, et al.. Effects of four factors on the quality of the male reproductive cycle in pikeperch "Sander lucioperca". Percid Fish Culture. From research to production, Jan 2008, Namur, Belgium. hal-02757581

\section{HAL Id: hal-02757581 \\ https://hal.inrae.fr/hal-02757581}

Submitted on 4 Jun 2020

HAL is a multi-disciplinary open access archive for the deposit and dissemination of scientific research documents, whether they are published or not. The documents may come from teaching and research institutions in France or abroad, or from public or private research centers.
L'archive ouverte pluridisciplinaire HAL, est destinée au dépôt et à la diffusion de documents scientifiques de niveau recherche, publiés ou non, émanant des établissements d'enseignement et de recherche français ou étrangers, des laboratoires publics ou privés. 


\section{EDITORS}

P. Fontaine, P. Kestemont,

F. Teletchea \& N. Wang

\section{Percid Fish Culture From Research to Production}

Namur (Belgium) 23 - 24 January 2008 


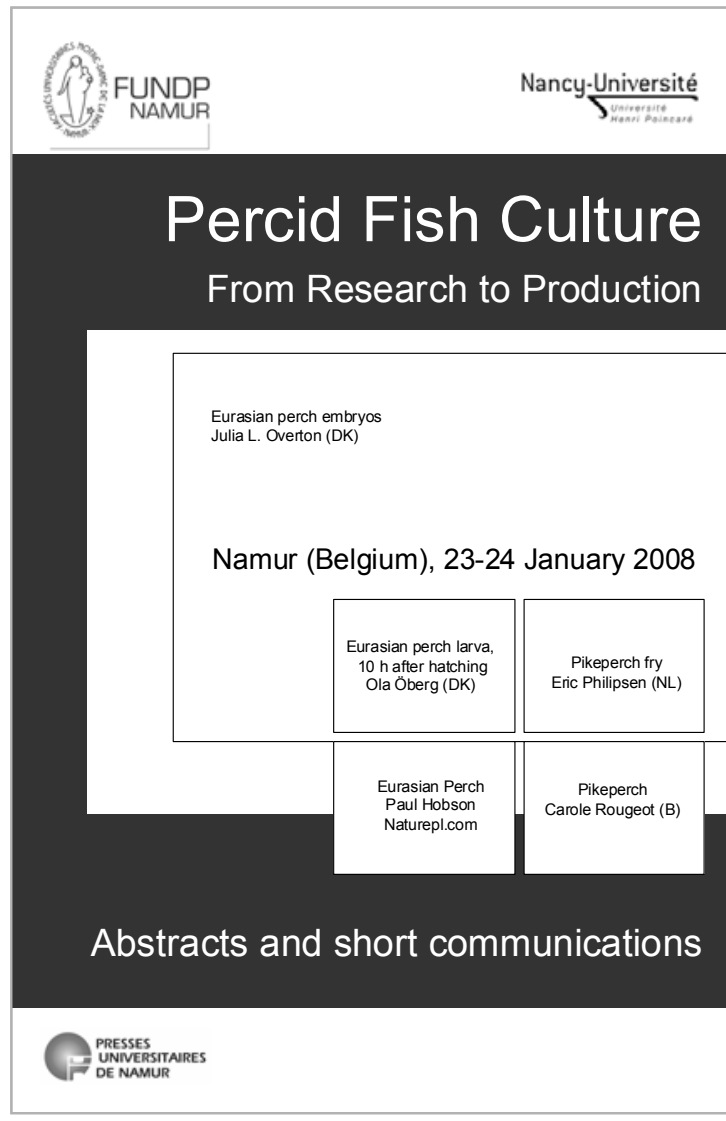

(C) Presses universitaires de Namur, 2008

Rempart de la Vierge, 13

5000 Namur (Belgique)

Tel : :+32 (0)81 724884

Fax : +32 (0) 81724912

E-mail : pun@fundp.ac.be

Site web : http://www.pun.be

Dépôt légal : D/2008/1881/11

ISBN : 978-2-87037-582-2

Imprimé en Belgique

Tous droits de reproduction, traduction, adaptation, même partielle, y compris les microfilms et les supports informatiques, réservés pour tous les pays. 


\section{STEERING COMMITTEE}

Chairmen

Prof. P. Kestemont (FUNDP, Belgium), Dr P. Fontaine (UNancy, France) \& Dr N. Wang (FUNDP, Belgium)

Members

Dr L. Watson (BIM, Ireland)

Dr C. Mélard (ULG, Belgium)

Dr C. Rougeot (ULG, Belgium)

Dr R. Mandiki (FUNDP, Belgium)

Mr Y. Mine (FUNDP, Belgium)

Prof. J. Brun-Bellut (UNancy, France)

Dr F. Teletchea (UNancy, France) 


\section{European Commission funded Projects}

\section{Securing juveniles production of Eurasian perch by improving reproduction and larval rearing}

Acronym: PERCATECH

Reference number: COOP-CT-2004-512629

\author{
University of Nancy (coordinator) \\ Lucas Perches \\ Fonden Bornholms Lakseklaekkeri \\ Earl Esox \\ Rybarstvi Nove Hradys.r.o. \\ Pds Irish Waters Perch Ltd \\ Gebr. Dil import-export b.v. \\ The University of Namur \\ University of Liège \\ Fisheries Research Institute \\ University of South Bohemia
}

\author{
France \\ France \\ Denmark \\ France \\ Czech Republic \\ Ireland \\ The Netherlands \\ Belgium \\ Belgium \\ The Netherlands \\ Czech Republic
}

Improving pikeperch larval quality and production by broodstock management and nutrition, husbandry and sex control

Acronym: LUCIOPERCIMPROVE

Reference number: COOP-CT-2005-017646

\author{
The University of Namur (coordinator) \\ Excellence Fish \\ Piscival lès Sources \\ Fish Farm Paseek \\ Nutreco Nederland \\ Viskweekcentrum Valkenswaard \\ Earl Esox \\ University of Liège \\ Fisheries Research Institute \\ University of Warmia \& Mazury \\ University of Nancy
}

\author{
Belgium \\ The Netherlands \\ France \\ Poland \\ The Netherlands \\ The Netherlands \\ France \\ Belgium \\ The Netherlands \\ Poland \\ France
}
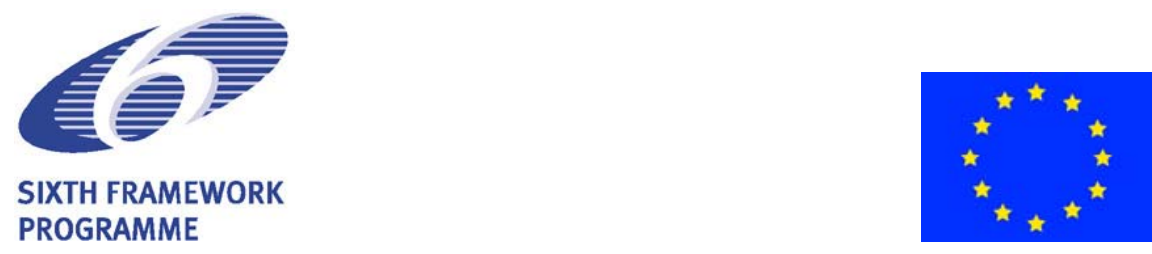


\section{Table of contents}

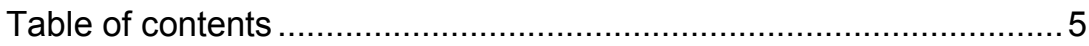

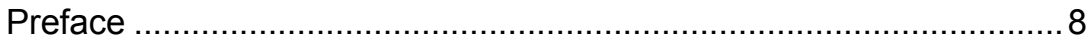

The European market for perch (Perca fluviatilis) ........................ 10

The European market of the pikeperch for human consumption ....... 15

The French Restocking market for percids ................................ 17

Recent improvements in the control of the Percid reproductive cycle 19 Sperm quality and cryopreservation in Perca fluviatilis

Feeding and nutrition of European percid broodstock and early life stages

Genetic improvement of growth in perch production: domestication, sex control, hybridization and strain selection

Bornholm Salmon hatchery: Control of Out-of-Season spawning of

Eurasian perch

Viskweekcentrum Valkenswaard : extensive vs intensive production of pikeperch juveniles.

Recent progress in feeding and nutrition of percid fishes during ongrowing

Growth and husbandry effects in percids 53

Perch culture and pathology control - Knowing your enemy..... 64

Lucasperches: Production of Eurasian perch in recirculating system 66 Excellence Fish : production of pikeperch in recirculating system ....66 67 German experiences with the intensive culture of pikeperch (Sander lucioperca L.) 68

Perch farming, Swedish experience 71

Production costs of perch and pikeperch juveniles ...................... 74

Production costs of perch and pikeperch juveniles .......................75

Overview and status of percid culture in Canada.......................... 80

Percid culture in the North central US.... .85

Effects of photothermal kinetic, photoperiod amplitude and duration on the rates of out-of-season spawning and egg fertilization in Eurasian perch Perca fluviatilis. 
Effects of husbandry and nutritional conditions on lipid metabolism of Eurasian perch, Perca fluviatilis 94 The possibilities of rearing pikeperch fry (Sander lucioperca) in recirculation systems - in different stocking densities and with different starter diets 96

Propagation of pikeperch (Sander lucioperca) - Hungarian methods and experiences 98 Two years observations of Eurasian perch (Perca fluviatilis L.) postlarvae performances in a illuminated floating cage in Lake Varese $(\mathrm{N}$ W Italy). 100

Endocrine sex control strategies of pikeperch (sander lucioperca (I.)) 102

Effect of domestication level on the physiological and immune response of chronically stress-confined Eurasian perch (Perca fluviatilis) juveniles. 104

The development of genomic tools for selective breeding of yellow perch, Perca flavescens 106

The new concept of salinity stress test for assessment of pikeperch seed quality. 108

Comparison of economic effectiveness of pikepersc summer fry production in dependence of reproduction methods

Effect of dietary phospholipid levels on the development of pikeperch larvae

Histological and biochemical analysis of reproductive system in male of Eurasian perch (Perca fluviatilis L.) during spawning and postspawning period

Artificial reproduction of pikeperch (Sander lucioperca L.) under controlled conditions.

Relationship between oocyte maturity stages in pikeperch (Sander lucioperca L.) and time of ovulation in captivity..... 118 Applications of chosen hormonal agents in pikeperch reproduction under controlled conditions - some economic aspects 
transfer of pahs by by trophic way to eurasian perch Perca fluviatilis in controlled environment 122 Induced artificial and semiartificial spawning by Supergestran IN perch (Perca fluviatilis L.) under different temperature 124

Deadhesion of the eggs of pikeperch (Sander lucioperca L.) ... 126 Developing Genetically Defined Yellow Perch (Perca flavescens) Broodstocks 128

Dry Feed Adaption and Rearing of one-year old Eurasian Perch (Perca fluviatilis) fed with dry feed with varying oil supplementation 130 The influence of environmental conditions of spawning success of pikeperch (Sander lucioperca I.). 132

Application of new spawning agents in artificial reproduction of pikeperch (Sander lucioperca I.). 134

Effects of four factors on the quality of the male reproductive cycle in pikeperch Sander lucioperca. 136

Ammonia toxicity in percids 138

Variations of the spawning quality over a spawning period in Eurasian perch Perca fluviatilis. 140

Rates of oxygen consumption and ammonia excretion of pikeperch (Sander lucioperca (I.)) reared in a water recirculation system

Slaughter value and flesh characteristics of wild and cultured pikeperch (Sander lucioperca (I.)) 


\section{Preface}

During the last five years, the aquaculture of percid fishes - namely the Eurasian perch Perca fluviatilis and the pikeperch Sander lucioperca - has gained an increasing interest in the freshwater aquaculture sector in Europe. Several new farms have been built in different European countries (e.g. Lucas Perches in France, Excellence Fish in The Netherlands, Percitech in Switzerland, Danish Pikeperch in Denmark, PDS Irish Waters in Ireland, etc.). In addition, many other projects will be operational in a very near future, with the creation of several new farms in Ireland, Sweden and Denmark. All these private initiatives augur a promising development of diversification activity for freshwater aquaculture.

Within the framework of two projects on percid fish funded by the European Commission (COOP 2004 - 512629 Percatech and COOP 2005 - 017646 Luciopercimprove), we have decided, as project coordinators, to join our efforts in order to organise a European workshop on Percid aquaculture.

This event, organized in Namur (Belgium) from the 23rd to the 25th of January 2008, aims to disseminate recent progress that has been achieved in the different aspects of percid fish technology (reproduction control, feeding and nutrition, genetic improvement, market), and has been mainly built-up for aquaculture professionals. As the workshop constitutes a major output of the two EC projects mentioned above, many speakers belonging to the consortium of Percatech or Luciopercimprove, either as RTD performers or as SMEs representatives, have been invited to present their recent achievements. The programme has been elaborated in such a way that the experience gained by the professionals, throughout their own current activities or thanks to their participation to the COOP projects, should be shared during several thematic sessions. We hope that this will be attractive to fish farmers who are already involved in this sector or to new potential investors in perch and pikeperch culture. The workshop constitutes a real opportunity for an in-depth exchange of experience between scientists and producers.

We are very grateful to the numerous scientists and professionals from many countries in Europe and abroad who have prepared interesting abstracts and/or short communications allowing the publication of this book.

Thanks also to the organizing committee of the workshop for their contribution to the preparation of this event. And last, but not least, we specially acknowledge the sponsors from different countries and sectors of activity (Irish Sea Fisheries Board BIM - Ireland, Direction Générale des Technologies, de la Recherche et de l'Energie - Région 
Wallonne - Belgium, Filière Lorraine d'Aquaculture Continentale France, Danafeed - Denmark, Nutreco - The Netherlands and DIL Import-Export - The Netherlands) for their interest to this initiative and for their valuable support in the organisation of this event.

\section{Pascal Fontaine}

Coordinator of PERCATECH

\section{Patrick Kestemont}

Coordinator of LUCIOPERCIMPROVE 


\title{
The European market for perch (Perca fluviatilis)
}

\author{
WATSON Lucy
}

Bord lascaigh Mhara (Irish Sea Fisheries Board), Crofton Road, Dunlaoghaire, Co Dublin, Ireland.

Email address: Watson@bim.ie

\section{Introduction}

Perch flesh is white with a small flake, delicate texture and mild flavour. Perch has been and continues to be an important food fish in Central Europe and Baltic Countries. According to FAO 2007 estimates, total perch production from wild capture in Europe (25 member states) in 2005 amounted to 21,492 tonnes. The majority of production is coming from Finland, Russia and Estonia with Finland producing the largest tonnage at 13,102 tonnes. Swiss landings have averaged over 400 tonnes a year however it is reported that there are diminishing returns from the lakes and the market is import dependent. Perch aquaculture is a relatively new phenomenon.

Total tonnage of farmed product produced in 2005 according to FAO 2007 statistics was 315 tonnes. The Russian Federation produced 170 tonnes of that total amount, Italy reported production of 55 tonnes, Czech Republic 18 tonnes, Romania 4 tonnes, Ukraine 68 tonnes and Macedonia <.5 tonnes. Although there are no figures provided for Switzerland, it is evident from trade contacts that some limited production exists.

\section{European fish consumption and production}

From a consumption perspective Europe has a fish deficit. The EU now imports $74 \%$ of its seafood requirements from third countries with nearly $90 \%$ of whitefsh products coming from third countries. Within the EU the main importing countries for perch of European origin are Switzerland and France and the main consumption market is Switzerland. The EU market for perch is undersupplied and Switzerland is the biggest importer.

Notwithstanding the general deficiency of accurate trade statistics which continues to exist, it is generally accepted that the main trade flows for perch are from Eastern Europe, and to a lesser extent from Northern Europe, to specific markets such as the Swiss, German and French. Swiss annual imports are estimated to be from 2,000 to 5,000 tonnes of perch fillets. Perch, or Egli is a typical dish in Swiss cuisine. Small sized fillets with skin on $(15 \mathrm{~g})$ are preferred in the Frenchspeaking part of the country, medium-sized fillets $(40 \mathrm{~g})$ in German speaking Switzerland and large sized ones (100-150g) in Lorraine. 
Perch is one of the ten most important freshwater species in Europe, the others being carp, trout, eel, Nile perch, the catfish Pangasius, tilapia, northern pike, sturgeon and pike-perch. Total finfish aquaculture production in 2006 in Europe amounted to 1,403,132 tonnes of which 420,101 tonnes or $30 \%$ was freshwater production. Rainbow trout, carp and eel are the main farmed species.

France, Germany and Italy are the leading European producers of aquaculture product with roughly $42 \%$ of the production volume and $45 \%$ of the value in the EU - 25 market.

Whereas most of the domestically produced freshwater species like carp, eel and trout are traded inside European countries, other species like Nile perch, tilapia and Pangasius are imported from non EU countries.

Table 1 European finfish aquaculture production all species. FEAP 2007.

\begin{tabular}{|c|c|c|c|c|c|c|c|c|}
\hline GROUP & 1999 & 2000 & 2001 & 2002 & 2003 & 2004 & 2005 & 2006 \\
\hline Carp & 75,429 & 79,300 & 77,664 & 72,743 & 73,265 & 73,039 & 73,327 & 72,490 \\
\hline Catfish & 3,359 & 4,490 & 4,071 & 3,756 & 5,458 & 5,510 & 6,434 & 6,295 \\
\hline Eels & 11,109 & 11,094 & 10,282 & 8,993 & 8,679 & 8,268 & 8,805 & 7,790 \\
\hline Flatfish & 3,969 & 5,007 & 5,029 & 5,730 & 6,004 & 7,035 & 7,464 & 8,730 \\
\hline $\begin{array}{l}\text { Other } \\
\text { Freshwater } \\
\text { fish }\end{array}$ & 619 & 595 & 420 & 496 & 528 & 481 & 539 & 350 \\
\hline $\begin{array}{l}\text { Other } \\
\text { Marine fish }\end{array}$ & 4,989 & 6,109 & 10,103 & 9,071 & 9,655 & 15,203 & 16,781 & 18,310 \\
\hline Salmon & 591,068 & 611,013 & 640,825 & 671,695 & 756,770 & 716,994 & 748,978 & 763,395 \\
\hline Sea Bass & 45,957 & 57,811 & 56,162 & 61,093 & 62,060 & 68,679 & 82,706 & 88,531 \\
\hline Sea Bream & 58,831 & 73,232 & 77,003 & 79,767 & 88,340 & 88,922 & 99,265 & 104,065 \\
\hline Sturgeon & 543 & 265 & 195 & 200 & 230 & 275 & 332 & 65 \\
\hline Tilapia & 200 & 150 & 150 & 150 & 450 & 450 & 700 & 750 \\
\hline Trout & 333,509 & 343,243 & 359,513 & 374,350 & 350,863 & 340,453 & 326,808 & 332,361 \\
\hline Grand Total & $1,129,582$ & $1,192,308$ & $1,241,417$ & $1,288,044$ & $1,362,302$ & $1,325,308$ & $1,372,138$ & $1,403,132$ \\
\hline
\end{tabular}

\section{Species matrix}

In order to understand the positions of single freshwater species within the overall European market place, a BCG matrix and SWOT analysis was developed by Tribiloustova (2005). A BCG matrix is a growth share matrix, developed in the early 1970s by the Boston Consulting Group. The vertical dimension is the growth rate of the market which is used by the BCG as a proxy variable for market attractiveness. High growth markets assumed to be more attractive because, market share 
gains in a growth market will be worth more in the future as the market develops. The horizontal dimension is relative market share which is used as a proxy for relative competitive strength, displaying in Tribiloustova's (2005) example, the available quantities / supply of the species which takes into account therefore the possible revenue generation of the species.

Briefly, 'cash cows' are products with high market share operating in low growth markets, because they have a high market share, profitability should be good. Trout and carp are the 'cash cow' products on the European freshwater fish market.

A 'star' is a market leader in a high growth market, in the future they will become the 'cash cows'. 'Stars' must have sales that continue to grow at a high rate in order to maintain their market position. African Nile Perch and Vietnamese Pangasius catfish are the examples of 'star'products in the EU freshwater fish market. 'Question marks' are products with low market share in high growth markets. They have high cash requirements because of their weak positions in resource hungry markets. Tilapia is an example of a question mark product. 'Dogs' have low market shares in low - growth markets. In this analysis the products are typically supplying niche markets that are relatively stable in their requirements. Perch, northern pike, pikeperch and sturgeon are given as examples of these products.

This simple exercise allows the positioning of products using a common system. In this particular analysis, the four species, perch, pike, pike-perch and sturgeon occupy a relatively exclusive position in the marketplace. Their markets are traditional and established in the main in countries where the fish are produced, except for perch which is traded internationally.

The species suffer from irregular supply in that the overriding supply of production comes from landings, except for sturgeon, and therein lies the opportunity for aquaculturalists.

The threat to this section of the marketplace is a decline in wild catches without the corresponding increase in farmed supply to make up the shortfall. 


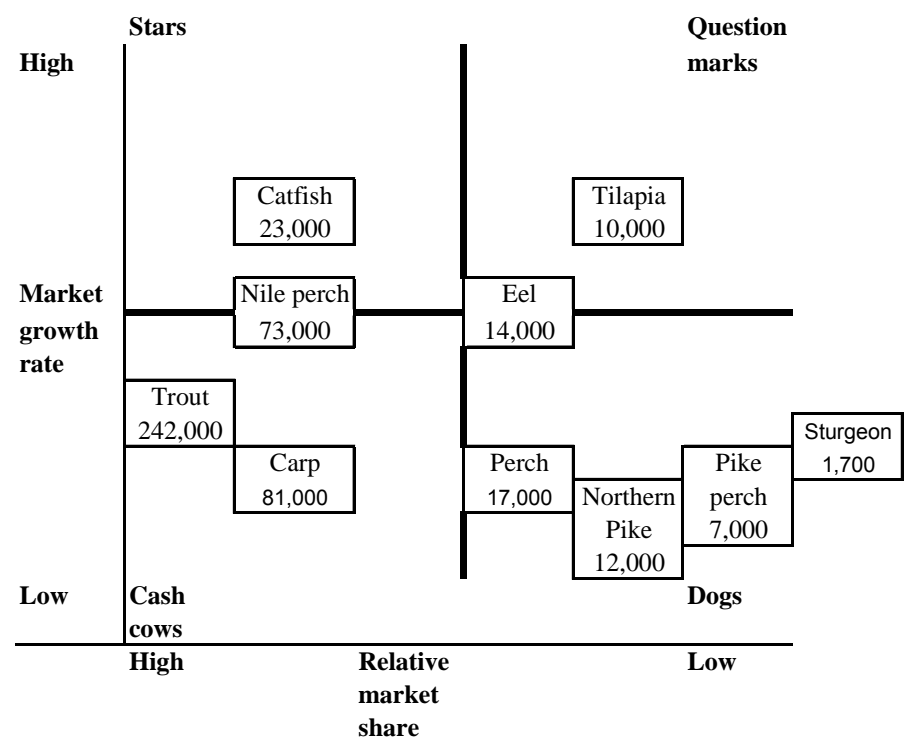

Figure 1 BCG matrix applied to the freshwater fish species (2003 volumes figures given in tonnes) on the EU market (taken from Tribiloustova 2005).

\section{Perch market and price analysis}

Compared to other fish species, perch markets are poorly documented. The main trade to the markets is in fresh or frozen fillet form from Eastern Europe and to a lesser extent Northern Europe. There is also trade in whole form from origins such as the Russian Federation to EU-certified operators in Estonia and Poland for subsequent shipment in fillet form to western markets. The Netherlands also plays a role in grouping fresh supplies from Scandinavia and eastern regions for re-export to the Swiss market. From contacts, it is likely that the estimated fillet market in Switzerland is now 6,000 tonnes.

The reference in quality, particularly at the upper end is that of perch from Lake Geneva. The estimated market size for perch fillets in Germany is put at 2,000 tonnes, in France 1,500 tonnes and in Austria at 500 tonnes. Markets are described as stable due to supply constraints.

The Swiss market is reported as having the capacity to expand and the German market could also absorb increased volumes. The price analysis for perch is complex. Taking Switzerland as an example there are a range of origins, qualities and specifications for the Swiss perch market. The market price of perch varies considerably and reported ex-farm price per tonne also act to skew the reality of the economics of production. FAO 2007 statistics, when calculated for total tonnage 
produced and total value realised, quote a $€$ /tonne production value of $€ 2,083 /$ tonne in 2005 up from $€ 1,499 /$ tonne in 2004. FEAP statistics most recent figure is 2004 which show an ex farm price of $€ 1,950 /$ tonne.

These figures are representative of total production and total value and must be interpreted as such. Market price in Switzerland, the main market, is dependent on origin, quality and specification.

Table 2 Switzerland. Value chain for Perch fillets $(€ / \mathrm{kg}) 2002$

\begin{tabular}{|l|l|l|}
\hline & chilled & Frozen \\
\hline Importer prices. & $11-13.50$ & $9-11$ \\
& & $8.80-10.90$ \\
\hline $\begin{array}{l}\text { Wholesale/retail group } \\
\text { buying prices. }\end{array}$ & $12-15$ & $9.50-11.50$ \\
\hline Wholesale selling prices. & 18.50 & \\
\hline Retail selling prices. & $23-44$ & $29-74$ \\
\hline
\end{tabular}

\section{Conclusion}

Accurate data on perch in the European market place is difficult to find. Wild fish landings constitute the main supply into the markets. Aquaculture production has an opportunity to capitalise on supplying the market with good quality product on a year round basis. Wild landings suffer from poor quality and seasonal supply.

Perch, as defined by the BCG matrix, is a stable product supplying a niche market. It is a low growth market and has a small market share. Notwithstanding this, the consumer, as evidenced by the high prices paid in the markets, is happy to pay top prices for this delicacy.

\section{$\underline{\text { References }}$}

Doyle P., 1994. Marketing Management and Strategy. Prentice Hall, 49pp.

O' Sullivan G., Lee T., 2002. European Market for Perch. BIM unpublished.

Rudiger J., 1998. The Markets for Freshwater Fish. Globefish 49, $56 \mathrm{pp}$.

Tribiloustova E., 2005. Freshwater Fish for European Markets. Globefish 81, 124pp. 


\section{The European market of the pikeperch for human consumption}

DIL Hein, Gebr. Dil Import - Export b.v., Postbus 25, 1920 AA

Akersloot, The Netherlands

\section{A survey in $2002-2003$}

A survey (2002-2003) done between the main wholesale dealers (Boulogne/Mer, Paris, Brussels, Strasbourg) has shown that they are interested in the product farmed pikeperch. It seems that the market will be mostly interested in the size $2 / 4 \mathrm{~kg}$ per piece. This is the size that is ideal for restaurants and it fetches a higher price than the sizes $700 / 1000$ and $1 / 2$. Wholesale-prices varied from 5-8 euros per $\mathrm{kg}$ for $1 / 2$ piece and from 6-9 euros for the 2/4. The demand for pikeperch of good quality remains high due to limited catches from the ljssellake in Holland. In terms of market, the most important country is France.

The advantages of farmed pikeperch are: (i) a higher quality because it can be fresher than wild pikeperch, (ii) a better determination of the periods of sales, for instance at Christmas, Eastern and other holidays, (iii) a better yield in filleting because there will not be food (smelt, roach, bream...) in stomach and gut, and (iv) for supermarket chains to develop special periods of sales (promotions). It is important to know that the quantity of wild pikeperch fillets from Eastern countries such as Estonia, Lettonia, Russia and Poland is huge. The market for fresh whole pikeperch is different: price level remained good in 2002-2003.

Because of the big quantities of farmed salmon, trout, bass and bream, some wholesalers are suspicious. They are afraid that the fish will be too small. Wild fish lasts longer in general. Therefore they mentioned to complete the farming with food similar to what the wild pikeperch eats. This is to prevent oily taste or soft fillets.

Another danger is the price level. In October 2002, the prices of wild pikeperch dropped enormously due to overfishing and a bad market situation. Imports from eastern countries were huge. Only, the price of the pikeperch 2/4 remained stable.

For marketing farmed pikeperch it may be requested to have a special mark on each fish or box which indicates the speciality of the pikeperch. Thus, it is easy to recognise the farmed ones to the wild ones. As soon as there will be a good quantity of $2 / 4$ pikeperch available, samples have to be distributed to the wholesalers all over Europe. A thorough investigation will have to be made after that in order to get all the results from restaurants, dealers and supermarkets. 
Farmed products can be very tasteful and good, but it is very important not to forget what the market really wants: good texture (size 2/4), firmness (freshness), shelflife (good marketing) and fair price (economic farming).

The European commission has a strategy for saving wild sea fish and development of aquaculture. The fisherman who lost their jobs could work now in the boosting fish farming.

\section{A survey in 2007}

Catches of wild pikeperch are decreasing worldwide, especially in Estonia where catches have fallen dramatically due to overfishing. In Europe, the major countries for pikeperch business are France (whole fish), Germany (Gutted fish) and Switzerland (fillets). The market keeps asking for the size 2/4. It must be noted here that this size is almost never reached with farming. Farming takes place in Holland (2 farms) and Denmark (2 farms).

In the months September and October prices for wild pikeperch were about 6 euros for the whole fish size $1 / 2$ and 4 euros for the size $700 / 1000$. Prices for $2 / 4$ reached the level of about 9 euros. At the end of October the fishing was stopped in Holland at the ljssellake because the price fell under 3 euros. These price fluctuations are of high influence on the economic results of farming pikeperch. To avoid low prices in future it is important to promote the product farmed pikeperch. 


\title{
The French restocking market for percids
}

\author{
TAMAZOUZT Lakhdar \\ Piscival-lés-sources, route de Vaux, 54400 Cosnes et Romain, France
}

Using phoning contacts over the year 2007, a survey has been down among almost French fish farmers, traders and fisheries managers concerned by inland aquaculture. The French production of Percid fish concerns 3 regions (Dombes, Lorraine, Brenne) whish ensure more than $50 \%$ of the total production.

\section{Pikeperch}

This species is considered as an indigenous species in France (first introduction in 1888), but not in Swiss where the restocking activity is forbidden (non indigenous species). In Luxembourg, for similar reason, the restocking level is limited to 3 lakes, closed areas (2.000 fish per year corresponding to $200 \mathrm{~kg}$ per year). In Belgium, his introduction is limited in public areas due to sanitary fears (bucephalose?).

In terms of production, the restocking market is supplied by pond productions using a semi-controlled reproduction method (natural reproduction with nests). The French production of pikeperch larvae is estimated between 3 and 4 millions of larvae per year (less than 10 hatcheries). The Dombes Region is the major French area for pikeperch production, this production seems highly related to the use of Pseudorasbora parva as main forage fish. They can production 2+ fish weighing $800-1000 \mathrm{~g}$, such mean weight needs 3 summers in Lorraine. The mean weight of 1+ pikeperch varies between 30-100 g in Lorraine, 60-150 g in Brenne and 100-250 g in Dombes. Pikeperch production seems inversely correlated to perch production. Perch and pikeperch mortalities are sometimes observed in ponds when temperature is above $30^{\circ} \mathrm{C}$. In France, besides pond culture, some trials have been done by 3 professional fishermen to catch pikeperch from lakes (Camargue, Rhin and Seine rivers) for the restocking markets but without success. Also, importation ( 7 tons for pikeperch and 10 tons for perch) from Czech Republic, Slovakia, Poland and Hungary exist, the success of the introductions in natural habitats seems very doubtful (problems related to transport conditions and changes in water quality).

\section{Eurasian perch}

This species is very appreciated for fishing. His interest for the restocking market only concerns fishes of a higher weight than $100 \mathrm{~g}$. yearling juveniles are frequently used as forage for other piscivorous species (pike mainly). 


\begin{tabular}{|l|l|l|l|l|}
\hline & Dombes & Lorraine & Brenne & $\begin{array}{l}\text { Total in } \\
\text { France }\end{array}$ \\
\hline Pond surface (ha) & 12.000 & 7.000 & 7.000 & 112.000 \\
\hline $\begin{array}{l}\text { Farmed surface } \\
\text { (ha) }\end{array}$ & $7.000^{*}$ & 5.000 & $6.000^{* *}$ & 68.000 \\
\hline Nbre of anglers & 18.300 & 54.200 & 9.400 & 1.200 .000 \\
\hline $\begin{array}{l}\text { Pikeperch } \\
\text { production (b.w. }> \\
100 \text { g) in tons }\end{array}$ & 14 & 12 & 8 & 54 \\
\hline $\begin{array}{l}\text { Perch production } \\
\text { (b.w. > 80 g) in } \\
\text { tons }\end{array}$ & 8 & 18 & 12 & 70 \\
\hline * only Ain Department, ** : only Indre Department, *** : Le pécheur
\end{tabular}

* : only Ain Department, ${ }^{* *}$ : only Indre Department, ${ }^{* * *}$ : Le pécheur de France, May 2007

\section{$\underline{\text { Perspectives }}$}

Whereas the number of anglers highly decreases in France (minus $30 \%$ over 10 years and minus 5\% between 2006 and 2007), the number of anglers concerned by piscivorous species increases, especially for pikeperch. All person surveyed estimate that an increase of their production in perch and pikeperch by two or three is possible without problem for commercialization. That means that the potential French market for both species can be estimated to 100-150 tons per year. The development of these productions will be real if the price will remain high (see table). For pikeperch, as it seems that this species consumes more forage than pike (9 euros per kilo), the price difference between these two species must be maintained. The pikeperch price increase progressively these last 5 years until 20 euros per kilo.

\begin{tabular}{|l|l|l|l|}
\hline & $\begin{array}{l}\text { One thousand } \\
\text { larvae }\end{array}$ & $1+$ fish & adulte \\
\hline Perch & 8-10 euros & 3-4 euros $/ \mathrm{kg}$ & $5-8$ euros $/ \mathrm{kg}$ \\
\hline Pikeperch & $11-14$ euros & $1.5-2$ euros $/ \mathrm{kg}$ & $13-16$ euros $/ \mathrm{kg}$ \\
\hline
\end{tabular}

\section{$\underline{\text { Mains problems }}$}

For fish farmers, the main problems to develop Percid production for the restocking markets are (i) high variability in production performances from one year to another one, (ii) the fish size at the 1+ stage (juvenile pikeperch sizing more than $12 \mathrm{~cm}$ show higher survival over winter period), (iii) the sensibility to transport and handling, and (iv) the impact of predator birds like cormorant. 


\title{
Recent improvements in the control of the Percid reproductive cycle
}

\author{
JANSEN H. ${ }^{1}$ and FONTAINE P. ${ }^{2^{*}}$ \\ ${ }^{1}$ Institute for Marine Research and Ecosystem Studies (Wageningen \\ IMARES), Haringkade 1, 1970 AB, ljmuiden, The Netherlands \\ ${ }^{2}$ Unité de Recherche Animal et Fonctionnalités des Produits Animaux, \\ Nancy Université - INRA, MAN, 34 rue Sainte Catherine, 54000 \\ Nancy, France \\ * Corresponding author. Tel.: +33 383308447 \\ E-mail address: pascal.fontaine@Isa-man.uhp-nancy.fr

\section{Introduction}

The production of perch and pikeperch juveniles is currently insufficient to sustain the planned production of market sized Eurasian perch and pikeperch. The low availability of weaned juveniles of both species corresponds to the major bottleneck for the development of the production in Europe. In addition, the low numbers of larvae currently produced do not allow selection of the best quality larvae for further production which often results in high levels of deformities (scoliosis, lordosis, jaw malformation...) (Kestemont et al., 2007). The major objective of both the Percatech (2004-2006) and the Luciopercimprove (2005-2007) CRAFT project was to improve the control of the reproductive cycle of both species in order to increase the juvenile availability for fish farmers. Control of the reproductive cycle allows delayed/advanced production (extension of the natural spawning period) or out-of-season spawning (outside the natural spawning period). In this perspective, environmental determinism (mainly photoperiod and temperature variations) of reproductive cycles has been specified and methods for spawning synchronization have been tested. The major results obtained in the framework of these projects are presented below.

\section{Control of the reproductive cycle}

\section{Eurasian perch}

Before the start of the Percatech project, previous work have demonstrated the roles of the seasonal photoperiod variations (Migaud et al., 2004a) and the timing, i.e. application of a photoperiod decrease before a decrease of water temperature (Wang et al., 2006) on the induction of gonadogenesis in males and females. It was also proved that an increase of photoperiod during the pre-inductive period (before the application of a photo-thermal program) and the lack of photoperiod (continuous lighting) inhibit the induction of a reproductive 
cycle (Migaud et al., 2003; Fontaine et al., 2006). During an entire and natural reproductive cycle (10 months), the effects of different photoperiod regimes on the reproductive performances (spawning rates, fertilization rate, larvae quality) were evaluated (Migaud et al., 2003, 2006). Under natural NP and simulated natural SNP photoperiods (SNP: with abrupt switches between photophase and scotophase, no simulation of dawn and dusk periods), percentages of spermiating males $(100 \%)$ and gravid females $(90-100 \%)$, female fecundity (120-130 eggs/g fish), and eggs size (2 mm) and weight (3.4-3.6 mg) were similar. However, significant higher spawning rates ( 85 vs $55 \%$ ) and fertilization rates (57 vs $7 \%$ ) were recorded by natural lighting. Thus, daily variations in lighting (light intensity) seem important for the spawning behavior. It was also observed that lighting conditions distant to natural conditions is associated to delayed spawning (Migaud et al., 2006).

In a complementary experiment, it was also observed that a long cooling duration, 5 months at $6^{\circ} \mathrm{C}$ (simulation of winter period) is necessary for the gonadogenesis process in females (Migaud et al., 2002). Despite the increasing knowledge on the reproduction biology in Eurasian perch, trials for inducing out-of-season spawning were associated with mediocre results in terms on spawning rate, eggs and larvae quality (Migaud et al., 2004b).

Based on a synthesis of these data, various protocols with different kinetics for initial temperature and photoperiod decreases (over 6 or 16 weeks) and different amplitudes for photoperiod decrease were evaluated. It was shown that a high amplitude in photoperiod reduction (4 or 8 hours) was associated to a high response level in both females and males (100\%) and to a normal gonadogenesis in females (compared to a natural reproductive cycle) (Abdulfatah et al., 2007). The thermo-photoperiodic kinetics applied didn't shown significant differences. Finally, after an increase of the water temperature from 6 to $14^{\circ} \mathrm{C}$ over 4 weeks, out-of-season spawning was obtained in November-December 2006 (spawning rate: 100\%). In Eastern France, natural spawning occurs in April. Females did spawn naturally without hormonal induction. Thus, a reliable protocol for inducing out-of-season spawning in Eurasian perch is now available for fish farmers.

\section{Pikeperch}

The elucidation of mechanism that governs reproduction in pikeperch requires a basic understanding of the gonadal and hormonal changes which occur during the productive cycle. The annual cycle of sex steroids has been established for related species such as Eurasian perch (Sulistyo et al. 1998; Sulistyo et al. 2000) and walleye (Malison et al., 1994) but not for pikeperch. Therefore an experiment was conducted in order to gain knowledge on the reproductive cycle and reproduction performance in pikeperch (Jansen et al., in preparation). Wild pikeperch breeders are most often used in pikeperch culture but 
in view of safe and controlled reproduction and breeding, it is of major importance to be capable of using own produced and reared offspring (F1) as broodstock. Since F1 broodstocks are expected to be least successful in reproduction, we assessed reproduction parameters of both wild and captive (F1) breeders. In total four groups were established: i) F1 breeders reared in an intensive recirculation system ii) F1 breeders extensively reared in a pond iii) wild breeders extensively reared in a pond and iv) wild breeders originating from fisheries. At monthly intervals GSI, sex steroid levels and gonad development were determined. Based on these results it can be concluded that neither fish origin nor production environment negatively affects the reproductive cycle. At the end of the reproductive cycle reproduction performance (fecundity and sperm quality) was determined for the first three groups. Since no lack of reproduction performance was observed for intensively reared F1 breeders (i), intensive (re)production of pikeperch seems feasible, without loss of reproduction performance and thus provides a strong perspective for intensive aquaculture of this species.

As photoperiod and temperature are generally considered as the most important cues in gametogenesis and spawning (Migaud et al., 2002) a photo-thermal protocol was applied in order to induce out-of-season reproduction in pikeperch. The protocol consisted of four successive periods; ongrowing stage, cooling down, cold period and reproduction phase. The aim of this study was to test the effects of different thermal regimes (lowest temperature of $8,10,13^{\circ} \mathrm{C}$ ) and different duration of winter periods (100 and 135 days) on reproduction performance in cultivated (F1) pikeperch. For all treatments gametogenesis was observed in at least a fraction of breeders. Those trials for inducing out-of-season spawning in cultured pikeperch were, however, associated with mediocre results in terms of spawning and fertilization rates.

\section{Conclusion}

The environmental determinism of the reproductive cycle in percid is now better understood, especially in Eurasian perch. A reliable protocol is now available for fish farmer for producing out-of-season spawning. However, further research is necessary to improve the gamete and larvae quality. That means a better understanding of all modulating factors such as nutritional and populational parameters.

\section{$\underline{\text { References }}$}

Abdulfatah A., Fontaine P., Marie M., 2007. Effects of photoperiod and temperature kinetics on the induction of the reproductive cycle in Eurasian perch. 8th International Symposium on Reproductive Physiology of Fish, June 3-8, St-Malo, France. 
Fontaine P., Pereira C., Wang N., Marie M., 2006. Influence of preinductive photoperiod variations on Eurasian perch Perca fluviatilis broodstock response to an inductive photothermal program. Aquaculture 255, 410-416.

Kestemont P., Xu X., Hamza N., Maboudou J., Imourou Toko I., 2007. Effect of weaning age and diet on pikeperch larviculture. Aquaculture 264, 197-204.

Malison, J.A., Procarione, L.S., Barry, T.P., Kapuscinski, A.R. \& Kayes, T.B., 1994. Endocrine and gonadal changes during the annual reproductive-cycle of the fresh-water teleost, stizostedion-vitreum. Fish physiology and biochemistry 13 (6), 473-484.

Migaud H., Fontaine P., Sulistyo I., Kestemont P., Gardeur J.N., 2002. Induction of out-of-season spawning in Eurasian perch Perca fluviatilis : effects of rates of cooling and cooling durations on female gametogenesis and spawning. Aquaculture 205, 253-267.

Migaud H., Mandiki R., Gardeur J.N., Kestemont P., Bromage N., Fontaine P., 2003. Influence of photoperiod regimes on the Eurasian perch gonadogenesis, spawning and eggs and larvae quality. Fish Physiol. Biochem. 28, 395-397.

Migaud H., Fontaine P., Kestemont P., Wang N., Brun-Bellut J., 2004a. Influence of photoperiod on the onset of gonadogenesis in Eurasian perch Perca fluviatilis. Aquaculture 241, 561-574.

Migaud H., Gardeur J.N., Kestemont P., Fontaine P., 2004b. Offseason spawning of Eurasian perch Perca fluviatilis. Aquaculture Int. $12,87-102$.

Migaud H., Wang N., Gardeur J.N., Fontaine P., 2006. Influence of photoperiod on reproductice performances in Eurasian perch Perca fluviatilis. Aquaculture 252, 385-393.

Sulistyo, I., Rinchard, J., Fontaine, P., Grandeur, J.N., Capdeville, B. \& Kestemont, P., 1998. Reproductive cycle and plasma levels of sex steroids in female Eurasian perch Perca fluviatilis. Aquat. Living Resour./Ressour. Vivantes Aquat 11 (2), 101-110.

Sulistyo, I., Fontaine, P., Rinchard, J., Gardeur, J.-N., Migaud, H., Capdeville, B. \& Kestemont, P., 2000. Reproductive cycle and plasma levels of steroids in male Eurasian perch Perca fluviatilis. Aquatic Living Resources 13, 99-106.

Wang N., Gardeur J.N., Henrotte E., Marie M., Kestemont P., Fontaine P., 2006. Determinism of the induction of the reproductive cycle in female Eurasian Perch, Perca fluviatilis : effects of environmental cues and modulating factors. Aquaculture 261, 706714. 


\title{
Sperm quality and cryopreservation in Perca fluviatilis
}

\author{
LINHART Otomar ${ }^{1 *}$, ALAVI Hadi S.M. ${ }^{1}$, RODINA Marek ${ }^{1}$, POLICAR \\ Tomas $^{1}$, PSENICKA Martin ${ }^{1}$ and ROUGEOT Carole ${ }^{2}$ \\ ${ }^{1}$ University of South Bohemia, Research Institute of Fish Culture and \\ Hydrobiology, \\ 38925 Vodnany, Czech Republic \\ ${ }^{2}$ University of Liege, Aquaculture research and Education Center, B- \\ 4500 Tihange, Belgium \\ ${ }^{*}$ Corresponding author. Tel.: +420 724357897 \\ E-mail address: linhart@vurh.jcu.cz (O. Linhart)
}

\section{Introduction}

Spermatozoa of freshwater fishes are immotile in the testis and acquire the potential for motility during transfer from the testis to the sperm duct. The motility of spermatozoa is prevented due to high osmolality of the seminal plasma. The motility of sperm would be triggered due to hypo-osmotic pressure of the activation medium (Alavi et al., 2007a).

Cryopreservation of sperm is considered as a valuable technique for developing the artificial reproduction, for maintaining genetic variability of fish broodstock with highly reduced hazardous transmission of diseases or infections and for biological conservation programmes (Wildt, 1997; Lubzens et al., 1993). Perch sperm cryopreservation can be applied in aquaculture neither for efficient utilization of sperm in highly valuable prized males after genomic manipulations or for wideranging artificial propagation (Rodina et al., 2007).

Little is known regarding sperm of European perch (Lahnsteiner et al., 1995; Rougeot et al., 2004; Krol et al., 2006). However, there is a lack for better understanding of factors triggering and regulating motility of sperm, the motility differences between stripped and testicular sperm and cryopreservation of the spermatozoa.

In the present study we tried (a) to characterize biological aspects of sperm, (b) to study the factors affecting sperm motility, (c) to determine the differences between stripped and testicular sperm motility parameters, and (e) to compare motility and fertilizing ability of frozen-thawed spermatozoa between neomales and normal males.

\section{Biological parameters of the spermatozoa}

Perch spermatozoa can be easily collected without hormonal treatment by pressure on abdomen and using a syringe. Sperm volume and density were measured in range between 0.5 to $7 \mathrm{ml}$ and 3.5 to $44 \times 109$ sperm ml-1, respectively. 
The means of osmolality and sodium, chloride, potassium and calcium ions concentrations were measured to be 298.1 mOsmol Kg-1, 131.0, $106.8,10.7$ and $2.4 \mathrm{mM}$ in the seminal plasma, respectively. At $15 \mathrm{sec}$ post activation, motility rate $(\%)$ and velocity $(\mu \mathrm{m} \mathrm{s}-1)$ of spermatozoa were $91.90 \pm 1.27$ and $115.54 \pm 1.25$, respectively and decreased significantly following sperm activation (Alavi et al., 2007c).

\section{Factors affecting sperm motility}

The motility of sperm is induced by hypo-osmotic pressure in fresh water. The optimal sperm motility was observed when the sperm was first diluted in immobilizing solution containing $\mathrm{NaCl} 200 \mathrm{mM}$, $\mathrm{NaHCO} 32.38 \mathrm{mM}$ (osmolality $380 \mathrm{mOsmol} \mathrm{Kg-1}$ ) in a ratio 1:50.

Then, the maximum sperm velocity was observed after dilution in an activation solution containing $2.5 \mathrm{mM} \mathrm{Ca}+, 50 \mathrm{mM} \mathrm{K}+$ and sucrose with osmolality $100 \mathrm{mOsmol} \mathrm{Kg}-1$. The osmolality more than 300 mOsmol Kg-1 or above suppressed totally sperm motility (Fig. 1) (Alavi et al., 2007c). Symmetric flagellar pattern was observed during motility of spermatozoa either in low or high osmolality of the activation medium (Fig. 2).

In a medium containing $20 \mathrm{mM} \mathrm{K+}$, sperm velocity and the percentage of motility were higher in stripped sperm compared to testicular sperm. Medium with Osmolality of $100 \mathrm{mOsmol} \mathrm{Kg-1}$ showed a significant effect on velocity of stripped sperm (Alavi et al., 2007b).

\section{Cryopreservation of sperm}

Testicular sperm of neomales (TSN) was used because of necessity to confirm the original of sex (XX) according to gonad morphology. Gonads of 7 neomales (body weight $30-50 \mathrm{~g}$ ) were cut into pieces, squeezed through a nylon mesh, pooled and kept on ice $\left(0^{\circ} \mathrm{C}\right)$.

As control, stripped sperm of normal males (SSNM) was also pooled and stored at $2-4^{\circ} \mathrm{C}$. Both TSN and SSNM were diluted with $300 \mathrm{mM}$ glucose solution at dilution ratio 1: 6 . DMSO was added as a cryoprotectant in final concentration $10 \%$. Diluted sperm was added into $0.5 \mathrm{ml}$ straws and frozen in a Styrofoam box $(3 \mathrm{~cm}$ above the $\mathrm{N} 2$ level) for $10 \mathrm{~min}$ and then transferred into N2. Frozen sperm was thawed at $40{ }^{\circ} \mathrm{C}$ water bath for $8 \mathrm{sec}$. 

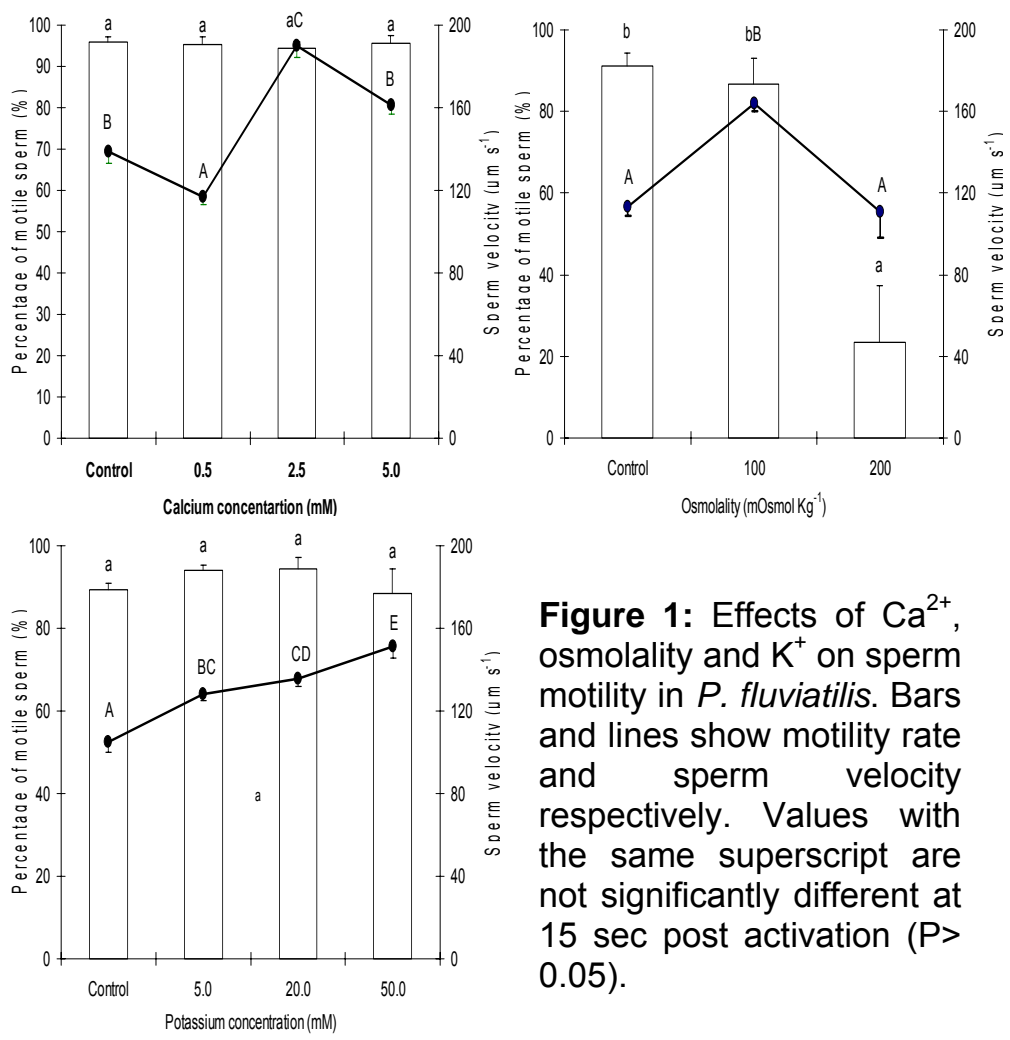

Figure 1: Effects of $\mathrm{Ca}^{2+}$, osmolality and $\mathrm{K}^{+}$on sperm motility in $P$. fluviatilis. Bars and lines show motility rate and sperm velocity respectively. Values with the same superscript are not significantly different at $15 \mathrm{sec}$ post activation ( $\mathrm{P}>$ 0.05).
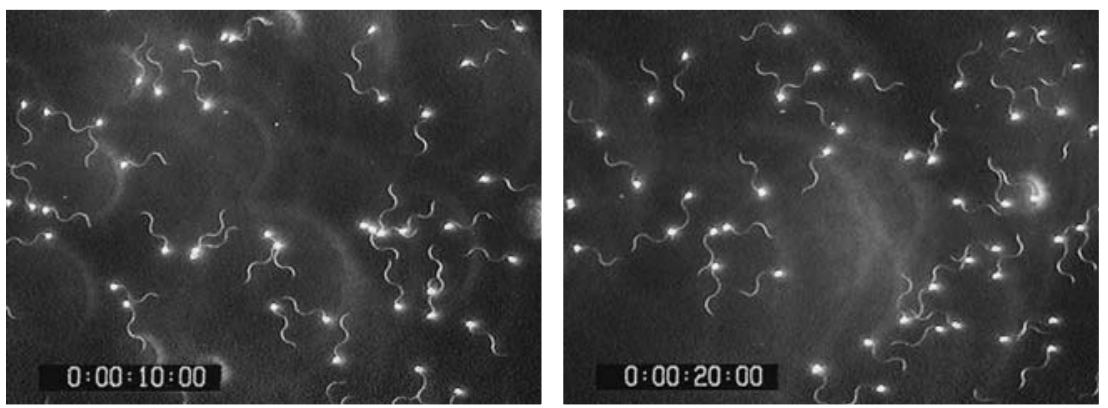

Figure 2: Fig. 1 Motility of sperm after activation in medium at 100 mOsmol Kg ${ }^{-1}$ at 10, 20 and $40 \mathrm{sec}$ post activation. Sperm shows symmetric flagellar pattern during movement.

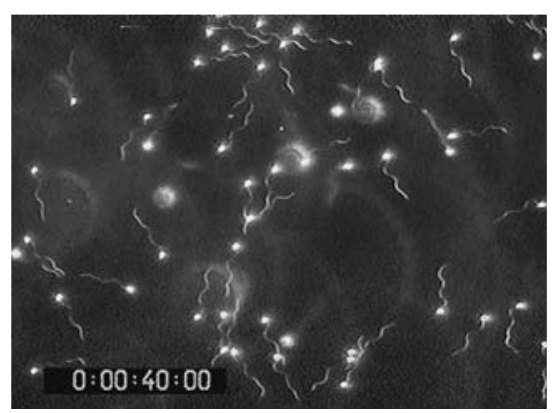

Every sample was used for eggs of 4 females as followed: $1 \mathrm{~g}$ eggs $(451)+12 \times 105$ and/or $2.4 \times 105$ TSN/SSNM per egg $+1 \mathrm{ml}$ hatchery 
water, stirring on a shaking table for $1 \mathrm{~min}$. Fertilized eggs were incubated and hatching rates estimated from $1 \mathrm{~g}$ of eggs per box.

Sperm concentration of the fresh TSN and the SSNM were estimated $45.3 \times 109$ and $37.8 \times 109$ spematozoa per $\mathrm{ml}$. Both sperm velocity and motility showed a significant decrease in the TSN $(134.6 \mu \mathrm{m} \mathrm{s}-1$ and $12.8 \%)$ compared to the SSNM (203.2 $\mu \mathrm{ms}-1$ and $94.7 \%)$ at $10 \mathrm{sec}$ post sperm activation. Similar no different hatching rate of fresh TSN and SSNM were 42.5 and $49.3 \%$ at $12 \times 105$ spermatozoa per egg, respectively.

Frozen/thawed SSNM exhibited similar hatching rates at $12 \times 105$ and $2.4 \times 105$ spermatozoa per egg ( $37.2 \%$ vs. $29.1 \%)$. Hatching rate of the frozen/thawed TSN was $7.3 \%$ with $12 \times 105$ spermatozoa per egg and did not show any difference with $2.4 \times 105$ spermatozoa per egg $(6.6 \%)$ (Fig. 3)

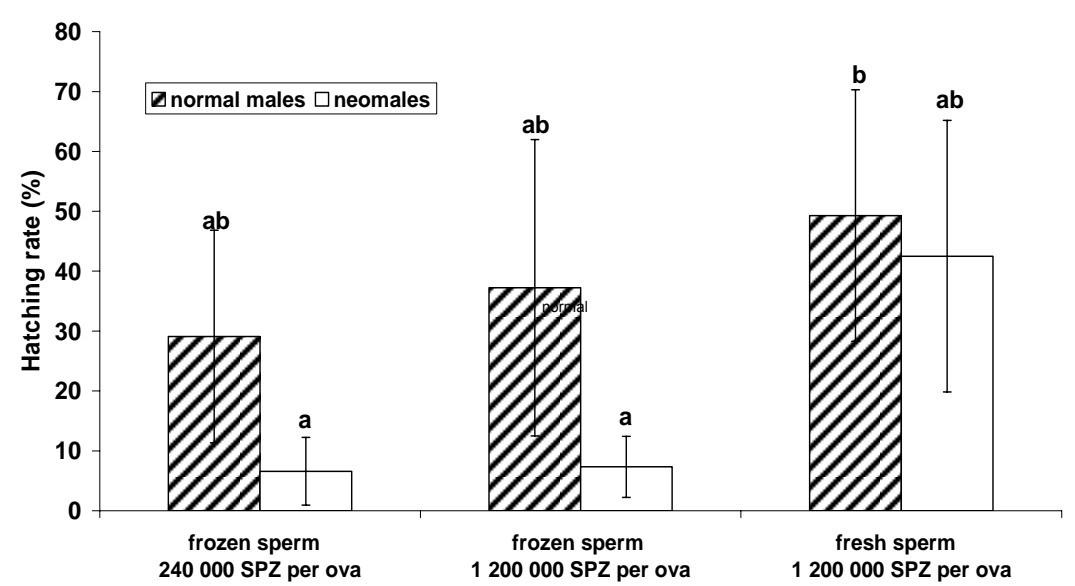

Figure 3: Effect of fresh and frozen stripped sperm of normal males and testicular sperm of neomales on hatching rate with different numbers of spermatozoa per ova (SPZ= sperm). Groups with a common superscript for each parameter do not differ significantly.

\section{$\underline{\text { Conclusions }}$}

This study also demonstrated that (a) perch sperm motility is of very short duration and sperm velocity rapidly decreases with time, (b) dilution ratio, $\mathrm{K}+$ and $\mathrm{Ca} 2+$ concentration as well as osmolality are factors affecting sperm motility parameters, (c) neither calcium nor potassium alone is sufficient to initiate sperm motility while a hypoosmotic shock is predominantly required, (d) testicular spermatozoa 
have potentiality for motility and (e) testicular and stripped sperm show differences in their motility characteristics.

Stripped sperm of normal perch could be successfully frozen, but squeezing of the tsetse is not recommended for collection of testicular sperm due to low velocity, motility and hatching rate observed in this study.

Thanks are expressed to projects: USB RIFCH MSM6007665809, GACR 524/06/0817 and EU COOP-CT-2004, 512629.

\section{$\underline{\text { References }}$}

Alavi S.M.H., Linhart O., Coward K., Rodina M., 2007a. Fish spermatology: Implication for aquaculture management. In: Fish Spermatology, Alavi, S.M.H., Cosson, J., Coward, K., Rafiee, R. (Eds.), Alpha Science Ltd, Oxford, UK. Pp. 397-460

Alavi S.M.H., Rodina M., Policar T., Cosson J., Kozak P., Psenicka M., Linhart O., 2007b. Physiology and behavior of stripped and testicular sperm in Perca fluviatilis L. 1758. Cybium, In press.

Alavi S.M.H., Rodina M., Policar T., Kozak P., Psenicka M., Linhart O., 2007c. Semen of Perca fluviatilis L: Sperm volume and density, seminal plasma indices and effects of dilution ratio, ions and osmolality on sperm motility. Theriogenology, 68: 276-283.

Krol J., Glogowski J., Demska-Zakes K., Hliwa, P., 2006. Quality of semen and histological analysis of testis in Perca fluviatilis L. during spawning period. Czech J. Animal Sci., 51, 220-226.

Lahnsteiner F., Berger B., Weismann T., Patzner, R.A., (1995). Fine structure and motility of spermatozoa and composition of the seminal plasma in the perch. J. Fish Biol., 47, 492-508.

Lubzens, E., Rothbard, S., Hadani, A., 1993. Cryopreservation and viability of spermatozoa from the ornamental Japanese carp (Nishikigoi). Bamidgeh, 45: 169-174.

Rodina M., Policar T., Linhart O., Rougeot, C., 2007. Cryoability of testicular neomales and stripped males sperm of European perch (Perca fluviatilis L.). In: The 1st International Workshop on the Biology of Fish Sperm, August 29-31, 2007, Vodnany, Czech Republic, pp. 83-84.

Rougeot, C., Nicayenzi, F., Mandiki, S. N. M., Rurangwa, E., Kestemont P., Melard, C., 2004. Comparative study of the reproductive characteristics of $X Y$ male and hormonally sex-reversed XX male Eurasian perch, Perca fluviatilis. Theriogenology 62, 790800.

Wildt DE., 1997. Genome resource banking: Impact on biotic conservation and society. In: Reproductive Tissue Banking, Karow A, Critser J (Eds.), New York: Academic Press, pp. 399-439. 


\title{
Feeding and nutrition of European percid broodstock and early life stages
}

\author{
KESTEMONT Patrick ${ }^{1}$, HENROTTE Emilie ${ }^{1}$, WANG Neil ${ }^{1}$, HAMZA \\ Neila ${ }^{1},{ }^{2}$, PAULSEN Helge ${ }^{3}$ and OVERTON Julia ${ }^{4}$ \\ 1. University of Namur (FUNDP), URBO, 61, rue de Bruxelles, B-5000 \\ Namur, Belgium \\ 2. Institut National des Sciences et Technologies de la Mer, 28, Rue 2 \\ Mars 1934, 2025 Salammbô, Tunisia \\ ${ }^{3}$. Danish Institute for Fisheries Research, Dept. Aquaculture and \\ Marine Ecology, Kavalergården 6, 2920 Charlottenlund, Denmark
}

\section{Introduction}

Although Eurasian perch and pikeperch are promising species for inland aquaculture, very little information is available about their specific nutritional requirements. These species can be reproduced in captivity, but the quality of their offsprings appears highly dependent on husbandry and feeding conditions. Since larvae of both species are quite small and display strong cannibalistic tendencies, steps have been taken to better understand the physiological and behavioural features of their larval stages in culture conditions.

\section{Broodstock nutrition}

One of the major bottlenecks for the development of percid fish culture is the supply of high quality eggs, especially with breeders fed an artificial diet (Kestemont et al., 2003). Generally, in newly cultured fish species, optimisation of broodstock nutrition is carried out in two steps. Firstly, the nutritional profile of commercial dry feeds are compared to natural food (the latter is assumed to be a reference). Thereafter, dry feed composition is progressively refined to optimise egg quality. Presently, research is addressing the first step for pikeperch and second step for Eurasian perch.

\section{Eurasian perch}

In a preliminary study (Kestemont et al., 2003), efficiencies of commercial diets enriched with vitamin E, vitamin C or highly unsaturated fatty acids (HUFA) were compared with that of natural food (NF, chironomid larvae and prey fish). In addition, effects of rearing conditions (tank vs. pond (C) fed NF) were assessed. Both diet and culture conditions significantly affected performances of the breeders, since fertilisation and hatching rates were highest in fish reared in ponds, but differences between NF and formulated diets were also significant (figure 1). The better egg quality of fish fed NF can be related to an improvement in their biochemical composition, namely the level of thyroid hormone (T3) as well as the $\mathrm{K}+/ \mathrm{Mg}++$ and 
$\mathrm{K}+/ \mathrm{Na}+$ ratios. Total lipid content and fatty acid composition of eggs were, however, not significantly different between treatments.

More recently, the influence of HUFA ratios (docosahexaenoic DHA/eicosapentaneoic EPA/arachidonic ARA acids) on reproductive performances and larval quality of perch were compared to a commercial diet and live food (forage fish) (Table 1). The results demonstrated that a compound diet with adequate ratio of DHA/EPA/ARA (2/1/1) can provide similar spawning performances and larval quality that a diet composed of forage fish, while inappropriate HUFA ratios (from both experimental or commercial diets) significantly impaired reproductive performances. The FA profiles of diets 1 and 4 were similar, both containing a high level of ARA ( $n-6$ HUFA) compared to the two other compound diets (diets 2 and 3 ), in which ARA was scarce. Diet 2 contained a high level of DHA, followed by EPA (two n-3 HUFA). Diet 3 produced eggs of poor quality and contained the highest level of EPA. Based on these results, it may be possible to improve the reproductive performances as well as egg and larval qualities of Eurasian perch by manipulating the FA composition of broodstock diet, especially ARA, while an excess of dietary EPA should be avoided in this species.

A

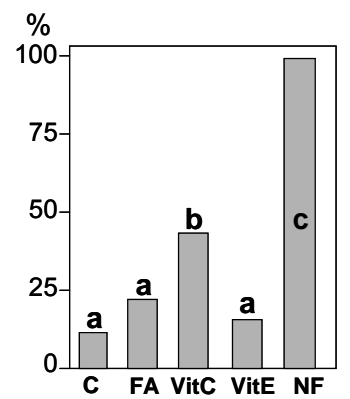

B

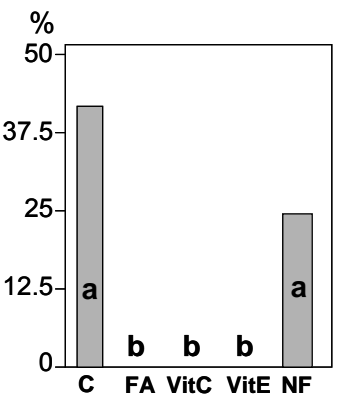

C

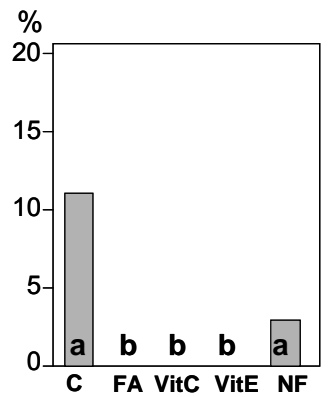

Figure 1. Influence of stocking and feeding conditions on ovulation (A), fertilization $(B)$ and hatching $(C)$ rates of Eurasian perch breeders. $C$ : control group reared in pond. FA, VitC et VitE : groups reared in recircultating system and fed commercial diets enriched with HUFA, vitamin $C$ and vitamin $E$, respectively. NF : fish reared in recirculating system and fed « natural » diet (forage fish + frozen chironomids). Bars with different letters are significantly different at $P<0.05$. 
Table 1. Spawning performances and indicators of larval quality in Eurasian perch, as affected by dietary treatment.

\begin{tabular}{llllll}
\hline & $\begin{array}{l}\text { Dietary } \\
\text { DHA/EPA/A } \\
\text { RA }\end{array}$ & $\begin{array}{l}\text { Fertilisation } \\
(\%)\end{array}$ & $\begin{array}{l}\text { rate } \\
(\%)\end{array}$ & $\begin{array}{l}\text { Latching survival } \\
\text { after } 90 \text { min } \\
\text { osmotic stress } \\
(\%)\end{array}$ & $\begin{array}{l}\text { LT 50 } \\
(\text { min. })\end{array}$ \\
\hline Diet 1 & $2 / 1 / 1$ & $63.46 \pm 22.98 \mathrm{a}$ & $63.48 \pm 3.8 \mathrm{a}$ & 39.17 & 85 \\
Diet 2 & $17 / 12 / 1$ & $62.01 \pm 18.85 \mathrm{a}$ & $44.61 \pm 19.09 \mathrm{a}$ & 2.92 & 40 \\
Diet 3 & $14 / 16 / 1$ & $26.17 \pm 16.64 \mathrm{~b}$ & $14.65 \pm 9.21 \mathrm{~b}$ & 0 & 20 \\
Diet 4 & $10 / 10 / 1$ & $66.12 \pm 13.50 \mathrm{a}$ & $40.28 \pm 21.67 \mathrm{a}$ & 10.50 & 40 \\
\hline
\end{tabular}

LT50 = time needed to observe $50 \%$ mortality of larvae during an osmotic stress (90 min. in $\mathrm{NaCl} 2 \%, 20^{\circ} \mathrm{C}$ ).

Significant differences $(P<0.05)$ are indicated with different letters.

\section{Pikeperch}

In pikeperch breeders, no dry diet has been proven efficient yet, and feeding with forage fish is the only way to obtain acceptable egg and larval quality. However, this method is costly, depends on live prey availability and presents risks of pathology and parasite transmission. Recently, a study investigated the impact of nutrition on the quality of reproduction in pikeperch, by comparing different feeding management during a whole reproductive cycle (Wang et al., submitted).

Three diets were tested: (i) a commercial dry diet recommended for broodstock nutrition of salmonids (DD), (ii) forage fish (FF, control) and (iii) a mixture of both (FD). The breeders were fed with the different diets from August (resting period) to May (post-spawning period) under natural conditions of temperature and photoperiod. FD consisted of feeding commercial food for four days, followed by feeding forage fish for the next three days. During the spawning season, pairs of breeders were injected with HCG to induce natural spawning. The eggs were incubated at $18-20{ }^{\circ} \mathrm{C}$ until hatching. Throughout the experiment, growth did not differ among treatments, indicating that all groups of fish were eating correctly their respective regimen.

Broodstock survival was lower when fish were fed DD (Table 2). In addition, fewer males were spermiating and spawning rate was lower than in the two other treatments. FD gave the highest amount of larvae whereas FF and DD gave only one spawning with a high hatching rate (>2000 larvae). 
At hatching, larval weight, length, body lipid composition, dry matter and results of challenge stress tests did not differ among treatments (data not shown), suggesting that larval quality was similar, regardless of dietary treatment. In conclusion, dry feed alone was clearly not sufficient to obtain acceptable reproductive performances while mixing dry feed and forage fish could be an effective mid-term method to obtain good quality spawning and larvae.

Table 2: Broodstock growth, survival and reproductive performances according to dietary treatment.

\begin{tabular}{ccccccccc}
\hline Diet & $\begin{array}{l}\text { Breeder } \\
\text { survival } \\
(\%)\end{array}$ & $\begin{array}{l}\text { Running } \\
\text { males } \\
(\%)\end{array}$ & $\begin{array}{l}\text { Injected } \\
\text { couples }\end{array}$ & $\begin{array}{l}\text { Spawn } \\
\text { ing } \\
\text { rate } \\
(\%)\end{array}$ & $\begin{array}{l}\text { No } \\
\text { hatch } \\
(\%)\end{array}$ & $\begin{array}{l}\text { Few } \\
\text { hatch } \\
(\%) \\
<1000 \\
\text { larvae }\end{array}$ & $\begin{array}{l}\text { High } \\
\text { hatch (\%) } \\
>2000 \\
\text { larvae }\end{array}$ & $\begin{array}{l}\text { Larval } \\
\text { weight (mg) }\end{array}$ \\
\hline FF & 86 & 76 & 8 & 100 & 38 & 50 & 12 & $0.40 \pm 0.01$ \\
FD & 75 & 89 & 8 & 88 & 14 & 29 & 57 & $0.40 \pm 0.05$ \\
DD & 57 & 54 & 7 & 57 & 50 & 25 & 25 & $0.34 \pm 0.22$ \\
\hline
\end{tabular}

\section{Larval husbandry and nutrition}

During the last years, scientific investigations on the improvement of husbandry conditions for percid fishes mainly focused on pikeperch, while only few nutritional studies were performed on Eurasian perch, despite a growing interest in the year-round production of weaned juveniles. However, some attempts have been made also at the production level, in order to determine the most appropriate feeding scheme from hatching.

\section{Eurasian perch}

Up to now, Eurasian perch larvae are still fed Artemia nauplii until they reach about $50 \mathrm{mg} \mathrm{b.w.,} \mathrm{and} \mathrm{then} \mathrm{can} \mathrm{be} \mathrm{trained} \mathrm{to} \mathrm{dry} \mathrm{feed} \mathrm{usually}$ formulated for marine fish larvae (Kestemont et al., 1996). However, the main pancreatic and intestinal enzymes are efficient from early developmental stages, suggesting that a compound diet could be provided very early to perch larvae (Cuvier-Pérès and Kestemont, 2002). Dynamics of total lipids and fatty acids during embryogenesis and early larval development suggest that docosahexaenoic acid (DHA), and to a lesser extent, EPA play a major role during early life stages of Eurasian perch and must be present at a sufficient level in larval diets to support growth performances (Abi-Ayad et al., 2001). Other variables improving the survival and growth of Eurasian perch juveniles include the mitigation of size heterogeneity and subsequent impact on cannibalism, by selecting early hatched larvae, increasing stocking density, using 24 hours bright light and, and providing sufficient feeding level (Kestemont et al., 2003). 
Recently, the use of dry food, either as full or partial replacement, was tested in conditions of commercial production on three years (Bornholms Hatchery, Denmark). The results on effects of replacement with dry food are summarized in Table 4. Feeding exclusively with Artemia to an age of ca. 20 days generally gave the highest growth and survival rates. Partial replacement with dry feed, either from day 0 or day 10, gave marginally slower growth but survival was unaffected. Full replacement from day 10 appeared to reduce growth and survival in 2004, but had no negative effect in 2005. Full replacement from day 0 was possible, but had a serious negative effect on both growth and survival compared to the other groups. Several brands of dry feed were also tested, indicating that the efficiency of dry feed largely depended on the brand used. The use of brackish-water rotifers (Brachionus plicatilis) was tested as a starter food complementary to Artemia nauplii and dry feed. No positive effects of feeding perch larvae with rotifers were observed, confirming the results of Kestemont et al. (1996).

\section{Pikeperch}

In pikeperch, early life stages can be fed Artemia nauplii directly after mouth opening ( 3 days after hatching) but small size nauplii are recommended. Enrichment of Artemia nauplii with HUFA and vitamin $C$ improves growth and significantly reduces the deformity rate (Kestemont et al., 2007). Different weaning ages (at 12, 19 or 26 days post-hatching, dph) and diets (dry feeds formulated for marine or freshwater larvae) were investigated, based on survival, cannibalism, deformity and growth rates.

Weaning at $19 \mathrm{dph}$ gave highest growth rate $(381 \mathrm{mg}$ at $36 \mathrm{dph})$ and lowest mortality $(48.1 \%)$ and deformity $(11.9 \%)$ rates, while weaning at $12 \mathrm{dph}$ gave lowest growth rate $(219 \mathrm{mg}$ at $36 \mathrm{dph})$ and the highest mortality $(68.6 \%)$ and deformity $(22.3 \%)$ rates. Feeding pikeperch larvae and juveniles with dry feed formulated for freshwater fish species (including low $\mathrm{Ca} / \mathrm{P}$ ratio) resulted in better growth (up to 230 $\mathrm{mg}$ at $36 \mathrm{dph}$ ) than feed formulated for marine fish (high $\mathrm{Ca} / \mathrm{P}$ ratio) (about $145 \mathrm{mg}$ at $36 \mathrm{dph}$ ) (Kestemont et al., 2007).

Histological observations of pikeperch digestive tract suggested that pikeperch larvae are able to synthesize and transport lipids already on $12 \mathrm{dph}$ and that high quality dry feed can be used from $5 \mathrm{dph}$ (Ostaszewska et al., 2005).

On the other hand, Hamza et al. (2007) reported that pikeperch larvae can be weaned from $15 \mathrm{dph}$ without impairing their digestive capacities while earlier weaning affected the maturation processes of the digestive system. Dry feed quality, as well as intrinsic characteristics of larvae (weight at hatching, yolk reserve, etc) can largely explain the differences observed between the feeding 
experiments. A recent study, comparing various levels of dietary phospholipids, suggested that pikeperch larvae has relatively high phospholipid requirements (at least 95 gkg-1 diet dry weight) and that EPA+DHA level around $1.25 \%$ (diet dry weight) is sufficient (Hamza et al., submitted) (Table 5).

Table 4. Mean total length $(\mathrm{mm})$ and survival of perch larvae fed Artemia and/or dry feed.

\begin{tabular}{|c|c|c|c|c|c|c|}
\hline & & Artemia & $\begin{array}{l}\text { Partial } \\
\text { from } \\
\text { day } 10\end{array}$ & $\begin{array}{l}\text { Partial } \\
\text { from } \\
\text { day } 0\end{array}$ & $\begin{array}{c}\text { Full from } \\
\text { day } 10\end{array}$ & $\begin{array}{c}\text { Full from } \\
\text { day } 0\end{array}$ \\
\hline $2004-d 24$ & length & $15.5+16.4$ & $14.2+15.2$ & $13.6+13.8$ & $12.8+13.1$ & $9.4+10.3$ \\
\hline $2004-d 26$ & surv.\% & $44.0+42.3$ & $51.8+52.3$ & $85.9+41.7$ & $50.4+25.0$ & $5.1+7.8$ \\
\hline 2005-d 17 & length & $12.7+13.4$ & & $11.8+12.2$ & $12.4+12.9$ & $9.1+9.7$ \\
\hline 2005-d.17 & surv. $\%$ & $69.1+76.5$ & & $57.8+88.7$ & $72.1+74.7$ & $13.1+22.7$ \\
\hline 2005-d 38 & surv. $\%$ & 52 & & 57 & 66 & nd. \\
\hline 2006-d 19 & length & 15.6 & 14.6 & $\begin{array}{l}11.3^{+} \\
12.1^{*}\end{array}$ & & \\
\hline 2006-d 19 & surv.\% & 29.5 & 26.3 & $10.2+19.6$ & & \\
\hline
\end{tabular}

Values of individual tanks in replicate experiments. * full from day 10.

Partial replacement $=$ Artemia at 8:00 and 20:00 hours, dry feed at 11:00, 14:00 and 17:00 hours.

Full replacement $=$ exclusively dry feed.

Table 5. Survival, growth and deformities in the three experimental groups of pikeperch larvae fed different levels of dietary phospholipids (Hamza et al., submitted).

\begin{tabular}{lccc}
\hline & PL1 & PL5 & PL9 \\
\hline Survival (\%) & $34 \pm 1.5$ & $36.6 \pm 2.5$ & $33 \pm 3.1$ \\
Final body weight (mg) & $160 \pm 9.6 \mathrm{a}$ & $191 \pm 22.1 \mathrm{~b}$ & $238 \pm 12.5 \mathrm{c}$ \\
CV weight (\%) & $24.2 \pm 4.4$ & $21.9 \pm 2.2$ & $22.1 \pm 6.1$ \\
SGR (\% day-1) & $14.1 \pm 0.2 \mathrm{a}$ & $14.8 \pm 0.5 \mathrm{~b}$ & $15.8 \mathrm{c} \pm 0.2 \mathrm{c}$ \\
Total deformity (\%) & $12.5 \pm 12.5$ & $12.5 \pm 15.0$ & $7.5 \pm 9.6$ \\
\hline
\end{tabular}

Initial body weight (day 10): $5.4 \pm 0.5 \mathrm{mg}$ Mean $\pm \mathrm{SD}(\mathrm{n}=4)$ Values with different letters in the same line are significantly different $(P<0.05)$

\section{Conclusions}

Survival and growth of early life stages of percid fishes have been significantly improved during this last decade, based on the progressive knowledge of their husbandry and nutritional requirements, as well as on the amelioration of compound diets.

Even though live preys like Artemia nauplii are still recommended as starting food, their use can be substantially reduced in both time and 
proportion. At least for Eurasian perch, the production of high quality eggs and larvae from breeders fed exclusively on dry feed is feasible, assuming that diets contain an adequate DHA/EPA/ARA ratio. Similar experiments are now conducted with pikeperch breeders. In this latter species, year-to-year variability of gamete and larval quality have been often observed under both experimental and commercial conditions. More research is still needed to overcome this variability which limits the sustainability of intensive pikeperch production.

\section{References}

Abi-Ayad S.M., Kestemont P. \& Mélard C., 2001. Dynamics of total lipids and fatty acids during embryogenesis and larval development of Eurasian perch Perca fluviatilis. Fish Physiology and Biochemistry, 23, $3: 233-243$.

Cuvier-Pérès A. \& Kestemont P., 2002. Development of some digestive enzymes in Eurasian perch larvae Perca fluviatilis. Fish Physiology and Biochemistry 24, 279-285.

Hamza N., Mhetli M. \& Kestemont P., 2007. Effects of weaning age and diets on ontogeny of digestive activities and structures of pikeperch (Sander lucioperca ) larvae. Fish Physiology \& Biochemistry 33, 121-133

Hamza N., Mhetli M., Ben Kemis I., Cahu C. \& Kestemont P., 9999. Effect of dietary phospholipid levels on husbandry aspects, enzymatic activities and fatty acid composition of pikeperch (Sander lucioperca) larvae (submitted).

Kestemont P., Mélard C., Fiogbé E.D., Masson G. \& Vlavonou R., 1996. Nutritional and animal husbandry aspects of rearing early life stages of Eurasian perch Perca fluviatilis. Journal of Applied Ichthyology, 12, 3-4: 157-165.

Kestemont P., Houbart M., Jourdan S., Mélard C., Paspatis M., Fontaine P., Kentouri M. \& Baras E., 2003. Size heterogeneity, competition and cannibalism in cultured predatory fish larvae: abiotic and biotic influences. Aquaculture, 227, 333-356.

Kestemont P., Xu X., Blanchard G., Mélard C., Gielen M., Brun-Bellut J. \& Fontaine P., 2003. Feeding and nutrition in European percid fishes - a review. In Barry T.P. \& Malison J.A., Eds : Proceedings of Percis III, The Third International Perked Fish Symposium, University of Wisconsin, Madison, USA, 39-40.

Kestemont P., Xu X., Hamza N., Maboudou J. \& Imorou Toko I., 2007. Effect of weaning age and diet on pikeperch larviculture. Aquaculture 264, 197-204.

Ostaszewska T., Dabrowski K., Czuminska K., Olech W. \& Olejniczak M., 2005. Rearing of pikeperch using formulated diets - first success with starter feeds. Aquaculture Research 36, 1167-1176. 
Genetic improvement of growth in perch production: domestication, sex control, hybridization and strain selection

ROUGEOT Carole and MELARD Charles

Centre de Formation et de Recherches en Aquaculture, 10 Chemin de la justice, 4500 Tihange, Belgium.

${ }^{*}$ Corresponding author. Tel.: +32 (0)85 274159

E-mail address: C.Rougeot@ulg.ac.be (C.Rougeot).

\section{$\underline{\text { Introduction }}$}

Because of the low growth rate of Eurasian perch (at least one years at $23^{\circ} \mathrm{C}$ to produce marketable fish), several techniques such as domestication, sex control, hybridisation and strain selection have been developed to improve the growth performances of Eurasian perch in intensive culture conditions.

\section{Domestication}

The domestication process do not include a selective breeding program: the domesticated strains were constituted year after year from an initial stock of wild breeders. The comparison of growth

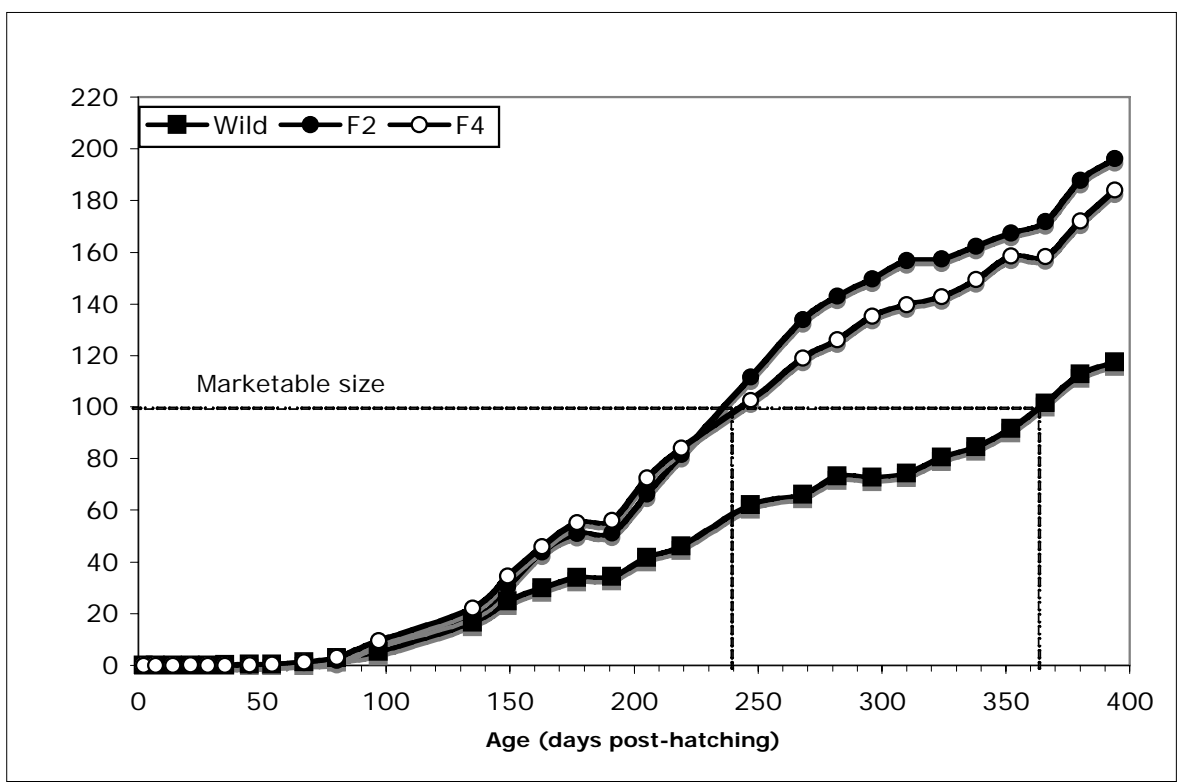

performances of 2 generations of domesticated strains (F2 and F4, originated from the Meuse river) to a wild strain (F1) reared in a recirculating system $\left(1.6 \mathrm{~m} 3\right.$ tanks, $\left.23^{\circ} \mathrm{C}\right)$ showed a significant improvement of growth performance with domesticated strains 
(Rougeot et al., 2007). After a 340-days rearing period, F2 and F4 generation display a final mean body weight 1.6-fold higher (184 and $196 \mathrm{~g})$ than the wild strain (117g, fig.1). With the domesticated strains (F2 and F4) it was possible to reach the marketable size $( \pm 100 \mathrm{~g})$ within 240 days, whereas wild strain attained this size after one year of rearing in the same conditions (fig.1).

Figure 1: Growth of wild (F1) and domesticated (F2 and F4) strains of juveniles reared under intensive conditions in a recirculating system (1.6m3 tanks, $23^{\circ} \mathrm{C}$ and $\left.\mathrm{O} 2>6 \mathrm{ppm}\right)$.

\section{$\underline{\text { Sex control and all-female production }}$}

Eurasian perch females grew $20-25 \%$ faster than males. Therefore, the improvement of growth could be attained using this sexual growth dimorphism and all-females populations. The production of all-females families is realised within two generations (Rougeot et al., 2002): production of hormonally sex-reversed XX males breeders in the first generation and the production of all-females progenies by crossing hormonally sex-reversed males and normal XX females in the second generation.

Hormonally sex reversed males breeders were obtained using a masculinizing sex steroid hormone (17 $\alpha$-methyltestosterone-17MT) incorporated into the food. Different hormonal doses $(5,10,20,30$, 40,60 and $80 \mathrm{mg} \mathrm{kg}-1$ food), treatment duration (30 and 80 days) and moment of application ( $45 \mathrm{mg}$ - 32 days post-hatching, $70 \mathrm{mg}-36$ $\mathrm{dph}, 150 \mathrm{mg}-42 \mathrm{dph}$ and $205 \mathrm{mg} 47 \mathrm{dph}$ ) were tested in order to determine the optimal protocol for sex reversal. Complete sex reversal $(100 \%$ male progenies) was obtained when the hormonal treatment was applied in fish initially ranging from 40 to $71 \mathrm{mg}$. Treatments using low hormonal doses (5 and $10 \mathrm{mg} \mathrm{kg}-1$ food) induced $80 \%$ of functional sex-reversed males (spermiating while stripping). All sexreversed males crossed with normal female gave between 95 and $100 \%$ of female in the progenies. After a 360-days rearing period, allfemales families displayed a mean body weight $30 \%$ higher $(143 \mathrm{~g})$ than the mixed-sex families (103g). The marketable size $(100 \mathrm{~g})$ was reached within 280 days with all-females families against 340 days with mixed-sex families. 


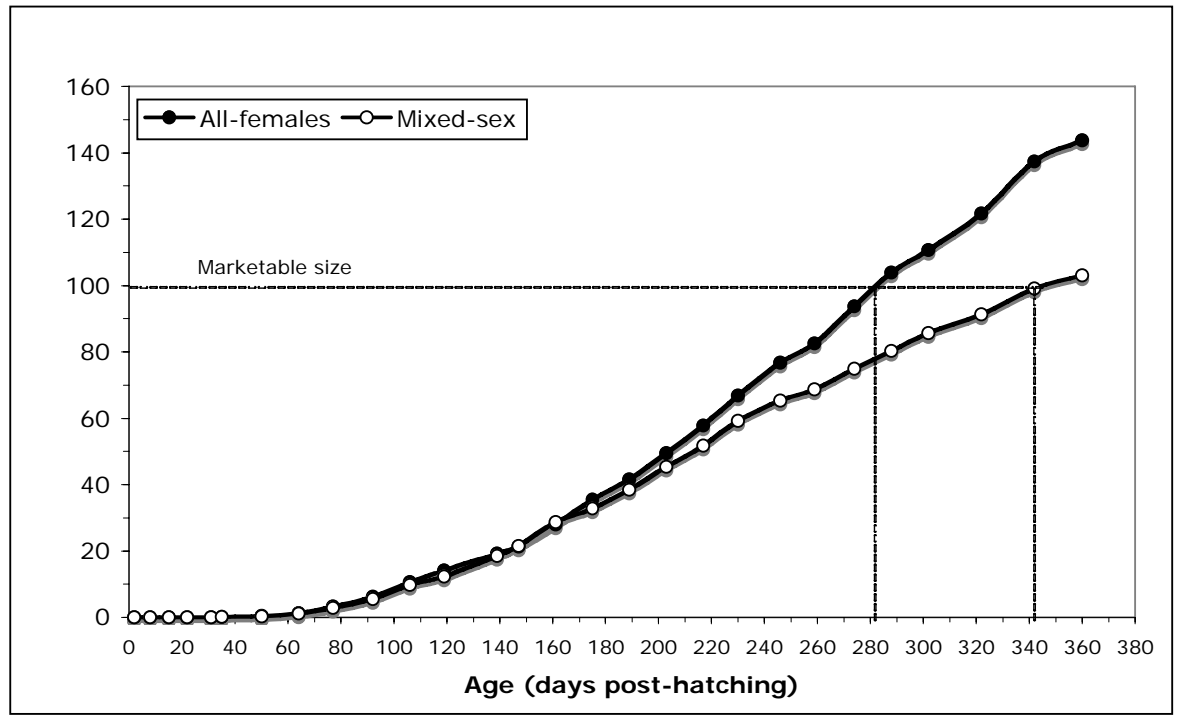

Figure 2 : Growth of all-females and mixed-sex juveniles reared under intensive conditions in $0.5 \mathrm{~m} 3$ tank in a recirculating system $\left(23^{\circ} \mathrm{C}\right)$ at an initial stocking density of 2000 fish.m-3.

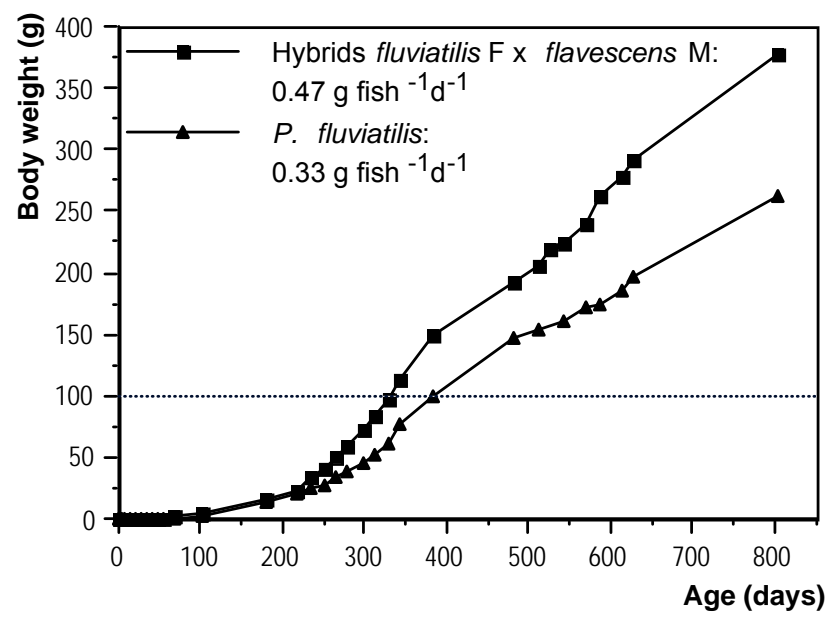

Figure 3 : Comparative growth of purebred $P$. fluviatilis and hybrids $P$. fluviatilis female $\times P$. flavescens male reared in a recirculating system at $23^{\circ} \mathrm{C}$.

\section{Hybridization}

Hybridisation was experimentally done between $P$. fluviatilis female $\mathrm{x}$ $P$. flavescens male in order to enhance the growth performances in intensive rearing systems. 
Hybrids were obtained by artificial fertilisation and their growth performances compared to purebred $P$. fluviatilis. The growth performances were compared in a recirculating rearing system supplied with water at $23^{\circ} \mathrm{C}$. After a 230 -days rearing period, hybrids showed a significant increase of growth compared to purebred (Fig.3). The marketable size $(100 \mathrm{~g})$ was reached in 11 months with hybrids vs 12 months for purebred $P$. fluviatilis.

\section{$\underline{\text { Strains selection }}$}

In order to select the best perch strain adapted to intensive culture conditions, wild perch originating from North Italy, South-West France, North-East France and Belgium were reared in recirculating system $\left(23^{\circ} \mathrm{C}\right.$ ) from hatching to 200 days post-hatching (a 120-days rearing period, Mandiki et al., 2003). After a 200-days rearing period, Belgian and North-East France strains displayed a mean body weight $56 \%$ and $76 \%$ higher respectively than South-West France and North Italy strains (Figure 4). The identification of the best strain adapted to intensive culture conditions is the first step to start a selection program.

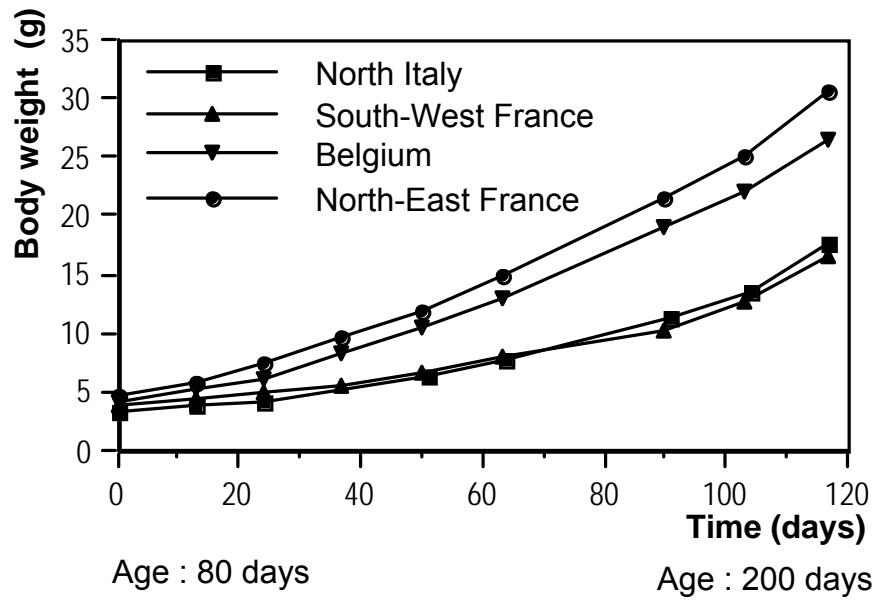

Figure 4. Growth of 4 different strains of Eurasian perch reared under intensive conditions in a recirculating system at $23^{\circ} \mathrm{C}$, two progenies / strain.

$\underline{\text { Triploidisation }}$

Triploidisation is used to produce partially or completely sterile fish. In natural temperature cycle (from 4 to $25^{\circ} \mathrm{C}$ depending on season) the production of triploids Eurasian perch would prevent sexual maturation of females and avoid the negative effects of gonadal development (GSI : 20-25\%) on growth. 
The most effective treatment to induce triploidy in perch is a thermal shock at $30^{\circ} \mathrm{C}$ applied on eggs 5 minutes post-fertilisation for 25 minutes duration (Rougeot et al., 2003). This treatment allows to obtain a yield of triploids of $43 \%$.

\section{$\underline{\text { Conclusion }}$}

Domestication process, sex control and all-female production, hybridisation and strain selection allowed to significantly enhance the growth performances of Eurasian perch (minimum 20\%).

The use of these methods in intensive production would allow to shorten the duration of production, to reach the marketable size in a shorter time and finally to decrease the production costs of Eurasian perch in intensive culture.

\section{$\underline{\text { References }}$}

Mandiki S.N.M., Blanchard G., Mélard C., Koskela J., Kucharczyk D., Fontaine P. and Kestemont P. 2004. Effect of geographic origin on growth and food intake in Eurasian perch Perca fluviatilis juveniles under intensive culture. Aquaculture 229, 117-128.

Rougeot, C., Bervillers, E., Prignon, C., Gustin, D., Del Giudice, M., Vandecan, M., Mélard, C. 2007. Growth improvement of Eurasian perch (Perca fluviatilis) using domesticated strains under intensive rearing conditions. Aquaculture, in press.

Rougeot, C., Jacobs, B., Kestemont, P., Mélard, C., 2002. Sex control and sex determinism study in Eurasian perch, Perca fluviatilis, by use of hormonally sex-reversed male breeders. Aquaculture 121, 81-89.

Rougeot, C., Minet, L., Prignon, C., Vanderplasschen, A., Detry, B., Pastoret, P.-P., Mélard, C. 2003. Induce triploidy by heat shock in Eurasian perch, Perca fluviatilis. Aquatic Living Resources 16 (2) : 9094. 
Bornholm Salmon hatchery: control of out-of-season spawning of Eurasian perch

OVERTON Julia L. ${ }^{1}$, PAULSEN Helge ${ }^{2}$, KUCHARCZYK Dariusz $^{3}$ and SZCZERBOWSKI Andrzej ${ }^{4}$

* Corresponding author. Tel.: +4556 493553

E-mail address: jlo@difres.dk (J.L. Overton)

1 Dept. of Aquaculture and Marine Ecology, Danish Institute of Fisheries Research, Technical University of Denmark, Bornholms Lakseklækkeri, Øster Flak 2, DK-3730 Nexø, Denmark.

${ }^{2}$ Dept. of Aquaculture and Marine Ecology, Danish Institute of Fisheries Research, Technical University of Denmark, North Sea Centre, DK-9850 Hirtshals, Denmark.

${ }^{3}$ Dept. of Lake \& River Fisheries, Warmia \& Mazury Olsztyn in Olsztyn, Poland

${ }^{4}$ Dept. of Aquaculture, Inland Fisheries Institute, Olsztyn, Poland

\section{Introduction}

Traditional and modern methods of perch production have relied on the natural seasonal spawning of broodstock. Perch are synchronous spawners, producing eggs for only 2-7 weeks of the year. This means that further development of perch aquaculture is hindered by the lack of supply of eggs and juveniles all year round. It is therefore not surprising that there is a growing interest in the development of a protocol to produce perch eggs and juveniles out of season. External factors such as photoperiod, water temperature, light, food availability etc. are recognized as important regulators to the timing of recrudescence of the reproductive processes (i.e. endogenous system) leading to spawning (Shepherd and Bromage, 1988; Ciereszko et al., 1997). The importance of temperature and photoperiod on the various stages of gonadal maturation and spawning in male and female perch has been well researched (e.g. Migaud et al., 2001, 2002, 2003). Although perch are fairly synchronous spawners, it may be desirable to synchronise spawning further in order to make most efficient use of hatchery facilities. Use of hormones to directly stimulate gonadal development or to stimulate the fish to produce their own gonadotropins has been investigated in perch (Dabrowski et al., 1994; Kucharczyk et al., 1996, 1998, 2001) with a resulting increase in synchronisation of ovulation in females and increase sperm production by males. 
A pilot project from 2004-2006 was conducted at Bornholms Salmon hatchery, Denmark, to demonstrate the possibility of altering the spawning season using photo thermal manipulation techniques. In particular, the aim was to alter the spawning period by six months so that the hatchery period of perch rearing could take place with indoors recirculation systems over winter, producing fingerlings for on-growing in spring. These fingerlings could then be delivered to on-growing facilities outdoors that could utilise the warm summer months for optimal growth of perch. With this strategy the production period to market size may be reduced significantly thereby reducing production costs.

a) Year 1: Wild fish were used as broodstock, with only limited success. Hormonal stimulation using Carp pituitary extract and "Ovopel" was used to synchronise spawning. Only one female spawned, resulting in eggs that did not survive. However the males proved to be well adapted to captive conditions, producing highly motile, concentrated sperm.

b) Year 2: One-year old cultured perch were used. These were virgin fish which had been raised in constant conditions before undergoing a programme of photo thermal manipulation. The fish were subjected to a priming cooling period plus an out-of-season thermophotomanipulation. The fish responded well and matured out of season. Hormonal stimulation using hCG and Ovopel was used to control spawning. These fish successfully spawned. The males produced highly motile and concentrated sperm. However, the eggs produced were of poor quality with fragmented egg strings and single eggs. Fertilization was between 5 and $50 \%$. One to two days after the fertilisation the eggs arrested development and died.

c) Year 3 Two-year old cultured perch were used. This fish had already gone through one year of seasonal manipulation and had been "primed" to an altered seasonal cycle. Some had spawned already in year 2 . The fish were allowed to spawn freely in the tanks. No hormonal manipulation was used. Good results were obtained with mass spawnings from 19th October that lasted over three weeks. The fish produced in total 83 egg strings. Egg strings were $80-100 \%$ fertilised. All egg strings produced were intact. The fertilised egg strings were weighed, disinfected and incubated. Good quality viable larvae were produced, that revealed a high survival, when tested for robustness using a 20 psu salt bath. 


\section{$\underline{\text { Conclusions }}$}

Best results were obtained with fish that had been cultured and been maintained in constant conditions before being altered to the desired seasonal regime.

A period of photothermal "priming" proved useful in proving a seasonal imprinting for the fish. This, followed by a second year on the same protocol resulted in mass spawning of good quality eggs and viable larvae.

Whether the good results were due to the a) age of the fish, b) that they were second time spawners to the same seasonal regime or c) due to minimal handling are unknown, but most likely due to a combination of these three factors.

\section{$\underline{\text { References }}$}

Ciereszko R.E., Dabrowski, K., and Ciereszko, A., 1997. Effects of temperature and photoperiod on reproduction of female yellow perch Perca flavescens: plasma concentrations of steroid hormones, spontaneous and induced ovulation and quality of eggs. Journal of the World Aquaculture Society, 28(4), 344-356.

Dabrowski, K., Ciereszko, A., Ramseyer, L., Culver, D., and Kestemont, P., 1994. Effects of hormonal treatment on induced spermiation and ovulation in yellow perch (Perca flavescens). Aquaculture, 210, 171-180.

Kucharczyk, D., Kujawa, R., Mamcarz, A., Skrzypczak, A. and Wyszimirska, E., 1996. Induced spawning in perch, Perca fluviatilis L. using carp pituitary extract and HCG. Aquaculture Research, 27, 847852.

Kucharczyk, D., Kujawa, R., Mamcarz, A., Skrzypczak, A. and Wyszomirska, E., 1998. Induced spawning of perch, Perca fluviatilis $\mathrm{L}$. Using $\mathrm{FSH}+\mathrm{LH}$ with pimoside or metoclopramide. Aquaculture Research, 29, 131-136.

Kucharczyk D., Szcerbowski, A., Luczyriski, M-J-. Kujawa, R., Mamcarz, A., Wyszomirska, E., Szabo, T. and Ratajski, S., 2001. Artifical spawning of Eurasian perch, Perca fluviatilis L. using Ovopel. Archives of Polish Fisheries, 9(1), 39-49.

Migaud, H., Gardeur, J.N. and Fontaine, P., 2001. Influence of the photoperiod regime on the broodstock maturation and egg and larval quality in Euarsian perch, Perca fluviatilis. LARVI 2001, Ghent, 375377. 
Migaud, H., Fontaine P., Sulistyo, I, Kestemont, P. and Gardeur, J.N., 2002. Induction of out of season spawning in eurasian perch Perca fluviatilis effects of rates of cooling and cooling durations on female gametogenesis and spawning. Aquaculture 205, 253-267.

Migaud, H., Mandiki, R., Gardeur, J.N., Kestemont, P., Fontaine, P., 2003. Influence of photoperiod regimes on the Eurasian perch gonadogenesis, spawning and egg and larvae quality. Abstract book of the 7th International Symposium on Reproductive Physiology of Fish, May 18-23, 2003, Mie, Japan:102.

Shepherd, J. and Bromage, N., 1988. Intensive fish farming. BSP Professional books, Oxford. 404pp. 


\section{Perch juvenile production in Ireland - Grasping the potential}

TONER Damien

Aquaculture Initiative EEIG, 14-15 Grays Lane, Park st, Dundalk, Co. Louth, Ireland.

Tel.: +353 (0) 429385074

E-mail address: toner@aquacultureinitiative.eu

\section{Introduction}

Ireland's aquaculture industry is dominated by salmon and trout production on the finfish side and mussel and oyster production on the shellfish side. The scarcity of new sites make the expansion of these species problematic and increasing market pressures continue to make these sectors volatile. In the late 1990's, BIM identified European Perch (Perca fluviatilis) as having potential in marginalised rural communities in Ireland. A publication "Cultivating Perch" was published in 1997 and Irelands first perch farm was established in 2000. Ireland is now at the forefront in development of perch farming in Europe with five licensed farms including two hatcheries. Total licensed production is 175 tonnes. The development of the industry into a sustainable aquaculture sector is not without challenges, and work to date has concentrated on the bottleneck of weaned juvenile production. Total juvenile demand exceeds 1 million juveniles per annum, and is a major curtailment to the future expansion of the sector.

\section{Juvenile Production in Ireland}

The Aquaculture Industry in Ireland and throughout Europe has long sought to diversify from core species to novel candidate species with potential for cultivation. This has proved successful in the past, with Salmon, Scallops and particularly the Pacific oyster all at one time or another considered novel. Diversification into novel species holds some great potential but also associated risks. Bord lascaigh Mhara (BIM) is the state agency charged with the development of Irelands fishing and aquaculture industries. The agency has a worldwide reputation for being innovative, motivated and forward thinking in its support of Irish companies seeking to add value and volume to the industry. The Aquaculture Initiative EEIG is a cross border body established by BIM to focus resources in Ireland's border regions.

A core part of BIM's innovative approach has been the development of novel species, as a way of creating market niches for product. Species such as Sea Urchins, Abalone, Sea horses, Ornamentals, Arctic Charr, Seaweed and Perch have all been actively investigated by BIM in partnership with commercial operators.

PDS Irish Waters Perch Ltd is Irelands first perch farm and is the countries largest hatchery. The farm was established in 2000 by Mr. 
Philip Simpson, in Gowna, Co. Cavan. PDS has been at the forefront in developing techniques of perch juvenile culture utilising both extensive and intensive systems. The hatchery has expanded in recent years to include a live feed unit, broodstock facility, larval unit and more recently a dedicated nursery unit capable of holding 400,000 juveniles per production run. Over the years the facility has tried many different techniques for producing perch, including some methods which have been successful and some less. The farm now has developed its own techniques and methods including out of season spawning, mesocosm systems, pond reared juveniles and intensively reared juveniles. Perch juveniles are produced for sale to ongrowing farms within Ireland.

In recent years Key Water Fisheries Ltd has also established a hatchery in Ireland and is up scaling its production to meet with growing demand. The future production from both hatcheries will be key to providing a stable supply of quality perch juveniles to ongrowing farms.

\section{Conclusion}

The future holds some key challenges for Ireland's emerging perch farming sector. The viability of perch farming remains a key challenge for the hatcheries in terms of driving down juvenile costs and increasing availibility. The existing hatcheries have taken a gamble that these issues will be resolved and that their investment will pay off in the short to medium term. The willingness and dedication of these promoters is something to applaud. Their vision and determination is central to grasping the potential and developing a bright and stable future for percid aquaculture.

\section{$\underline{\text { References }}$}

Anonymous., 2002. Report of the Aquaculture Working Group on New Species Development, Department of Communications Marine and Natural Resources.

Ashe, D., 1997. Cultivating Perch. BIM Aquaculture Explained Manual No. 20. 48pp.

Toner, D., 2003. Perch farming makes breakthrough. BIM Aquaculture Newsletter 46, 1-2.

Watson, L., 2005. Seahorses to Sea Urchins, The next big splash in Irish aquaculture.BIM. $68 \mathrm{pp}$ 


\section{Viskweekcentrum Valkenswaard: extensive vs intensive production of pikeperch juveniles}

VAN MECHELEN, J.

Viskweekcentrum Valkenswaard has a large freshwater hatchery with larval rearing systems, egg incubators and fingerling rearing systems (recirculation).

Also the company has a 10 hectare area with 23 earth ponds for fish production. 12 of those ponds are very well protected for bird predation by a "bird net".

The company produces ornamental fish such as: Goldfish, Shubunkin, Orfe, Goldorfe, Blueorfe and Koi. Furthermore the company also produces inland species such as, Pike, Pikeperch, Carp, Grascarp, Orfe, Tench and Roach.

The inland species are used for restocking or recreational fisheries, most of the fish is sold in the Dutch market. Ornamental fish is sold in the retail and/or wholesale market in the Netherlands and also for export.

Part of the farm is dedicated to research and development for Coppens International, a year round research program takes place in 4 separate rearing systems, with larvae, fingerlings and bigger size fish. Fresh and also saltwater species are used for this research program such as: trout, salmon, carp, eel, tilapia, catfish and seabass.

One of the products of Viskweekcentrum Valkenswaard is pond reared pikeperch for restocking purposes. Pikeperch is substrate spawned in the hatchery and after hatching and first feeding in the hatchery ponds are stocked with larvae. Ponds are harvested in June and sold to clients. Part of these fingerlings are dry feed weaned and sold to the Aquaculture industry. Viskweekcentrum Valkenswaard also weans pikeperch larvae direct after artemia to dryfeed.

During the workshop a presentation will be given about the reproduction of pikeperch at Viskweekcentrum Valkenswaard (substrate spawning), first feeding, stocking and harvesting of earth ponds, also packing and transport of fingerlings. Also the weaning to dry feed of these fish will be discussed. Figures about brood stock used, spawning success, stocking numbers, pond area and harvest success will be presented. Furthermore a weaning protocol and survival rates and some growth figures will be presented.

Based on the presentation some remarks will be made about future development of pike perch industry.

The presentation will also contain pictures of the whole process presented. 
Recent progress in feeding and nutrition of percid fishes during ongrowing

\author{
BLANCHARD Gersande, WANG Neil and KESTEMONT Patrick
}

University of Namur (FUNDP), URBO, 61, rue de Bruxelles, B-5000 Namur, Belgium

\title{
Introduction
}

Percids are lean fish that store lipids in the peri-intestinal cavity. Therefore, since the ability to spare protein by increasing the levels of dietary lipid is usually considered as quite limited in percids, these species generally require diets presenting high protein and low lipid contents. From the two European Percids cultivated, Eurasian perch was far more studied in the last decade and data on pikeperch growth are very scarce. Consequently, this short review will mainly focus on Eurasian perch and synthesise the available information for pikeperch growth and nutrition.

\section{Eurasian perch}

Perch juveniles, starting the ongrowing phase, are usually fed diets formulated for salmon, trout or sea bass. Containing more than $40 \%$ proteins and $20 \%$ lipids, the composition of such diets seems appropriate in terms of protein requirements but could be better adapted to the lipid requirements of Percid fish. Indeed, as a lean fish, perch accumulates diet energy excess in the mesenteric and hepatic tissues. Main effects observed when high fat diets are used in cultivated perch juveniles are a decrease of growth performances and stress resistance. Therefore, studies in feed and nutrition of perch juveniles were performed in order to adapt a diet satisfying the nutritional requirements of the species.

In the early 2000s, studies were performed in order to determine the optimal diet lipid content for perch allowing good growth performances without alterations of the carcass composition by deposition of excess lipid. Kestemont et al. (2001) demonstrated that dietary lipid content of $12 \%$ or $19 \%$ enriched with ethoxyquin, were both beneficial for growth but led to different cytological and histological modifications of the liver, depending on the dietary lipid levels. They also confirmed that perch was particularly sensitive to lipid peroxidation. Xu et al. (2002) evaluated the effects of a commercial diet enriched with three fat levels $(11.7,15$ and 19.3\%) on growth performances and biochemical composition of tissues. They demonstrated that increasing dietary fat content increased growth, feed efficiency and protein utilization but also affected significantly the lipid deposition in the viscera and liver of perch that might depress the immune responses. Contradictory results between studies may be explained because of differences in lipid 
sources used to produce the dietary treatments. Lipid sources are known to influence lipid utilization and feed efficiency in fish. In perch, as adequate dietary lipid supplies, in terms of n-3/n-6 fatty acid ratio or DHA/EPA ratio, were still unknown. Xu \& Kestemont (2002) dedicated a study to the influence of different lipid sources on the fatty acid composition and metabolism in Eurasian perch, and demonstrated the great ability of perch for bioconversion of $n-3$ and $n-6$ fatty acids leading to DHA accumulation in muscles as well as the ability of perch to use alternative vegetable oil rather than fish oil in feed formulations. Mathis et al. (2003) designed an experiment to determine the optimal dietary protein/energy ratio for growth, feed efficiency (FE), nitrogen output and fillet yield, as well as the composition and quality of the flesh.

They observed an improvement of FE and protein efficiency with the decrease of protein/energy ratio and a limited influence of dietary treatment on biochemical and organoleptic characteristics of the flesh. Aside from the nutritional aspects, an experiment was conducted by Mairesse et al. (2005) in order to characterize some quality descriptors of reared perch in comparison to wild perch and the most interesting result indicated that reared perch possessed wild-like quality characteristics, except for some technological variables like the viscerosomatic index and fillet yield.

More recently, studies were dedicated to investigate the mechanisms implicated in the diet lipid utilization in order to reduce the accumulation of fat in hepatic tissues. A wide range of factors can be attributed to the syndrome of fatty liver observed in some cultured fish species. The objective of the study was therefore to quantify different hepatocyte ultrastructure features as potentially influenced by 12 nutritional and husbandry factors, in order to discriminate the most influent factors in Perca fluviatilis (Blanchard et al., 2007a). Rearing temperature, through its influences in the general metabolic activity, seems to be the main factor modifying mainly lipid droplet accumulation and RER development. Factors that could be pooled under the designation of factors leading to food accessibility and lipid and protein quality, intensify or compensate the effect of temperature. After this experiment, two research orientations were mainly assessed: the dietary antioxidant supplementation and the dietary lipid source effects.

Like most animals, Percids are unable to perform de novo synthesis of carotenoids, which are fat-soluble pigments widely distributed in nature. In the aquaculture industry, carotenoids are usually incorporated in Salmonid food as a source of pigments, but recent progress have highlighted the special biological positive effects of some carotenoids as antioxidant and particularly astaxanthin (ASX). In perch, a study was designed to test the effect of vitamin-E and ASX (300 and 100 ppm per kg of diet, respectively) supplementation in high 
fat diets (19\% lipid content), mainly on the liver status and growth parameters (Blanchard et al., 2007b). It was concluded that antioxidant supplementation partially compensates deleterious effect of high fat diets and significantly improve the specific growth rate of fish (1.03 and $0.96 \%$ day-1 for ASX and vitamin-E supplementation, respectively compared to $0.84 \%$ day-1 for non-supplemented diet). The protein efficiency ratio of fish fed ASX-supplemented diet was also significantly improved in comparison to fish fed non supplemented diet or diet supplemented with vitamin-E.

A recent experiment was dedicated to the influence of $n-3 / n-6$ dietary lipid ratio on the growth performances, fatty acid composition of tissues and liver status (Blanchard et al., 2007c) because n-3/n-6 imbalance was recognised to be highly deleterious, mainly in terms of growth performances, feed efficiency and health of different fish species. Cod liver, safflower and linseed oil combinations were used to perform 4 isoenergetic diets, all supplemented with ASX, with different $n-3 / n-6$ ratios.

Better growth performances and protein efficiency ratio were obtained using diets with a $n-3 / n-6$ ratio close to 1 . This could indicate good perspectives for the aquaculture industry of perch as the species seems to have fatty acid nutritional requirements allowing the use of alternative vegetable oil in combination to fish oil rather than pure fish oil in feed formulations.

An experiment dedicated to evaluate the effects of dietary factors, stocking biomass and domestication on the nutritional and technological quality of the perch allow Mairesse et al. (2007) to identify two main factors, i.e. domestication and diet composition, which influence both technological and nutritional variables.

In conclusion, regarding recent progress in feed and nutrition of Eurasian perch during ongrowing, the production of a diet meeting the specific requirement of the species namely $40 \%$ protein and $19 \%$ lipid content with astaxanthin supplementation (100 ppm and n-3/n-6 ratio close to 1 , could be recommended.

\section{Pikeperch}

Nowadays, knowledge on optimal conditions for pikeperch ongrowing is scarce. Regarding environmental conditions, optimal rearing temperature for pikeperch growth seems to be around $28^{\circ} \mathrm{C}$, making it the most thermophilic cultivated Percid studied so far (Hilge et al., 1996 ; Wang et al., submitted). In addition, feeding behaviour ceases at $32^{\circ} \mathrm{C}$ (Willemsen, 1978). Concerning nutrition, no commercial diet has been especially designed for pikeperch yet. However, gross requirements of protein, lipid and carbohydrate contents have been identified. The most important is that feed must be highly proteic (47$54 \%$ ) and protein/energy ratio should be within 23.7 and 24.5 g.MJ-1 
(Hilge et al ., 1996 ; Nyina-Wamwiza et al., 2005 ; Schulz et al., 2007). At this level, carbohydrates content of the diet may range between 10 and $20 \%$ without affecting growth. However, this matter should be further investigated.

According to Schulz et al. (2007), lipid content should ideally be around $17 \%$, even though Zakes et al. (2004) and Nyina-Wamwiza et al. (2005) found no growth difference with diet containing from 10 to $22 \%$ lipid and $45-50 \%$ protein. In addition, partial replacement of fish oil by linseed or soybean oil seems possible (Schulz et al., 2005).

Wang et al. (submitted) found optimal feeding rates of $1.5 \%, 1.8 \%$ and $2.0 \%$ for growth of pikeperch reared at 20,24 and $28^{\circ} \mathrm{C}$, respectively. When feed is adequate and optimally delivered, it was found that its efficiency generally ranges between 0.8 and 1.0 (Zakes et al., 2003 ; Nyina-Wamwiza et al., 2005 ; Wang et al., submitted).

To sum up, on the basis of the actual knowledge, a recommended diet for pikeperch would contain about $50 \%$ protein, $17 \%$ lipid and $10-20 \%$ carbohydrates. Pikeperch should be reared at $28^{\circ} \mathrm{C}$, possibly under continuous light. Under these conditions, optimal feeding rate is probably higher than $2 \%$ of fish body weight.

These results should be taken with extreme caution since these recommendations are based on few literatures available for pikeperch growth. Therefore, much more studies are required to complete our knowledge on the nutritional - and also environmental - requirements of pikeperch during the ongrowing stage.

\section{$\underline{\text { Conclusion }}$}

In conclusion, nutritional requirements of Eurasian perch and pikeperch seem similar. Pikeperch may need slightly more protein and fewer lipids than perch, what could be explained by the fact that pikeperch display a faster growth. While, to our mind, knowledge on Eurasian perch nutrition could now allow commercial production of dry feed, much more studies are required for pikeperch to identify the optimal rearing conditions for its production.

\section{References}

Blanchard, G., Gardeur J.-N., Mathis, N., Brun-Bellut, J., Kestemont, P. 2007a. Ultrastructural features of hepatocytes in cultured Eurasian perch (Perca fluviatilis L.) as affected by nutritional and husbandry conditions. British Journal of Nutrition (in press).

Blanchard, G. Henrotte, H., Corraze, G. and Kestemont P. 2007b. Effects of dietary levels and antioxidant supplementation on growth performance, fatty acid composition, hepatic metabolism and ultrastructure in Eurasian perch, Perca fluviatilis L. Aquaculture Nutrition (submitted). 
Blanchard, G, Makombu, J. G., Kestemont, P. 2007c. Effects of different $n-3 / n-6$ ratio diets on growth performance, tissues fatty acid composition and hepatic ultrastructure in Eurasian perch, Perca fluviatilis L. Aquaculture (submitted).

Gardeur J.N., Mathis N., Kobilinsky A. \& Brun-Bellut J. 2007. Simultaneous effects of nutritional and environmental factors on growth and flesh quality of Perca fluviatilis using a fractional factorial design study. Aquaculture, in press.

Hilge, V., Steffens, W. 1996. Aquaculture of fry and fingerling of pikeperch (Stizostedion lucioperca L.) - a short review. Journal of Applied Ichthyology 12, 167-170.

Kestemont, P., Vandeloise, E., Mélard, C., Fontaine, P. and Brown, P. 2001. Growth and nutritional status of Eurasian perch Perca fluviatilis fed graded levels of dietary lipids with or without added ethoxyquin. Aquaculture 203, 85-99.

Mairesse G., Thomas M., Gardeur J.-N., Brun-Bellut J. 2005. Appearance and technological characteristics in wild and reared Eurasian perch, Perca fluviatilis (L.). Aquaculture 246, 295- 311.

Mairesse G., Thomas M., Gardeur J.-N., Brun-Bellut J. 2007. Effects of dietary factors, stocking biomass and domestication on the nutritional and technological quality of the Eurasian perch, Perca fluviatilis. Aquaculture 262, 86- 94.

Mathis N., Feidt C., Brun-Bellut J. 2003. Influence of protein/energy ratio on carcass quality during the growing period of Eurasian perch (Perca fluviatilis). Aquaculture 217 453-464.

Molnar T., Szabo A., Szabo G., Szabo C. \& Hancz C. 2006. Effect of different dietary fat content and fat type on the growth and body composition of intensively reared pikeperch Sander lucioperca (L.). Aquaculture Nutrition 12, 173-182.

Nyina-Wamwiza L., Xu X.L., Blanchard G. \& Kestemont P. 2005. Effect of dietary protein, lipid and carbohydrate ratio on growth, feed efficiency and body composition of pikeperch Sander lucioperca fingerlings. Aquaculture Research 36, 486-492.

Schulz C., Huber M., Ogunji J. \& Rennert B. 2007. Effects of varying dietary protein to lipid ratios on growth performance and body composition of juvenile pike perch (Sander lucioperca). Aquaculture Nutrition 13, 1-8.

Schulz C., Knaus U., Wirth M. \& Rennert B. 2005. Effects of varying dietary fatty acid profile on growth performance, fatty acid, body and tissue composition of juvenile pikeperch (Sander lucioperca). Aquaculture Nutrition 11, 403-413.

Wang, N., Xu, X., Kestemont, P. 2007. Effect of temperature and feeding frequency on pikeperch (Sander lucioperca) growth: research of optimal conditions. Aquaculture Research, submitted.

Willemsen, J. 1978. Influence of temperature on feeding, growth and mortality of pikeperch and perch. Verh. Internat. Verein. Limnol. 20, 2127-2133. 
Xu X \& Kestemont P. 2002. Lipid metabolism and fatty acid composition of Eurasian perch tissues as influenced by dietary fat. Lipids 37 (3), 297-304.

Xu, X., Fontaine, P., Mélard, C. \& Kestemont, P. 2002. Effects of dietary fat levels on growth, feed efficiency and biochemical compositions of Eurasian perch Perca fluviatilis. Aquaculture International. 9, 437-449.

Zakes Z., Przybyl A., Wozniak M., Szczepkowski M. \& Mazurkiewicz J. 2004. Growth performance of juvenile pikeperch, Sander lucioperca (L.) fed graded levels of dietary lipids. Czech Journal of Animal Science 49, 156-163.

Zakes Z., Szkudlarek M., Wozniak M., Demska-Zakes K. \& Czerniak S. 2003. Effects of feeding regimes on growth, within-group weight variability, and chemical composition of the juvenile zander, Sander lucioperca (L.), body. Electronic Journal of Polish Agricultural Universities 6, http://www.ejpau.media.pl/ series/volume6/issue1/fisheries/art-04.html 


\title{
Growth and husbandry effects in percids
}

\author{
MELARD Charles
}

Aquaculture Research and Education Center (CEFRA), University of Liège, 10, Chemin de la Justice B-4500 Tihange, Belgium.

Tel.: +3285274153

C.Melard@ulg.ac.be

\section{Introduction}

During the last years, developments in Eurasian perch (Perca fluviatilis) control of reproduction (Fontaine et al., 2006), larval rearing (Kestemont et al., 2003; Kestemont and Mélard, 2000) and genetic improvement (Rougeot et al., 2002) results in large scale intensive rearing tests at experimental level and pilot scale, both with juveniles and adults.

This review synthesises the results of experiments conducted in "commercial like" production environments (recirculating system, large tanks) and focuses on most relevant factors influencing growth and production in intensive rearing systems.

\section{Effect of water temperature and body weight}

In intensive culture conditions, the maximum growth rates $(0.06$ to $1.80 \mathrm{~g}$ fish-1 d-1 for 3 to $300 \mathrm{~g}$ fish) of monosex female F4 perch is observed at $23^{\circ} \mathrm{C}$. Rearing at higher $\left(27^{\circ} \mathrm{C}\right)$ or lower temperatures $(11$ to $20^{\circ} \mathrm{C}$ ) result in lower growth rates (Figure 1).

The intensive culture of perch at a constant $23^{\circ} \mathrm{C}$ water temperature allowed much higher growth rates than usually observed in conventional, extensive systems under natural thermal regimes (Mélard et al., 1996).

High and constant temperature also inhibited the sexual maturation in females. In intensive rearing systems at $23^{\circ} \mathrm{C}$ and at a maximum stocking biomass of $50 \mathrm{~kg} \mathrm{~m}-3$, perch juveniles $(0.5 \mathrm{~g}$ initial body weight) reach the minimal commercial size $(100 \mathrm{~g})$ after 9 months (figure 1). 


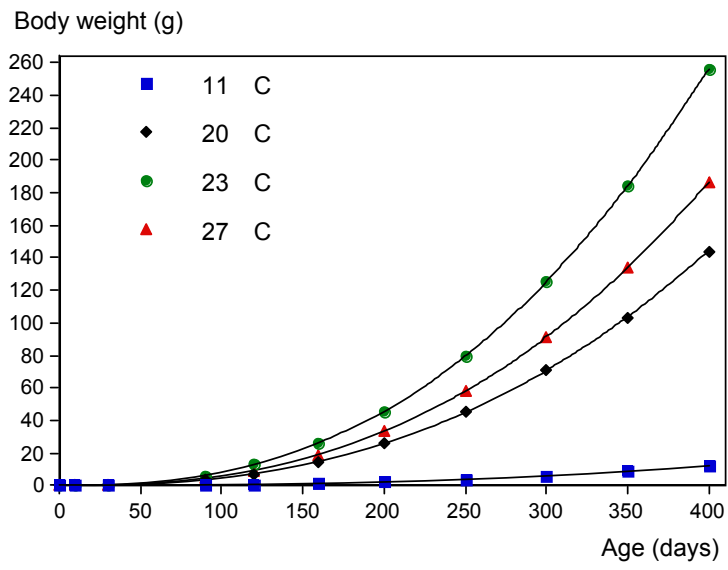

Figure 1. Growth curves of perch reared in recirculating system at different temperatures. Maximum food ration; stocking biomass: 24-50 $\mathrm{kg} \mathrm{m}$-3. (after Mélard et al., 1996)

\section{Effect of oxygen and ammonia}

The oxygen level in the rearing tanks should be $\geq 5 \mathrm{ppm}$, higher oxygen concentrations do not increase the growth rate. Ammonia (NH3) resulting from the fish excretion can be a critical factor mainly in recirculating system when biofilter does not work properly. LD5096h is around $0.8 \mathrm{mg} / \mathrm{l} \mathrm{N}-\mathrm{NH} 3$ for perch reared at $23^{\circ} \mathrm{C}$. However, the critical $\mathrm{NH} 3$ level for growth is reached at a much more lower value, around $0.04 \mathrm{mg} / \mathrm{l} \mathrm{N}-\mathrm{NH} 3$ (figure 2). Concentrations up to $0.3 \mathrm{mg} / \mathrm{l} \mathrm{N}-\mathrm{NH} 3$

\section{$\operatorname{SGR}\left(\% \mathrm{~d}^{-1}\right)$}

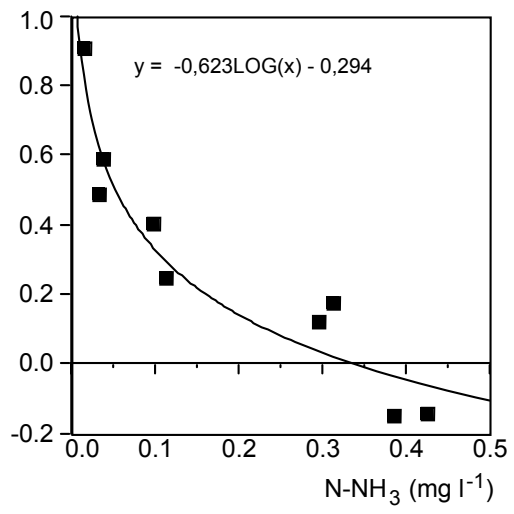
induce a decrease of body weight (figure 2).

Figure 2. Effect of ammonia on growth rate of perch. Mean BW= $150 \mathrm{~g}$; temperature $=23^{\circ} \mathrm{C}$. 


\section{Effect of stocking density and biomass}

Perch rearing at low stocking biomass $<5 \mathrm{~kg} \mathrm{~m}-3$ results in a decrease of growth in comparison to the growth of fish reared at higher stocking biomass $>10 \mathrm{~kg} \mathrm{~m}-3$ (figure 3). This seems to originate from a density dependent inhibition of territorial and agonistic tendencies that potentially limit access to food at low density (Mélard et al., 1996). Higher stocking densities inhibit territoriality. However, growth rate decreased with increasing stocking densities for biomass up to 20-60 $\mathrm{kg}$, depending of body weight (figure 3 and 4).

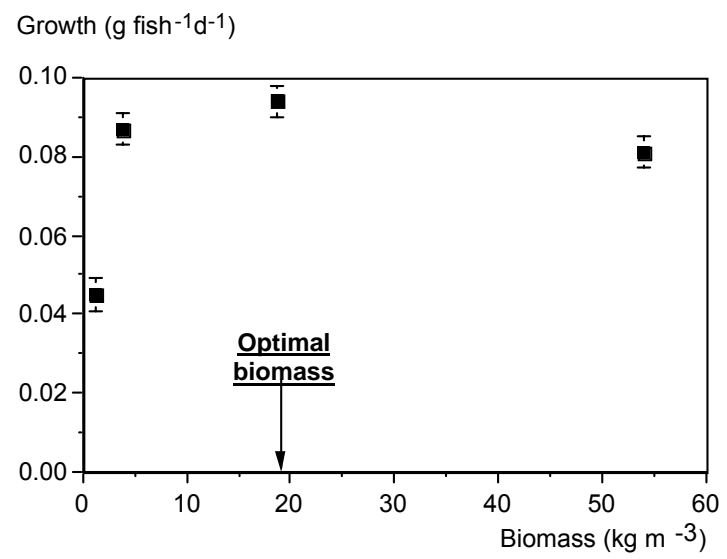

Figure 3. Effect of stocking biomass on growth rate of perch. Body weight: $10 \mathrm{~g}$, temperature $23^{\circ} \mathrm{C}$ (After Mélard et al., 1996)

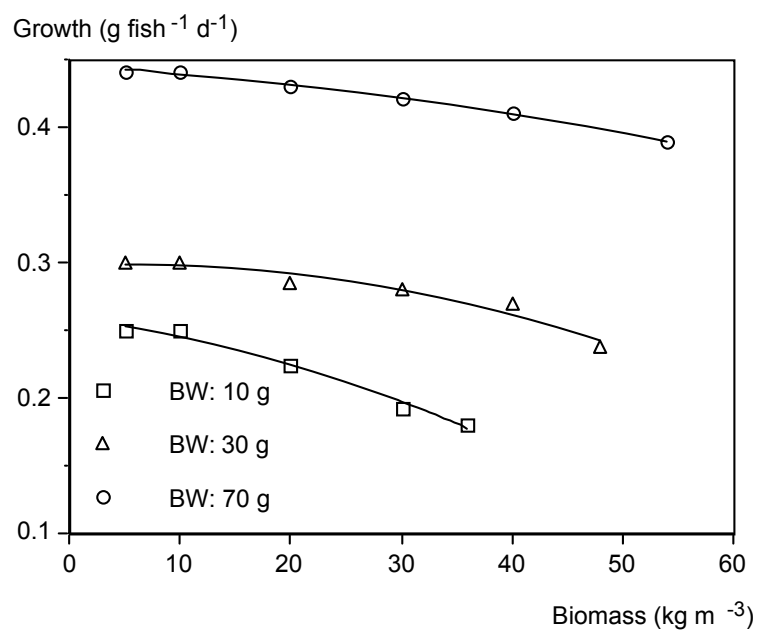

Figure 4. Effect of stocking biomass on growth rate of perch reared at $23^{\circ} \mathrm{C}$.

The optimal stocking biomass that gives the higher production level depends of the body weight. Optimal biomass ranging from $35 \mathrm{~kg} \mathrm{~m}-3$ 
for $5 \mathrm{~g}$ fish to $75 \mathrm{~kg} \mathrm{~m}-3$ for $150 \mathrm{~g}$ fish, provide production levels of $600 \mathrm{~g} \mathrm{~m}-3 \mathrm{~d}-1$ and $320 \mathrm{~g} \mathrm{~m}-3 \mathrm{~d}-1$ respectively (figure 5).

Production $\left(\mathrm{g} \mathrm{m}^{-3} \mathrm{~d}^{-1}\right)$
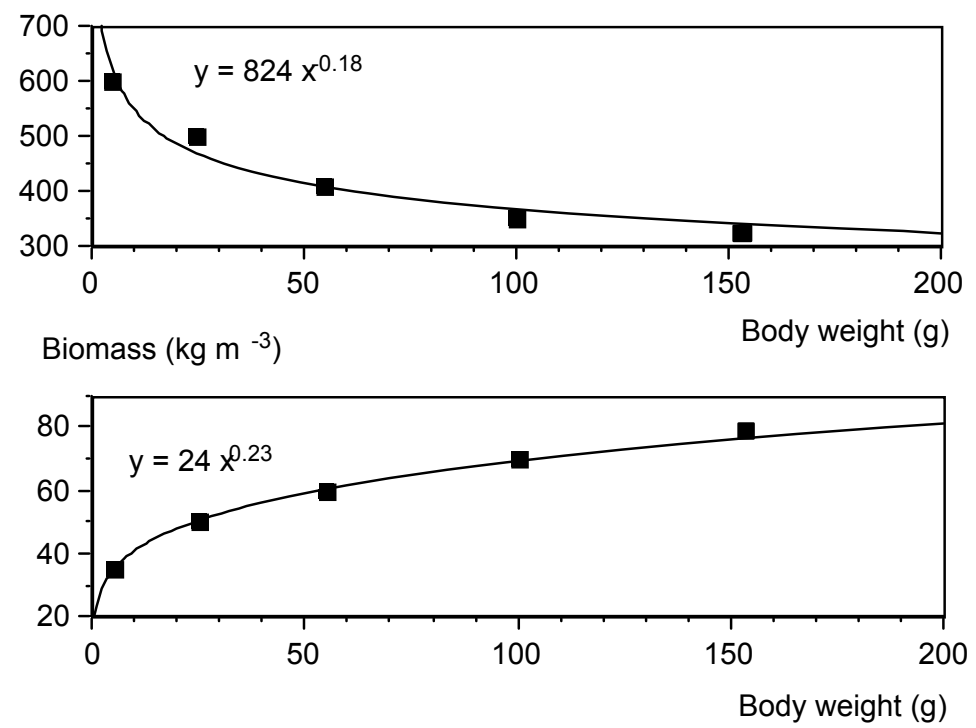

Figure 5. Relationships between body weight, optimal biomass and production level in perch reared at $23^{\circ} \mathrm{C}$.

\section{Growth heterogeneity}

Growth heterogeneity constitutes a major constrain in perch culture and may induce huge cannibalism during the juveniles on growing phase. Size grading results in the emergence of fast growing fish in each sorted group and strongly reduces cannibalism. However, the sorting process do not improved the global productivity in comparison to non-sorted populations of the same origin and body weight (figure $6)$. 


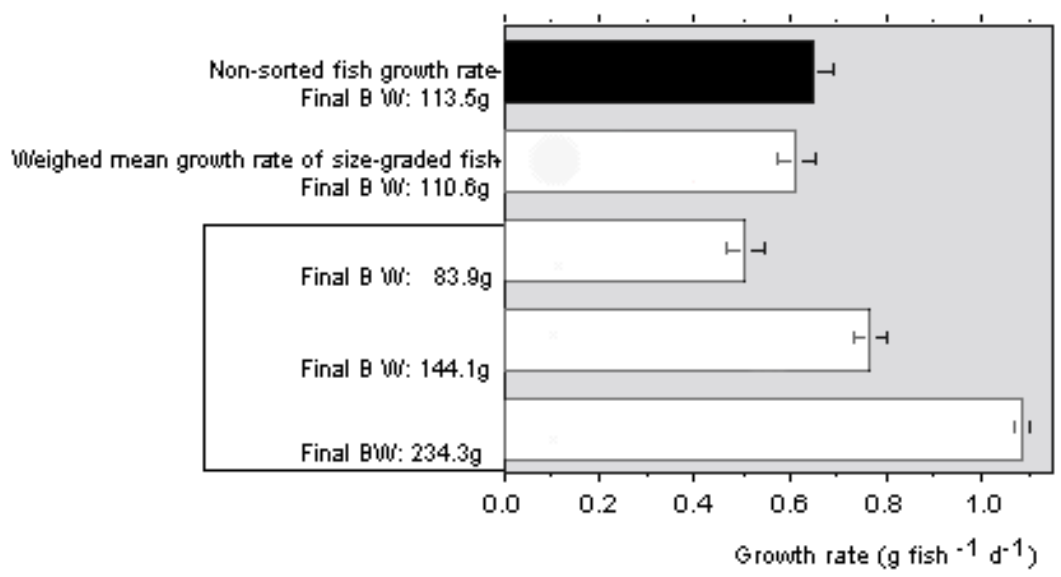

Figure 6. Growth rate of non-sorted and sized-graded perch reared at $23^{\circ} \mathrm{C}$ during 70 days. (After Mélard et al., 1996)

\section{Survival}

High mortality may take place at any stage of perch rearing within the 1-160 g body weight range. In general, an overall $60-70 \%$ survival rate was recorded after 12 months of rearing. Parasites, bacteria, stress and cannibalism are the most frequently encountered causes of mortality. The occurrence and impact of diseases are largely reduced in recirculating systems where the survival rate is higher than the values observed in flow-through rearing systems.

\section{$\underline{\text { Conclusion }}$}

The intensive culture of perch at a constant $23^{\circ} \mathrm{C}$ water temperature allowed much higher growth rates than usually observed in conventional, extensive systems under natural thermal regimes. Further improvements of growth and productivity in intensive perch rearing will closely rely on techniques such as the selection of fast growing strains and monosex female fish production (Mélard et al, 2003).

\section{References}

Fontaine, P., Pereira, C., Wang, N., Marie, M., 2006. Influence of preinductive photoperiod variations on Eurasian perch, Perca fluviatilis, broodstock response to an inductive photothermal program. Aquaculture 255, 410-416.

Kestemont, P., Mélard, C., 2000. Chapter 11 - Aquaculture. In : Craig, J.F. (Ed.) Percid Fishes - Systematics, Ecology and Exploitation, Blackwell Science, Oxford. pp. 191-224. 
Kestemont, P., Xu, X., Mélard, C., Fontaine, P., 2003. Recent progress in nutrition of Eurasian percid fishes - a review. In Proceedings of Percis III: The Third International Percid Fish Symposium (Barry, T.P. and J.A. Malison, Eds.), University of Wisconsin Sea Grant Institute, Madison, WI. fish products, Advances in meat research series, Volume 11. Blackie Academic and Professional, London, pp. 118-149.

Mélard, C., Kestemont, P., Grignard, J.C., 1996. Intensive culture of juvenile and adult Eurasian perch (Perca fluviatilis): effect of major biotic and abiotic factors on growth. J. Appl. Ichthyol. 12: 175-180.

Mélard, C., Rougeot, C., Mandiki, S.N.M., Fontaine, P., Kestemont, P., 2003. Genetic growth improvement of Perca fluviatilis: a review.. In Proceedings of Percis III: The Third International Percid Fish Symposium (Barry, T.P. and J.A. Malison, Eds.), University of Wisconsin Sea Grant Institute, Madison, WI. fish products, Advances in meat research series, Volume 11. Blackie Academic and Professional, London, pp. 175-180.

Rougeot, C., Jacobs, B., Kestemont, P., Mélard, C., 2002. Sex control and sex determinism study in Eurasian perch, Perca fluviatilis, by use of hormonally sex-reversed male breeders. Aquaculture 121, 81-89. 


\title{
Quality attributes in farmed and wild Eurasian perch
}

\author{
THOMAS Marielle(*), GARDEUR Jean-Noël, MAIRESSE Guillaume, \\ BRUN-BELLUT Jean
}

Unité de Recherche Animal Fonctionnalités des Produits Animaux, Equipe Domestication en Aquaculture Continentale, Nancy Université - INRA, 34 rue Sainte Catherine - 54000 Nancy, France

${ }^{*}$ Corresponding author. Tel.: +33 (0)3 83308447

E-mail address: marielle.thomas@lsa-man.uhp-nancy.fr (M. Thomas)

\section{$\underline{\text { Introduction }}$}

In order to satisfy the current increase of human fish consumption, aquaculture is rising along with the necessity of supplying diversified products of high quality. In this context, the domestication of the Eurasian perch Perca fluviatilis opens out with in parallel the necessity to understand the multifactorial determinism of the quality building. Today, consumer's quality reference is wild fish. Indeed it is widely believed that wild fish acceptability is greater than that of farmed fish. So one question of fish farmer is to know where their products are to be placed in comparison with wild fish. Within this framework, the objectives of this work are i) to describe the quality attributes of farmed perch by considering different rearing contexts (extensive versus intensive), ii) to precise how the quality of farmed fish differ the one of wild fish and also iii) to determine the environmental factors which operate on the quality construction. For that, several quality attributes are taking into consideration: global appearance of perch (morphology and colour in both whole fish and flesh), different technological parameters and also nutritional traits.

\section{Fish collection}

Farmed perch were sampled in October 2003 (period of market consumption) from three different rearing systems: extensive system (pond, Gelucourt, France), semi-extensive system (tank, Lindre, France) and intensive unit (water recirculating system, pilot farm Lucas Perches, Hampont, France). In the extensive system, fish were fed natural preys. Fish from the semi-extensive system were fed both natural and artificial food (Bio-Optimal ST - BioMar). In the intensive system, fish were exclusively fed artificial food (Ecolife 15 - BioMar). To collect the wild perch, two natural sites were selected on the basis of their very different typological and physico-chemical characteristics: Rhine River (Boven-Hardinxveld, NL) and Lake Geneva (Lugrin, F). Perch were sampled at four different periods (July 2002, October 2002, January 2003, and April 2003). 
The sample size ranged from 23 to 48 perch per rearing system or per site and per season. All fish were slaughtered by a thermo-shock in a melting ice bath and then the different quality attributes were measured.

\section{$\underline{\text { Colour measurements }}$}

Data were recorded in the CIE-L* (lightness), $a^{*}$ (redness) and $b^{*}$ (yellowness) system using a Minolta Chromameter CR-300. Immediately after death, the colour measurements were done on whole fish in duplicate in four different locations (caudal fin, strip, interstrip, and ventral parts). Colour of fillet was measured in duplicate on the internal side of the antero-dorsal part, immediately after filleting, using both stacked fillets.

\section{Morphometric measurements}

Seven morphological indices were calculated from 12 morphological measurements taking into account the curvature of the fish (Figure 1). The data were standardized to eliminate size-related differences, as described in Mairesse et al. (2005).

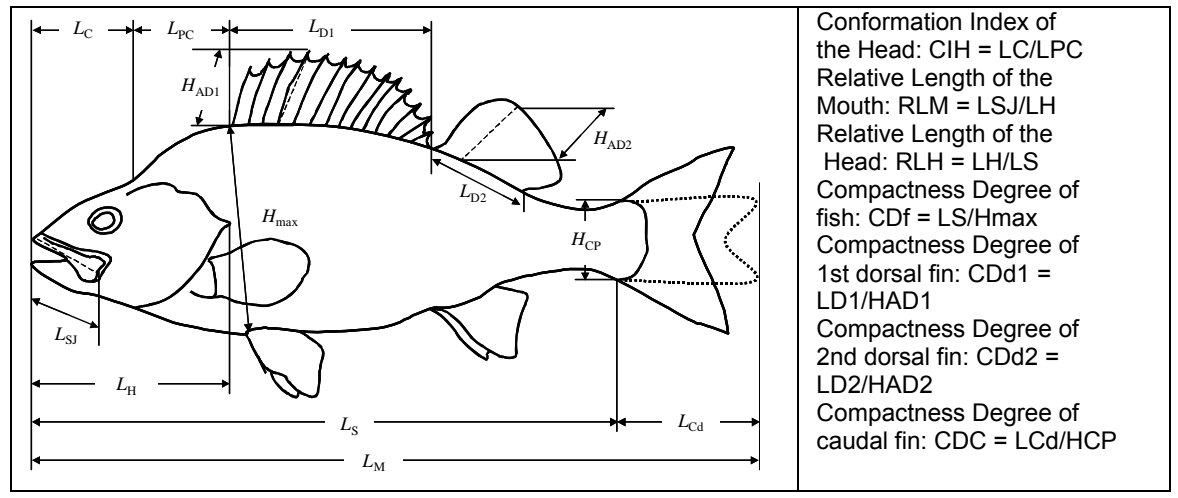

Figure 1: Morphometric measurements of Perca fluviatilis and the calculated indices.

\section{$\underline{\text { Technological measurements }}$}

Gonadosomatic, hepatosomatic, viscerosomatic and perivisceral fat indexes, named IG, IH, IV, IPF respectively, were calculated on fresh fish as percentages of total fish weight $(\mathrm{Wt})$. The condition factor of perch was evaluated according to: $\mathrm{K} 2(\%)=(\mathrm{Wt}-\mathrm{WG}) / \mathrm{LS} 3$, with WG $=$ weight of the gonads $(\mathrm{g})$ and $\mathrm{LS}=$ the non-standardized standard length $(\mathrm{cm})$. Fish were filleted by the same professional fish transformer after the rigor mortis state (i.e. 48h post mortem). The fillet yield, specified by YF, was calculated using the following formula: Yf $(\%)=\mathrm{Wf} / \mathrm{Wt}$ (with $\mathrm{Wf}=$ weight of the two fillets without skin in gram). 


\section{Nutritional characteristics}

The lipid extraction of both fillets of each fish and the fatty acid composition were determined according to the protocol described in Mairesse et al. (2006). Total lipids were expressed as a percentage of the fillet weight and the fatty acids (FA) composition was assessed using Gas-Liquid Chromatography. Only FA $>1 \%$ of total FA were reported in the results.

\section{$\underline{\text { Statistical analysis }}$}

Principal Component Analyses (PCA) were performed on the four groups of variables (colour, morphometric, technological and nutritional attributes). A comparison between farmed and wild perch was made using farmed fish as illustrative individuals.

\section{$\underline{\text { Results }}$}

No discrimination between male and female is shown, whatever the quality attributes considered in the present study.

Among all colour variables, the one of the fillet was not a main discriminating factor for the origin of fish. The individuals from the semi-extensive and the extensive rearing systems tend to possess similar colour attributes, while the intensive rearing unit produces fish with other colour characteristics. Perch from intensive rearing system have brighter caudal fins and ventral part and also less pronounced contrast between strip and interstrip. Compared with wild fish, perch from intensive systems are close to the Lake Geneva and the Rhine River fish caught in July, whereas the two other rearing systems tend to produce Rhine River-similar fish according to colour attributes. Indeed, fish caught in the Rhine River are darker and possess a more reddish caudal fin than fish from the Lake Geneva. Moreover, a high degree of inter-seasonal variability exists for the Rhine perch whereas the colour of fish from the Lake Geneva presents low inter seasonal variation. Besides, a relationship between standard length and all colour components of caudal fin and lightness of ventral part exists in the wild fish.

Considering morphometric variables, the farmed perch do not present great differences compared to their wild-caught counterparts. Indeed extensive and semi-extensive reared perch possess attributes closely related to perch from the Rhine River. These ones have both compact body and caudal fin. They also possess both longer mouths and heads than fish from the Lake Geneva. Nevertheless, high variability between seasons in morphology was observed particularly on the Rhine River. However, intensive farmed perch present CDf and CDc measurements significantly different from wild fish independently of 
their origin. Furthermore, each rearing system produces fish with different RLM and CDf: RLM decreases and CDf increases between an extensive to an intensive system.

The study of technological attributes allows discriminating perch from each rearing system. The lowest fillet yields are recorded in perch from semi-extensive system (33.2\% versus 39.8 and $42.3 \%$ in the other systems). On the other hand, intensification of farming conditions induces a significant increase of IPF (from $1.86 \%$ in extensive system to $4.88 \%$ in intensive rearing). Technological attributes are not the most discriminating variables between fish from Lake Geneva and the Rhine River. Only the condition factor K2 allows a distinction between wild fish (1.9 and 2.3 in fish from Lake Geneva and Rhine River respectively).

Considering nutritional quality, intensively reared perch displayed higher lipid content $(1.48 \%)$ than the other farmed perch $(1.26 \%$ for the semi-extensive system and $1.16 \%$ for the extensive system). In the natural sites, a significant difference in the total lipids of perch muscle was observed between fish collected from the Rhine River $(1.21 \%)$ and the Lake Geneva (1.43\%). The season had a significant effect on the total lipid content only for the fish from the Rhine River. On the other hand, the most important differences in FA composition between the wild and the farmed fish were in their MUFA and PUFA content. The farmed fish had a higher MUFA content than wild fish (16-19\% versus $12-14 \%$ of total FA). Arachidonic acid $20: 4 n-6$ was identified as the primary n-6 PUFA in fish coming from the Rhine River, the Lake Geneva, and the extensive system $(71,75$ and $61 \%$ of total n-6 PUFA respectively), i.e. fish fed natural food, whereas linoleic acid 18:2n-6 was predominant in fish reared in the semi-extensive and the intensive system ( 66 and $69 \%$ of $n-6$ PUFA respectively). Finally the wild fish displayed significantly more EPA (13.2-12.5\% of total FA) than the farmed perch (9.2-10.9\%), whereas no difference was found for DHA between the lacustrine perch $(31.9 \%)$ and the intensively farmed fish (33\%) on the one hand and between the Rhine River fish (37.1\%) and semi-extensively farmed fish (36.9\%) on the other hand. A seasonal variation in FA composition appeared in wild fish. It concerns in particular the n-6 PUFA.

\section{Conclusion}

This study shows that both the appearance and the technological attributes in reared perch are similar to those in wild perch. Whereas only the technological parameters are discriminatory in reared perch, it is possible to differentiate the wild Eurasian perch by considering either the global morphology or the caudal fin colour attributes (see the synopsis in Figure 2). These quality attributes varied according to site and season. In the same way, we showed that the nutritional quality of the perch varied according to the geographic source, rearing 
system, and season. All these variations in the quality attributes in wild and farmed Eurasian perch result from the characteristics of the physico-chemical and trophic environments. Moreover, the influence of intrinsic factors on the quality attributes must also be considered. In sum, the concept of 'wild reference' has not really a sense and it is now necessary to further explore the multiple factors that influence the quality building.

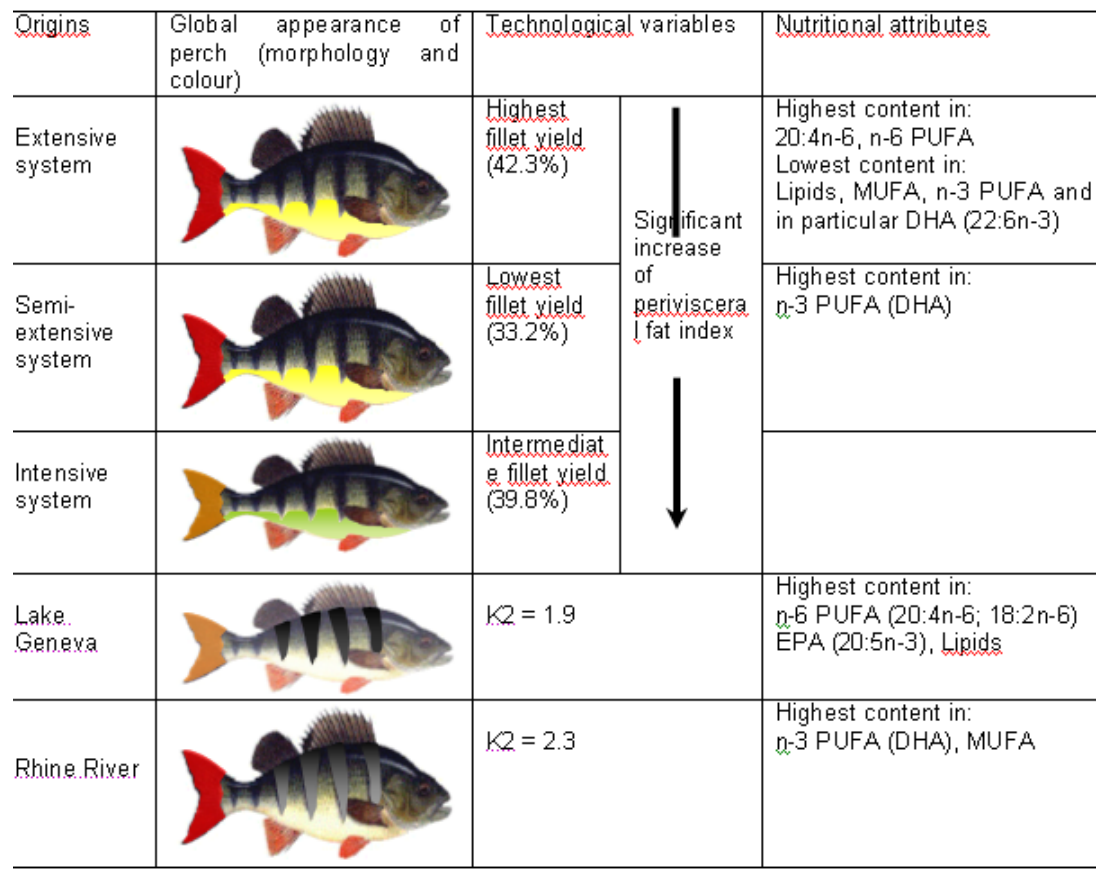

Fig. 2: Synopsis of the quality attributes of farmed and wild perch (PUFA, poly-unsaturated fatty acid; MUFA, mono-unsaturated fatty acid).

\section{$\underline{\text { References }}$}

Mairesse G., Thomas M., Gardeur J.N., Brun-Bellut J., 2005. Appearance and technological characteristics in wild and reared Eurasian perch Perca fluviatilis (L.). Aquaculture, 246, 295-311.

Mairesse G., Thomas M., Gardeur J.N., Brun-Bellut J., 2006. Effects of geographic source, rearing system, and season on the nutritional quality of wild and farmed Perca fluviatilis. Lipids, 41(3), 221-229.

Mairesse G., Thomas M., Gardeur J.N., Brun-Bellut J., 2007. Effects of dietary factors, stocking biomass and domestication on the nutritional and technological quality of the Eurasian perch Perca fluviatilis. Aquaculture, 262, 86-94. 


\title{
Perch culture and pathology control - Knowing your enemy
}

\author{
ARIEL Ellen \\ Danish Technical University, National Veterinary Institute, Fish \\ Disease Section, Hangøvej 2, Denmark \\ Email: ear@vet.dtu.dk
}

For many years capture fisheries seem to have reached a plateau in the volume harvested from the aquatic environment and there are concerns that even the current level of harvest will eventually deplete this natural resource. Aquaculture shows great potential for meeting some of the growing needs of consumers for animal protein and the past decade has taken the industry into large scale production units of traditionally cultured species and a search for new species of potential for aquaculture.

The obstacles to the continued development of this industry are several, but the primary constraint is disease.

Therefore the future of aquaculture is much dependent on a baseline knowledge of the individual diseases of concern to the industry, accurate detection and early warning systems combined with preparedness plans for controlling and containing the diseases, while still facilitating trade and expansion.

A common factor for all diseases is that prevention is better than cure and this puts the emphasis on one of the major challenges to pioneering a new species in aquaculture, which is the availability of disease free brood stock. To test the brood stock for freedom of diseases, one must know which specific diseases we are looking for. Knowing the enemy!

Good management practise, once established for perch, will in many cases prevent problems caused by parasites, bacteria and virus. However, pioneer culture of a species such as perch reveals that normally innocuous microbes turn pathogenic when the fish are cultured under new and abnormal conditions that in one way or the other will influence the immunesystem-pathogen balance in favour of the pathogen. A catalogue of microbes will prepare the farmer for the situation where disease breaks out. Many of these pathogens we already know and we know how to reduce their impact via prevention, management or treatment.

Treatments are available for many parasites and bacteria. Even so, it is important to consider resistance development in the pathogen population and the detrimental effects some of these treatments may have on the environment. The availability of legalised treatments in the different countries could also be a consideration. Hence, identification of the pathogen and recommended actions for control is done in cooperation with a fish disease laboratory and a veterinarian. 
This leaves us with those troublesome primary pathogens that are specific for perch and for which we have little or no knowledge yet. Worth while mentioning, are the viruses epizootic haematopoietic necrosis virus (EHNV) and perch rhabdovirus that are reported to infect perch with highly detrimental effects at times.

For viruses there are no treatment options, only prevention of entry into the facility or in case of infection: eradication of stock and disinfection of facility before restocking with disease free stock. Studies are currently underway to assess the impact of the OIE listed disease EHNV on European perch culture.

Perch rhabdovirus has been reported from several countries in Europe, often associated with mortalities in wild populations. Both of these diseases should receive high attention when assessing the potential impact of diseases on perch aquaculture in Europe. 


\title{
Lucas Perches: production of Eurasian perch in recirculating system
}

\author{
MARTIN Benoît and VANDEVORDE David \\ Moulin du Cany, 57260 Hampont, France
}

Created in 2001, the company LUCAS PERCHES aims to produce, to transform and to trade 100 metric tons of Eurasian perch Perca fluviatilis. When the company was created, it obtained the European status of "pilot farm". All the production is supported by water recirculating systems. Water resource is provided by a small river ("la petite seille") and a geothermal pumping. The mixture of these two types of water allows maintaining an optimal water quality for perch growth.

Perch fingerlings are bought at an initial weight of $1 \mathrm{~g}$ and then reared until the commercial weight $(100 \mathrm{~g})$. The duration of the production cycle fluctuates between 4 and 10 months according to their growth potential. The production cycle is divided into two phases: the first one concerns the rearing of fish from $1 \mathrm{~g}$ until $20 \mathrm{~g}$ and the second from 20 $\mathrm{g}$ to $100 \mathrm{~g}$. The capacity of production of the pilot farm is 25 tons per year, an extension of this capacity will ensure in the closed future the production of 100 tons.

A high part of the production is sold as whole fish placed in polystyrene boxes and under ice. In order to satisfy a demand more and more important (Switzerland market), a part of the production is filleted at the farm. This activity is possible because the Lucas perches company has a European sanitary agreement and specific rooms (cooling chambers).

Finally, since its creation, Lucas Perches has developed partnerships with numerous partners implicated in the local Inland aquaculture development (FLAC, University of Nancy) or in research on Percid culture (Percatech and Percinnov projects). We intend to continue such collaborations in order to continue to progress. 


\title{
Excellence Fish : production of pikeperch in recirculating system
}

\author{
PHILIPSEN, A.
}

Excellence Fish BV is located in the south of the Netherlands. Since 1998, Excellence Fish are producing African catfish for the consumption market and Ornamental fish for the garden shops in indoor recirculation systems. These markets are limited and subjected to changing trends.

In 2000 Excellence Fish was looking for a new fish species which has an existing high market value. Pikeperch fitted well to these requirements.

In the same year, Excellence Fish were starting with the first experiments on pikeperch in cooperation with IMARES IJmuiden.

The results were very promising and Excellence Fish decided to go further with this species. In cooperation with some Universities and IMARES, we created a new consortium to solve the farming problems on pikeperch.

After two European research projects, Excellence Fish is investing in a new production facility divided in a hatchery and a ongrowing system, to test the broodstock lines and go into further development to increase grow rate and domestication level.

Nowadays, Excellence Fish has the control on year round out-of season broodstock and spawning production, from domesticated indoor breeding lines.

The strategy for the coming three years are set on yearly one million fingerlings and a production of 40 till 50 tons pike-perch (whole fish 1$2 \mathrm{~kg})$.

Consultancy and business development are playing more and more a role for Excellence Fish, because the philosophy from Excellence Fish is that we need a profitable business for our customers after our fingerling production.

In cooperation with our customers we go for the market potential from pikeperch. 


\title{
German experiences with the intensive culture of pikeperch (Sander lucioperca L.)
}

\author{
WEDEKIND, Helmut
}

Institute for Fisheries, Bavarian Federal State Center for Agriculture, Weilheimer Str. 8, 82319 Starnberg, Germany

Tel. ++49 (0)8151-2692100

E-mail address: helmut.wedekind@|fl.bayern.de

\section{Introduction}

Pikeperch (Sander lucioperca) is a highly demanded species from inland and brackish waters of Germany and other European countries. Traditionally, this species in cultured on an extensive level in open pond culture, predominantely in combination with common carp. At present, about $66 \%$ of pond farmers are practicing propagation and production of 1- or 2-year old pikeperch (50 t/a) in Germany. In addition, there is about $140 \mathrm{t} / \mathrm{a}$ wild catch in the market.

As a recent development, pikeperch is produced in intensive aquaculture at a low, but increasing level (recirculation-systems: 2.5 $\mathrm{t} / \mathrm{a}$, net cages: $2 \mathrm{t} / \mathrm{a}$ ).

Due to the fact, that pikeperch is a high price product in Germany $(6,50-16,--€ / \mathrm{kg})$, research is carried out to promote this possibility of diversification in fish farming.

\section{Experiences in Germany \\ Reproduction}

The most common method for pikeperch propagation in Germany is still the natural reproduction in ponds. Mature males and females (1:1 or 2:1) are placed in fertile carp ponds. They are allowed to spawn freely. Harvest takes place in autumn, when up to 15,000 yearlings can be yielded from one hectare of pond surface.

The second way of pikeperch reproduction in Germany can be called semi-natural, when a set of spawners (1:1) is placed in basins or netcages. The fish are accepting artificial brushes or mats as spawning substrate. After spawning eggs are taken into aquaculture facilities for hatching. Usually, the fry is transferred into ponds for growout, but first feeding with zooplancton (e.g. Artemia salina) in hatcheries is more and more practiced.

Artificial reproduction was carried successfully at some places by injecting releasing hormones (LHRHa) to ripe spawners. With this method it is possible to produce fry at early spring, about 3 months earlier, when compared to the natural cycle (Müller-Belecke et al. 2006). 


\section{Weaning}

In several on-farm investigations and in research project the development of methods for the production of pikeperch in aquaculture, based on cheap fingerlings from pond farming, was aimed at (e.g. Baer et al. 2001, Wedekind et al. 2003).

Weaning of pikeperch fry (initial weight $0.5 \mathrm{~g}$ ) from natural food to dry feed was carried out successfully in several trials. It was experienced, that the majority of juvenile pikeperch (50-90 \%) can be adapted to extruded dry feed during a transition period of 3-4 weeks. Frozen chironomids were found to be the most effective natural foodstuff for the weaning of pikeperch fry (Baer et al. 2001), but more recently ad hoc-weaning was proven to be another, less laborious possibility. However, this method resulted in a lower survival of dry feeds accepting fingerlings (38-60\%) (Wedekind \& Schmidt 2006).

\section{Growout}

As a first step, the performance of pikeperch using commercial dry feed for growout was investigated at several places in Germany (research institutions and fishfarms). Growth experiments in recirculation-systems based on high energy extruded trout diets resulted in a specific growth rate of $1.2-1.3 \% \mathrm{~d}$ at a water temperature of $20^{\circ} \mathrm{C}$. E.g. an average body weight of $170 \mathrm{~g}$ was reached after 270 days. Feed conversion ratio was 0.8 to 1.1 in this period. In some cases, growout experiments were continued in net cages under natural temperature conditions. At the end of the growout season (October/November) the pikeperch reached a body weight around 700 g. In the second year feeding started in May. After a growout-period of 6 months a significant percentage of the population reached marketing size (>1.5 kg) (Zienert et al. 2005).

Growout in recirculation systems up to market size was proven to be possible experimentally at relatively high stocking densities (30-50 $\left.\mathrm{kg} / \mathrm{m}^{3}\right)$, but is not yet practiced in commercial fishfarms.

\section{Feeding}

In laboratory studies extensive investigations if pikeperch feeding have been carried out by Schulz et al (2007). Under controlled environmental conditions it was concluded, that a protein/energy-ratio of 26 (g CP/MJ ME) might be optimal. However, the deposition of large amounts of visceral fat and excessive fat storage in the liver are a major concern in this context.

\section{$\underline{\text { Conclusions }}$}

In research projects the development of methods for the production of this species in aquaculture was aimed at. As a first step, the performance of pikeperch using commercial dry feeds for growout was 
intensively investigated. The results demonstrate a certain potential for pikeperch production in German aquaculture. The weaning from natural food to artificial diets was possible, but was found to be very labour intensive. Moreover, a relatively high risk of introduction of pathogens to the fishfarm exists. Under practical conditions a percentage of $50-90 \%$ of pond raised fry can be adapted to artificial diets.

Pikeperch can successfully be reared in closed recirculation systems, as well as in outdoor facilities, e.g. net cages, as long as a minimum temperature level above $15{ }^{\circ} \mathrm{C}$ is maintained. Fish growth and feed conversion is similar to other carnivorous aquaculture species. However, production table-size pikeperch in such systems appears to be economically difficult due to cheap imports. In contrast, the market for pikeperch to be stocked in natural waters is very promising. Consequently, there are specialized practitioners in Germany going for this market (Z1 and Z2).

It was observed, that in the case of production in net cages treatment of parasites is necessary. On the other hand, net cage fishfarming in Germany is strongly restricted environmetal legislation.

With regard to artificial reproduction and nutritional aspects, it appears that further research is needed in this species.

\section{$\underline{\text { References }}$}

Baer, J., Zienert, S., Wedekind, H., 2001. Neue Erkenntnisse zur Umstellung von Natur- auf Trockenfutter bei der Aufzucht von Zandern. Fischer \& Teichwirt 7, 243-244.

Müller-Belecke, A., Tusche, K., Zienert, S., 2006. Die Aufzucht von Zandern in der Aquakultur - Untersuchungen zur Bereitstellung von Frühbrut. Fischer \& Teichwirt 8, 286-288.

Schulz, C., Huber, M., Böhm, M., Rennert, B., 2007. Einfluss der Futtermittel-zusammensetzung auf Wachstum und Körperzusammensetzung von Zandern (Sander lucioperca). Fischer\&Teichwirt 4, 143-146.

Wedekind, H., Zienert, S., Knösche, R., 2003. Intensive culture of pikeperch (Sander lucioperca) based on artificial feeds. Aqua Nor, Beyond Monoculture, Trondheim, EAS spezial publication 33, 364365.

Wedekind, H., Schmidt, G., 2006. Ad hoc-Umstellung von vorgestreckten Zandern (Zv) auf ein handelsübliches Trockenfutter. Jahresbericht der Bayerischen Landesanstalt für Landwirtschaft, Institut für Fischerei, 65-66.

Zienert, S., Heidrich, S., Wolf, P., Göthling, U., Knösche, R., Wedekind, H., 2005. Aufzucht von Zandern in der Aquakultur. Schriften des Instituts für Binnenfischerei e.V. Potsdam-Sacrow. 63 p. 


\title{
Perch farming, Swedish experience
}

\author{
ÖBERG Ola
}

Department of Land and Water Resources Engineering, Royal Institute of Technology, Stockholm, Sweden

Corresponding author. Tel.: +46 (8) 7907462

E-mail address: olaoberg@kth.se

Perch and pikeperch are well known and appreciated food in Sweden. Wild catch have been and are the main source. Pike perch are to some extent hatched and grown to juveniles in ponds and sold to lake owners to support wild stock. Perch have not been grown commercially. Wild perch are caught in lakes and on the Baltic coast. The availability of wild catch in the Baltic differs a lot from area to area but has diminished during last decade. In some areas catch are only $10 \%$ of catch 10 years ago.

In 2006 a group of fishermen families at the south east coast of Sweden joined together in the company Stannafisk $A B$, with the ambitions to farm perch for the Stockholm market. Experience of farming rainbow trout, of wild perch behaviour and the fact that perch fillet always sold out encouraged the group. More encouragement came with technical support from the Royal Institute of Technology and financial support from an EC fund (the Financial Instrument for Fisheries Guidance) administrated by the Swedish Board of Fisheries and Swedish funds (the Östsam Regional Development Council, the Swedbank Alfa Foundation and the Innovationsbron).

In September 2007 the company, is holding 160000 perch within the size $10-80$ grams and is operating:

-4 indoor recirculation units, $5 \mathrm{~m} 3$ each.

-3 in sea neat cages $5 \times 5 \times 2 \mathrm{~m}$.

-4 in sea floating circular ponds $5 \times 2 \mathrm{~m}$.

-2 in sea floating rectangular ponds $12 \times 2 \times 2 \mathrm{~m}$.

-1 rectangular pond on land $30 \times 10 \times 1 \mathrm{~m}$.

The floating ponds are constructed in fiber glass armed PVC tarpaulin. Future constructions are a number of floating ponds for ongrowing for a total production of $6 \times 30$ tons yearly. Two on land indoor ongrowing units for a production of 15 ton. Currently the ponds are ventilated with fresh water from the sea by means of a pump. Sludge are collected on the bottom of the ponds and sucked out when needed. The aim is to recirculate the water as much as it is economically relevant. To develop in the coming years are aeration and biofilters.

At present juvenile production take place in 3 different sites on commission. The goal is to construct a hatchery with a capacity covering the needs within 2 years from now.

Conclusions from the first year

Perch is less stressed in ponds than in net cages. 

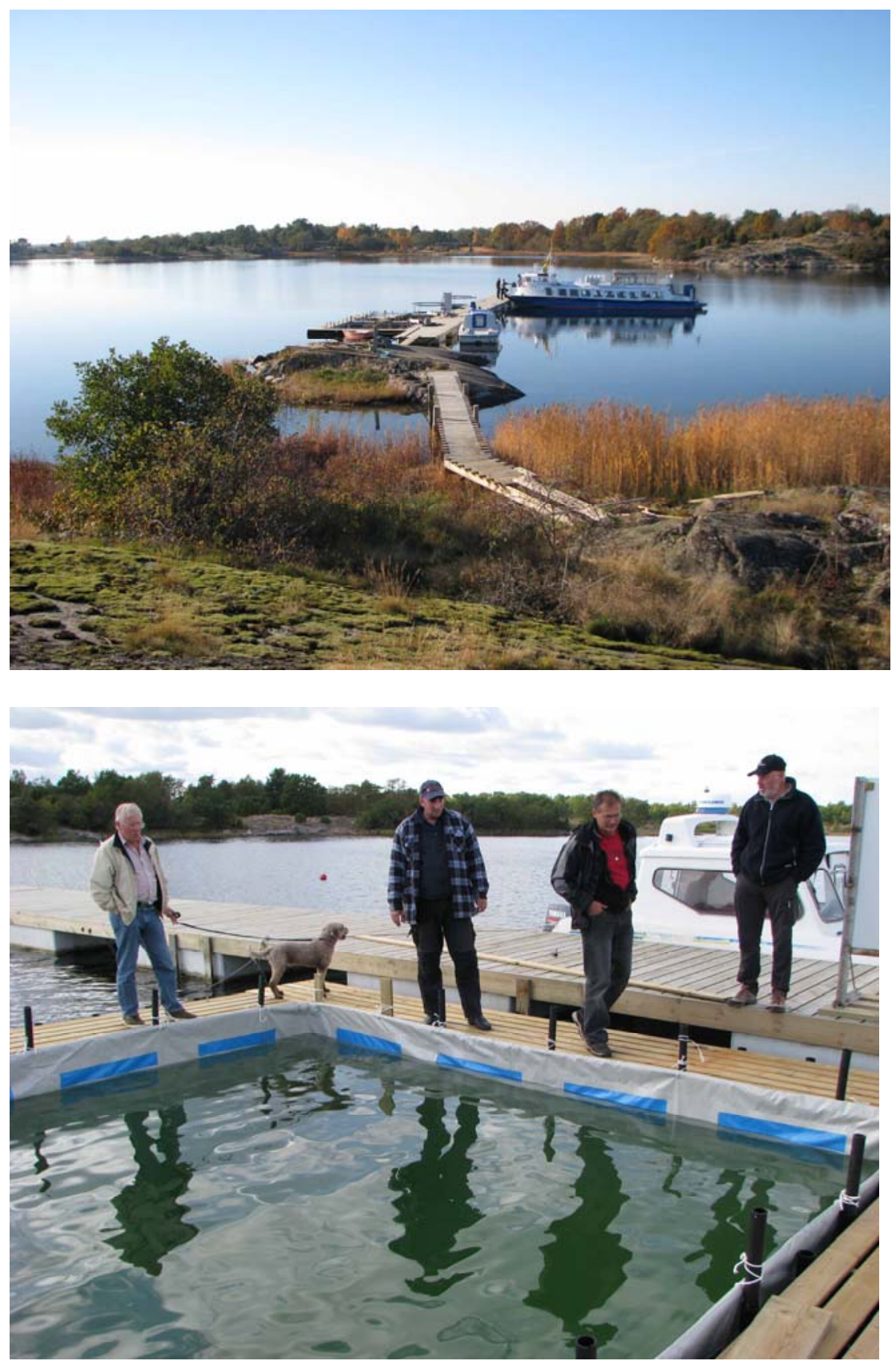

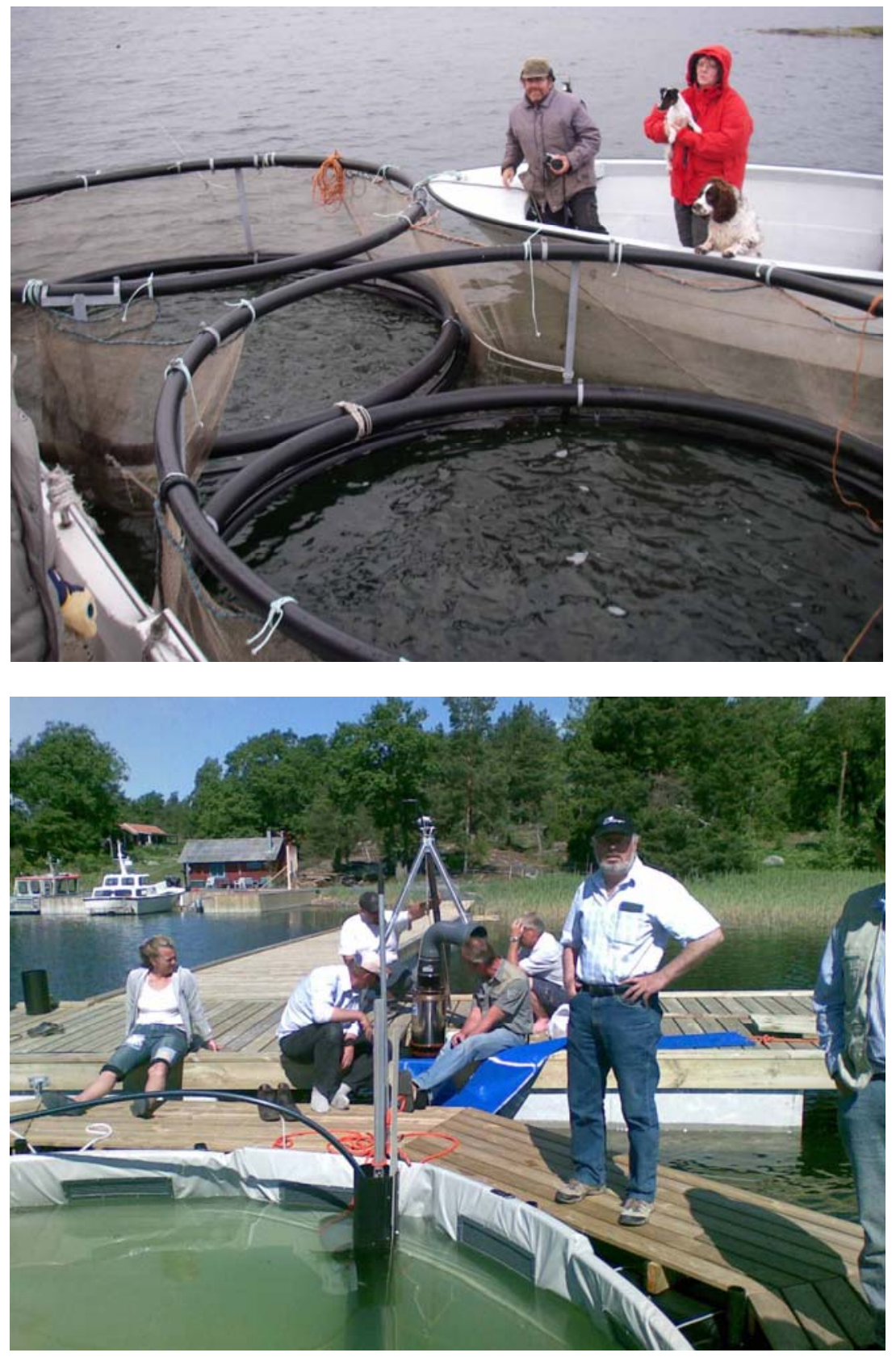

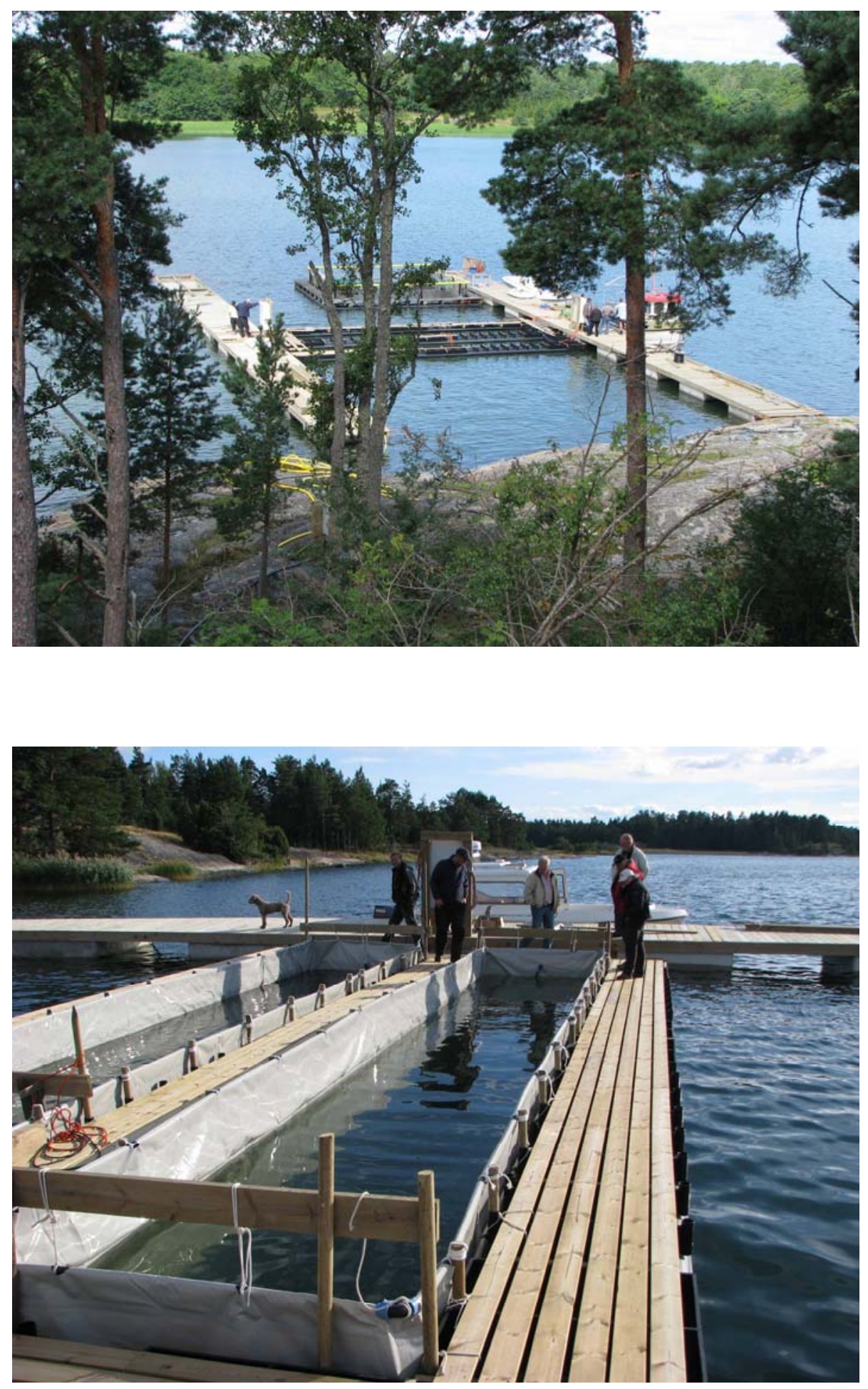


\title{
Production costs of perch and pikeperch juveniles
}

\author{
SCHRAM, E \\ Introduction
}

As in any aquaculture industry the production of market size perch and pikeperch relies on a secure supply of sufficient amounts of good quality juveniles. Security of juvenile production not only concerns technical and biological aspects but also demands cost efficiency. Therefore insight in the cost price of juvenile production is required in order to demonstrate economic security.

For this purpose a hatchery model has been developed. This model allows cost price calculations for existing hatcheries but also predicts the cost price of juveniles produced in yet to be build hatcheries.

In the following paragraphs the hatchery model will be described, examples of perch and pikeperch hatcheries will be given and means to evaluate cost prices will be discussed.

\section{Calculation of juvenile cost price}

In order to calculate the juvenile cost price a hatchery model has been developed. The model is an Excel workbook with 6 linked sheets which each cover relevant aspects of the hatchery.

The Input/Output sheet gives an overview of key economic figures like investments, running costs, feed costs and a market price, all generated in other sheets. The user has to fill out the total (expected) production of juveniles and the number of batches in which this number will be produced.

In the sheet feeding schedule, the growth of the fingerlings and the feed needed is described for a period of 90 days. Day 1 is the day of first feeding. An exponential model is used to describe growth rate $(S G R)$ in relation to body weight $(W): S G R=a \cdot W^{\wedge} b$. A mortality rate over 90 days has to be fed to the model and is used to calculate the required number of fry on day 1 .

The daily mortality in the model is concentrated in week 3 and 4 during weaning to artificial diet, which can be changed according to other insights. Using growth rate and mortality, the change in biomass is calculated. The daily amount of feed needed is calculated from the daily change in biomass and a feed conversion. The model takes into account the different feeds used and the percentage of the daily feed ration covered by different diets has to be fed to the model according to the specifications of the user.

The percentages are used to calculate the feed ration for each individual feed. Based on the calculated feed requirements and the 
unit costs for each feed (to be filled out by the user in the Prices sheet), the costs for the different feeds are calculated.

The feeding schedule sheet can also be used as a stand-alone document to calculate the feed ration for individual batches. The sheet hatchery design presents calculations on the equipment needed for every phase in the hatchery. There are four different phases identified: broodstock, incubation, first feeding and fingerlings. Live feed culture (Artemia) is also covered; in a separate box the requirements for space (building and land), flow and biofiltration are calculated. The user can manually adapt calculated dimensions and numbers of facilities for existing hatcheries.

The sheet Investments gives an overview of the infrastructure and equipment needed to realize a certain production capacity. Some of the investments can be considered 'fixed' in the sense that there is no relationship between production capacity and the investment in this item. For all the other items a linear relation is postulated between the amount invested and production capacity. The sizes of the different rearing units are taken from the sheet Hatchery design and multiplied with an estimated unit cost. There is an allowance made for $10 \%$ of the costs being 'unforeseen'.The depreciation for the different investment item is calculated based on user defined depreciation terms (linear).

In the sheet Costs the total production costs are calculated including capital costs (depreciation and interest). Division of the total production costs by the number of juveniles produced results in the juvenile cost price. The feed costs are taken directly from the sheet Feeding schedule. The costs for electricity are calculated from the installed pump capacity (sheet Hatchery design), a factor for the number of batches (\#batches/4), a factor for the capacity used during the rearing of a specific batch $(0,75)$ and a price per $\mathrm{kWh}$.

The costs for heating (gas) are calculated from the building area (sheet hatchery design) and a factor relating building area to yearly gas consumption $(30 \mathrm{~m} 3 / \mathrm{m} 2)$. The oxygen consumption of the fish is related to the feed consumption; a consumption of $1 \mathrm{~kg} / \mathrm{kg}$ feed is used. Costs for maintenance are estimated to be $2 \%$ of the investments. Insurance is estimated to be $0.3 \%$ of investments. General costs are considered to be fixed for an amount of 2000 euro and variable for an amount of 20 euro per 1000 fingerlings.

These figures can however by adapted by the users if necessary.Labour is a very important cost item in a hatchery. In the model there are three categories of labour applied. The default capacity of each category needed is considered to exist of a fixed part (0.05 man-year) and a variable part related to the number of fingerlings produced $(0.35,0.50$ and 1 man-year for the respective 
labour categories). This variable part is difficult to estimate. From literature it is known that the maximum number produced per person is in the order of 1 million fingerlings. For existing farms it is recommended to the user of the model to fill out the actual labour capacity and/or costs at the farm.Depreciation is copied from the sheet Investments. An interest is calculated over $2 / 3$ of the investment. The interest rate (\%) needs to be filled out by the user. No interest in calculated over the fish stock.

\section{Cost price of perch and pike perch juveniles}

The hatchery model was used to calculate the cost price of hatchery produced perch and pikeperch juveniles for different existing hatcheries. In this chapter the examples are given for a perch and a pikeperch hatchery. Table 1 gives an overview of hatchery characteristics. The breakdown of the juvenile production costs is given in Fig. 1 for pikeperch and fig. 2 for perch. It should be noted that these figures are indicative examples and may not apply to individual hatcheries.

Table 1 Hatchery characteristics

\begin{tabular}{|l|l|l|l|}
\hline Item & Unit & Perch hatchery & $\begin{array}{l}\text { Pikeperch } \\
\text { hatchery }\end{array}$ \\
\hline Production & (\#/year) & 800,000 & 100,000 \\
\hline Final size & $(\mathrm{g})$ & 5.5 & 10 \\
\hline Mortality & $(\%)$ & 70 & 80 \\
\hline Rearing period & (days) & 90 & 90 \\
\hline Batches & (\#/year) & 4 & 2 \\
\hline $\begin{array}{l}\text { Production } \\
\text { strategy }\end{array}$ & & Year-round & In season \\
\hline Total investments & (Euro) & 330.000 & 130.000 \\
\hline Cost price & (Euro/piece) & 0.33 & 0.40 \\
\hline
\end{tabular}

\section{$\underline{\text { Scenario analysis }}$}

The hatchery model allows for the analysis of the effects of different scenarios on juvenile cost price. As an example the effect of increased production based on out of season reproduction is given for a perch hatchery (Fig. 3). The additional costs for out of season reproduction have been taken into account. This analysis clearly demonstrates the large effect of actual production on the costs price. Sensitivity analysis using the hatchery model revealed that of all factors affecting cost price, production has the largest impact. Cost price reduction is therefore best achieved by increasing the production of an existing facility. It should be noted that market demand of juveniles is not considered here. 


\section{Evaluation of juvenile costs}

Once the cost price of perch or pikeperch juveniles has been calculated for existing hatcheries or predicted for yet to be established hatcheries, there is a need to evaluate this result. In other words, is the cost price high or low and is the hatchery production economically feasible? A projected market price for juveniles is a good reference for the calculated cost price. The market price can be estimated based on:

1) The market weight of the consumption sized fish (g); 2) Mortality rate during ongrowing $(\%) ; 3)$ The market price of the consumption sized fish $(€ / \mathrm{kg})$; 4) The desired margin between cost price and market price of consumption sized fish (\%);

5) The relative contribution of juvenile costs to the cost price of consumption sized fish (\%).

The projected market prices for juveniles vary between hatcheries as a result different ongrowing procedures and final products of the customers of the hatcheries, therefore only examples can be provided (Table 2) for perch and pikeperch. The higher projected market prize for pikeperch juveniles results from the difference in market weight of consumption sized fish for both species and thus the number of juveniles required per $\mathrm{kg}$ consumption fish. As a result pikeperch juvenile production allows higher costs. This is clear from comparing the juvenile cost prices for both species (Table 1) to the projected market prices (Table 3 ). In these examples the cost price for perch juveniles is higher than the projected market prices, whereas a considerable margin exists between cost price and projected marker price for pikeperch.

Table 2 Calculation of the projected market price of perch and pikeperch

\begin{tabular}{|l|l|l|l|l|}
\hline Item & Unit & $\begin{array}{l}\text { Perch } \\
1\end{array}$ & Perch 2 & Pikeperch \\
\hline $\begin{array}{l}\text { Market weight consumption sized } \\
\text { fish }\end{array}$ & $(\mathrm{g})$ & 200 & 100 & 1500 \\
\hline Mortality during ongrowing & $(\%)$ & 15 & 40 & 15 \\
\hline \# Juveniles & $(\# / \mathrm{kg})$ & 5.8 & 14 & 0.8 \\
\hline $\begin{array}{l}\text { Market price consumption sized } \\
\text { fish }\end{array}$ & $(€ / \mathrm{kg})$ & 7.20 & 1.50 & 6.0 \\
\hline Profit margin & $(\%)$ & 20 & 35 & 20 \\
\hline Cost price & $(€ / \mathrm{kg})$ & 5.76 & 0.98 & 4.8 \\
\hline Costs juveniles & $(\%$ of cost price $)$ & 20 & 20 & 20 \\
\hline Projected market price juveniles & $(€ / \mathrm{pc})$ & 0.20 & 0.014 & 1.25 \\
\hline
\end{tabular}




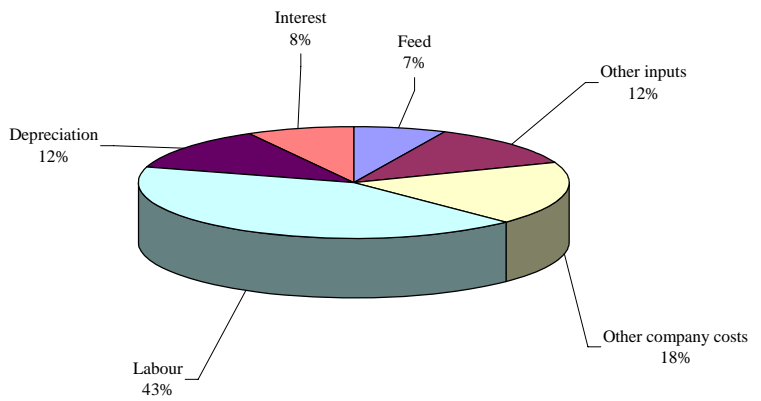

Fig. 1 Breakdown of juvenile pikeperch production costs.

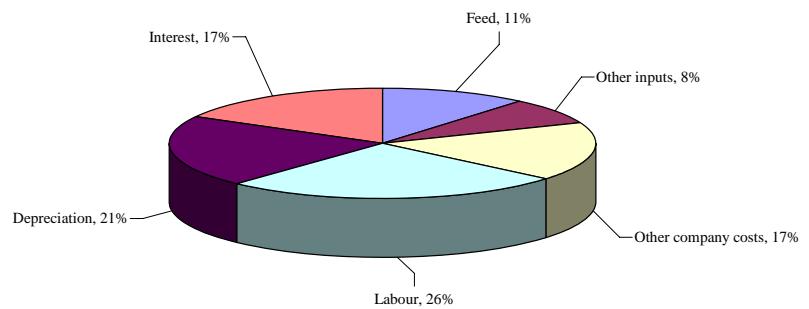

Fig. 2 breakdown of juvenile perch production costs.

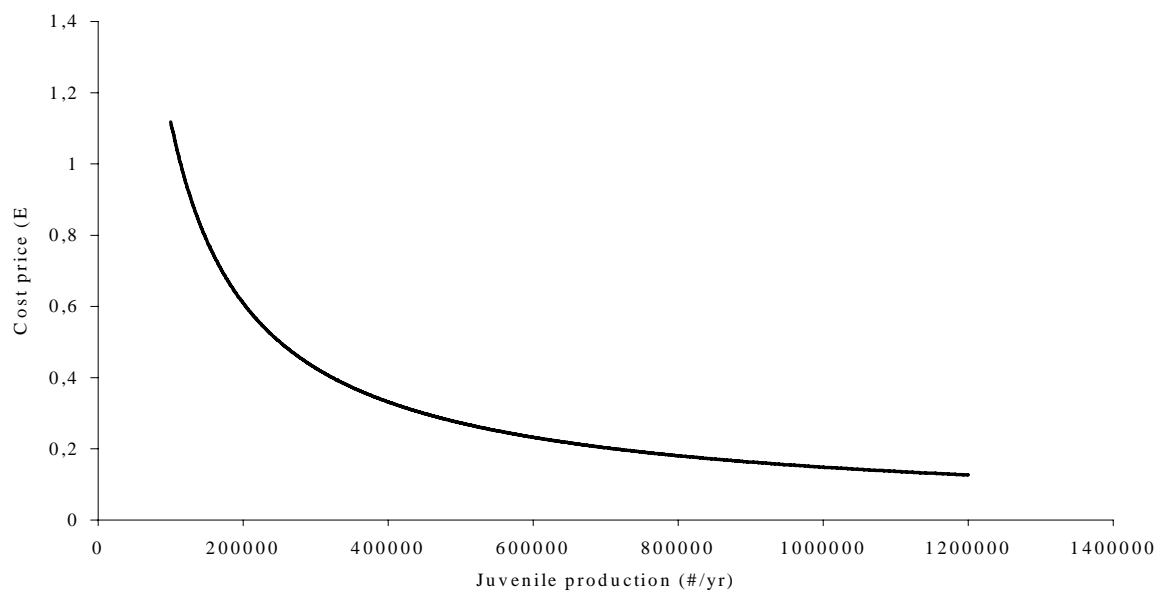

Fig. 3 The effect of the annual production (\# juveniles/year) on the cost price of perch juveniles. 


\section{Overview and status of percid culture in Canada}

\section{THERRIEN Louise}

Ministère de l'Agriculture, des Pêcheries et de l'Alimentation du Québec, Direction générale des pêches et de l'aquaculture commerciales, Direction de l'aquaculture et du développement durable, 200, chemin Ste-Foy, Québec, Canada

Tel.: +1 418-380-2100 ext. 3592

E-mail address: Louise.Therrien@mapaq.gouv.qc.ca

\section{$\underline{\text { Introduction }}$}

To date, considerable percid culture research and technology transfer has been conducted in order to introduce commercial production to diversify Canada's aquaculture industry. Thus far, egg-to-egg production has been achieved for two species: walleye (Stizostedion vitreum) and yellow perch (Perca flavescens). In terms of domestication, spectacular strides have been made thanks to initiatives to develop promising pure lines for perch culture. However, commercial culture is late in getting off the ground. One of the main constraints is the availability of quality egg supplies from domestic strain broodstocks.

\section{A few economic statistics}

Canadian aquacultural production was at 145,840 tons, worth $\$ 526$ million in 2005. Trout farming was the freshwater aquaculture industry's leading activity, with 5,600 tons, or $3.6 \%$ of total production, for a value of $\$ 29.6$ million. Percid fishes, such as walleye and yellow perch, are freshwater species whose commercial production is slowly developing and for which quantitative data are rare (protected). The annual production volume of these species is estimated to account for less than $0.1 \%$ of Canada's freshwater aquaculture sales.

\section{Perch farming}

\section{Species of interest}

In order to diversifying fish production in Canada, the aquaculture industry and its partners are turning to walleye and yellow perch. Each of these native species-walleye (Stizostedion vitreum), sauger (Sander canadense) and yellow perch (Perca flavescens)-is found in several provinces of Canada (figure): British Columbia ${ }^{1}$, Alberta, Saskatchewan, Manitoba, Ontario, Quebec, New Brunswick and Nova Scotia. Two of them, walleye and yellow perch, are also found in the Northwest Territories, their most northern location in North America.

Culture methods 
Currently, egg incubation and hatching are carried out using standard methods, namely, jars for walleye and meshed hatchery troughs for yellow perch.

Generally, larval culture is done in fertilized outdoor ponds into which newly hatched larval fish is introduced. Juvenile walleye is harvested at a minimum average weight of 0.3 to $0.5 \mathrm{~g}$ for transfer to indoor basins and weaning on artificial feed. Yellow perch fry is directly pond weaned on artificial feed.

In the case of walleye, intermediate and final growout occur in an open system, a recirculation system (REFB) or a combination of both. See section on Research and Development and Technology Transfer for growout systems for yellow perch.

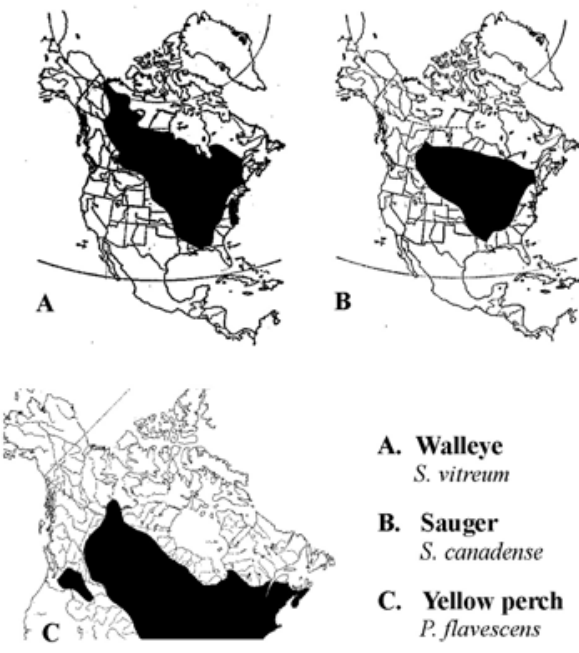

\section{Distribution maps}

Figure 1. Distribution of three percid species in Canada (Adapted from Scott and Crossman. 1974)

\section{Percid production}

\section{Production}

Public sector/Government fish farming

Ontario's provincial government carries out annual walleye production primarily for its recreational fish stocking program. Walleye culture development began a little more than 35 years ago in Ontario's government facilities. Quebec has a government walleye production program for repopulation using native species in public waters.

Private sector/Private fish farming operations

Currently, the few businesses that produce and sell walleye are located in Quebec and Ontario. Yellow perch farming is at the 
experimental and pilot-project phases in Quebec, Ontario and Manitoba. In general, these fish farming operations also produce trout. Yellow perch produced on commercial fish farms is sold for stocking market.

\section{Sales and Markets}

\section{Stocking market}

At present, walleye sales are primarily aimed at the fish stocking market, and a small portion of production is sold for growout in other fish farming operations. Demand outstrips supply in the fish stocking market.

\section{Table fish market}

The main potential for development of the walleye sector lies in the table fish market. Walleye is highly prized for the quality and tenderness of its flesh. Current prices for walleye are high compared with those of other farmed species available on the market.

Current initiatives in yellow perch farming focus on the table fish market. Fish stocking market demand for yellow perch is slight. Development prospects exist for the sale of juveniles for growout to market size to other fish farms.

\section{Research and Development - Technology transfer}

\section{Recent and current projects}

In Manitoba, Ontario and Quebec, recent work has enabled identification and development of pure lines from native populations for the purpose of walleye and yellow perch culture and domestication. Quebec walleye and yellow perch lines show promising growth performance and evident domesticated behaviour. Delayed reproduction has been achieved with two lines of yellow perch in Quebec. Percid-specific molecular markers have also been developed within the framework of these projects.

In Ontario, a successful weaning strategy has been developed to convert walleye fry to artificial feed in closed systems with a wild stock selected for domestication.

One of the aims of the projects underway or about to be completed is to document the technical and economical parameters of yellow perch production in aquaculture ponds in Ontario. Promoters are also seeking to determine how the lipid content of existing commercial salmonid fish diets influences the productivity parameters of yellow perch reared in aquaculture ponds year round and the reproductive output of female fish. Preliminary results show that the fat content of farmed yellow perch is higher than that of wild fish regardless of the commercial feed used. 
In Manitoba, a technology transfer project is aimed at supporting the start up and development of a commercial aquaponics facility that combines indoor recirculating perch culture and greenhouse plant production. The facility is supplied with pond-reared juveniles from Manitoba yellow perch broodstock. The first commercial sales of yellow perch are scheduled within the next two years.

In Quebec, there is a technology transfer project to develop and optimize specific broodstock culture techniques in order to achieve self-sufficient supply of eggs and larvae capable to sustain profitable commercial production. The idea is to test the effect of 3 diets on the reproductive success of pure lines of domesticated yellow perch and walleye in relation to the essential lipid acid needs of percid. The project, in addition to diets essays, also involves testing of tank and pond systems environments in order to achieve optimal gonadic development and better pre- and post-reproduction survival rates. Even though preliminary results are divided on the question of reproductive success and husbandry techniques, they nonetheless indicate the need to formulate and develop artificial feed fully consistent with the dietary needs of broodstock percid.

All of these projects were or are being carried out with private promoters, private fish farms involved in fish production diversification, governments and educational institutions.

\section{$\underline{\text { Conclusions }}$}

In itself, the development of domesticated pure lines goes a long way towards diversifying freshwater commercial aquaculture production in Canada. Much remains to be done in terms of developing techniques for intensive broodstock rearing and reproduction. What has emerged is the knowledge that nutritional needs of juvenile fish and brookstock are crucial to reach commercial production at a level similar to farmed salmonids. More specifically, the availability of affordable artificial feed for broodstock and juvenile weaning must be given immediate attention. Otherwise, the genetic selection and domestication efforts undertaken thus far will not be used to their full potential.

\section{Consulted references}

Bernatchez, L., S. Higgins, J.-C. Therrien et J. Keays. 2005. Programme québécois d'amélioration génétique en aquaculture d'eau douce de l'Omble de fontaine (Salvelinus fontinalis), souche Rupert et du Doré jaune (Stizostedion vitreum), souche Ferme-Neuve. SORDAC. Document de transfert technologique $\mathrm{N}^{\circ} 2005.2,82 \mathrm{p}$.

Canadian Aquaculture R\&D Review. 2007. Diet formulations and fat content under investigation for yellow perch, $\mathrm{p} 5$. 
Canadian Aquaculture R\&D Review. 2007. Advancing the culture of walleye in ponds \& recirculation systems, p 5.

Drouillard, Ken. (Consulted: July 9th, 2007). University of Windsor, Ken Drouillard, GLIER: Growth Efficiency and Reproductive Output of Pond Raised Yellow Perch Fed Commercially Available Finfish Formulations. [On line]. URL address: http//www.uwindsor.ca/users//k/kgd/main.nsf/inToc/E8825474900 8820D85256D A200563887?OpenDocument

Dubé, P. 2005. Missions scientifiques sur la stabulation des géniteurs, l'élevage larvaire intensif et le développement de lignées d'élevage de doré (Stizostedion vitreum) et de perchaude (Perca flavescens) réalisées en Ontario, France, Belgique et Pays-Bas, du 15 au 25 novembre 2005. SORDAC. Document de veille technologique $\mathrm{n}^{\circ} 2005.2,35 \mathrm{p}$.

Dumas, A. et M. Blanchet. 2003. Premiers résultats relatifs au développement d'une lignée génétique de Perchaude à partir de populations naturelles du Québec. SORDAC. Document de transfert de technologie ${ }^{\circ} 2003.1,10$ pages, 2 annexes.

Dumas, A. et M. Blanchet. 2006. Domestication et contrôle de la reproduction de la perchaude (Perca flavescens). SORDAC. Document de transfert de technologie $\mathrm{n}^{\circ} 2006.5,30 \mathrm{p}$.

Fisheries and Oceans Canada. (Consulted: July 9th, 2007). Aquaculture Collaborative Research and Development Program (ACRDP) - Current Projects [On line]. URL address: http://www.dfompo.gc.ca/science/aquaculture/acrdp-pcrda/projects_ca_e.htm Geiling, Doug. 2007. Fisheries and Oceans Canada, Central and Arctic Region, Great Lakes Laboratory for Fisheries and Aquatic Sciences, Sault Ste. Marie, Ontario. (Pers. comm.) McNaugton, Paul. Alberta Aquaculture Association. (Pers. comm.) Papst, Micheal. 2007. Fisheries and Oceans Canada, Central and Arctic Region, Freshwater Institute, Winnipeg, Manitoba. (Pers. comm.)

Scott, W.B. and E.J. Crossman. 1973. Freshwater fishes of Canada. Fisheries Research Board of Canada Bulletin 184: 966 pages.

SORDAC. 2006. Plan stratégique 2005-2008 - Plan annuel 2006, 47 p.

Statistics Canada. 2006. Aquaculture Statistics 2005. Minister of industry, Statistics Canada, Agriculture division, Livestock section, cat. $\mathrm{N}^{\circ}$ 23-222-XIE, Ottawa, Ontario, $50 \mathrm{p}$. 


\title{
Percid culture in the North central US
}

\author{
MALISON, J.
}

University of Wisconsin-Madison Aquaculture Program; 1675 Observatory Dr., Madison, WI 53706 USA

Tele. 608 263-1242

E-mail address: jmalison@wisc.edu

\section{$\underline{\text { Introduction }}$}

The yellow perch (Perca flavescens) and walleye (Sander vitreus) are the two most economically important percid fishes in the northern US. Both species are popular food and sport fish, and this is a summary of the current status of aquaculture for both of these species.

\section{Yellow perch}

Market. Prior to 1970 the entire supply of yellow perch came from capture fisheries in the U.S. and Canada, principally the Great Lakes. Markets readily absorbed the peak harvests of $>15$ million $\mathrm{kg} / \mathrm{yr}$ in the 1950s and 1960s, but wild harvests have now declined to $\tilde{5} 8$ million $\mathrm{kg} / \mathrm{yr}$ or less. Because of the changing ecology and management of the Great Lakes, the peak wild harvests of the 1950s and 1960s are not expected to return. The management of these populations does not include the stocking of juveniles, and therefore little effort is made by public hatcheries to produce yellow perch. A fledgling commercial industry is developing, but presently contributes less than 100,000 $\mathrm{kg} / \mathrm{yr}$. The commercial industry also produces a sizeable number of fingerlings and adults that are sold to private pond owners for recreational fishing.

Wholesale prices for yellow perch in the round range from $\$ 5$ to $\$ 7 / \mathrm{kg}$. Most yellow perch are sold to retailers and restaurants as scaled, skinon fillets. Fillet yield ranges from 35 to $50 \%$, and the cost of processing yellow perch is high $(\$ 3-6 / \mathrm{kg})$ because of their small size. Wholesale prices for fillets range from $\$ 14$ to $\$ 20 / \mathrm{kg}$ ), and retail prices from $\$ 20$ to $\$ 34 / \mathrm{kg}$. Other products, especially baby European zander (Sander lucioperca), are being sold illegally as yellow perch in the US, but enforcement of current laws has been insufficient to stop this practice. Fingerling yellow perch for stocking are usually sold by length, and prices range from $\$ 0.03$ to $\$ 0.06 / \mathrm{cm}$.

Brood Stock Management and Fry Propagation Methods. Except for some producers who have raised several successive generations of captive yellow perch, no efforts have been made to genetically select or domesticate yellow perch. To induce normal sexual maturation, yellow perch brood stock must be held outdoors in ponds or indoors 
under conditions that mimic the normal seasonal changes in temperature and day length. Yellow perch spawn once each year in the spring concurrent with increasing photoperiod and water temperature. Egg ribbons normally contain 7,000̃30,000 eggs. One line of research was to develop methods for inducing out-of-season spawning so that yellow perch eggs would be available at multiple times of the year. The method tested was to hold groups of adult yellow perch under environmental conditions in which the chill period was shifted to occur at different times of the year. Although early results were promising, the successful commercial application of this method has not yet been demonstrated, and further research efforts are warranted. Hormones including hCG and LHRH can be used to synchronize the spawning of a group of female brood fish, and shorten the spawning season from three weeks to three to four days.

The simplest method of producing yellow perch fry is to stock several male and female brood fish in a pond containing suitable spawning substrate (such as brush piles), and allow the fish to spawn and the eggs to hatch naturally. Although simple, this method provides little control over when the fish spawn or the number of fry that are eventually released into the pond. Another method of fry production is to collect fertilized egg ribbons from a pond or the wild, and incubate and hatch them in tanks. The most sophisticated method of fry production is to hold brood fish in tanks during the spawning season, manually strip the eggs from ripe females into a bowl, fertilize them, and incubate the eggs in tanks until hatch. Obtaining milt from males is a simple process, and semen extenders (e.g., a solution of $0.7 \%$ $\mathrm{NaCl}$ ) can be used to dilute semen and allow it to be stored for several days after collection.

Routine (wet or dry) spawning methods can be used to achieve fertilization rates greater than $95 \%$. Egg strands are usually incubated by suspending the ribbons in tanks on wires or racks. Incubation time from fertilization until hatch is temperature dependent, ranging from $\tilde{5} 25$ days or longer. Under a thermal regime that rises gradually from 10-15 C, hatch begins about 12 days after fertilization. Most producers use a regular formalin treatment (e.g., $0.01 \%$ for $15 \mathrm{~min}$ per day) to retard the growth of fungus on the eggs. Some producers find that eggs must be subjected to a significant amount of turbulence to induce good hatch.

Fingerling Production. The tank culture method of fingerling production has focused on feeding yellow perch fry live foods for the first few weeks of life because yellow perch fry do not accept any currently available formulated foods. This method relies on raising progressively larger food organisms (e.g., algae, protozoans, rotifers, copepods, cladocerans, and brine shrimp) indoors and feeding them to larvae that are held in separate indoor tanks. First feeding yellow perch fry are known to consume a wide range of organisms, but studies 
comparing the survival and growth of fry consuming different organisms are needed. As the fish reach approximately $1 \tilde{5} 20 \mathrm{~mm}$ in length, a size reached in 3 to 4 weeks, they are gradually weaned onto a diet of ground beef liver, and subsequently onto a formulated starter food. Although successful on a laboratory scale, tank culture of yellow perch fingerlings is not practiced commercially. It is highly labor and capital intensive, and there are problems associated with producing live food organisms that meet the basic nutritional needs of the fish at critical early developmental stages. In addition, a significant percentage of tank-raised fry do not undergo normal swim bladder inflation.

The tandem pond-tank rearing method used by most commercial producers involves stocking yellow perch larvae into fertilized production ponds where they feed on natural food in the ponds. Optimal fertilization methods can vary widely from location to location. Once the fish reach approximately $20-35 \mathrm{~mm}$ in length, a size reached in 4 to 6 weeks, they are harvested and stocked into tanks where they are trained to accept conventional starter diets. The use of highlyflavored and scented diet additives (e.g., krill) are extremely beneficial in the feed-training process. The principal advantages of this method are that large numbers of fish can be produced in ponds (typically over $120,000 /$ ha) at a low cost compared to the tank culture method. Skeletal and other deformities often observed in tank-cultured fry are rarely observed in yellow perch reared initially in ponds. Disadvantages to the tandem pond-tank method are that it requires separate pond and tank systems, and fingerlings can be subjected to excessive stress during pond harvest.

Grow-out. The grow-out of perch can be accomplished in open ponds, net pens, flow-through systems and recirculating aquaculture systems (RAS). Indoor RAS has the advantage of continuous, year round growth, because these systems can be kept at near-optimal temperatures $\left(19-21^{\circ} \mathrm{C}\right)$. The other three systems are generally limited to a 6-7 month growing season because of reduced temperatures during winter. Perch raised under the comparatively low densities used in open pond culture can normally be raised at higher temperatures (up to $26{ }^{\circ} \mathrm{C}$ ) without risking disease or other health problems. The normal market size for yellow perch is $100-150 \mathrm{~g}$, and thus the time from fingerling to market size can range from 10 to 18 months. Most producers use trout diets that contain at least $40 \%$ protein and $10 \%$ fat, as well as a high percentage of fish meal. Researchers have demonstrated, however, that most trout diets exceed the protein and fat requirements of yellow perch.

Yellow perch raised in outdoor systems can be subject to infection by several types of parasites, including protozoans and trematodes. Most bacterial diseases affecting yellow perch are caused by facultative pathogens induced by stress, and are more problematic in high 
density systems and in RAS with reduced water quality. Yellow perch are vulnerable to several viral diseases, and the recent outbreak of VHS in the northern US may be problematic to the aquaculture industry.

A recent study conducted by the North Central Regional Aquaculture Center generated data on key performance parameters of yellow perch raised in the four system types. This same study also generated data on the production costs of raising yellow perch to market size. At the present time pond systems are the most economical method for raising yellow perch, and pond systems are responsible for more than $80 \%$ of the total US production. It should be noted, however, that the study showed a wide range of production costs for RAS, from approximately $\$ 8.00$ to $\$ 20.00 / \mathrm{kg}$ depending on system type and management. Future improvements in technology may improve the prospectus of yellow perch aquaculture in RAS. The study also showed that, regardless of system type, the cost of purchasing fingerlings ranged from $30 \%$ to over $50 \%$ of total production costs. One reason for such high fingerling costs is that yellow perch are marketed at a relatively small size, and therefore require a high number of fingerlings. Clearly, more research efforts are needed at reducing fingerling costs.

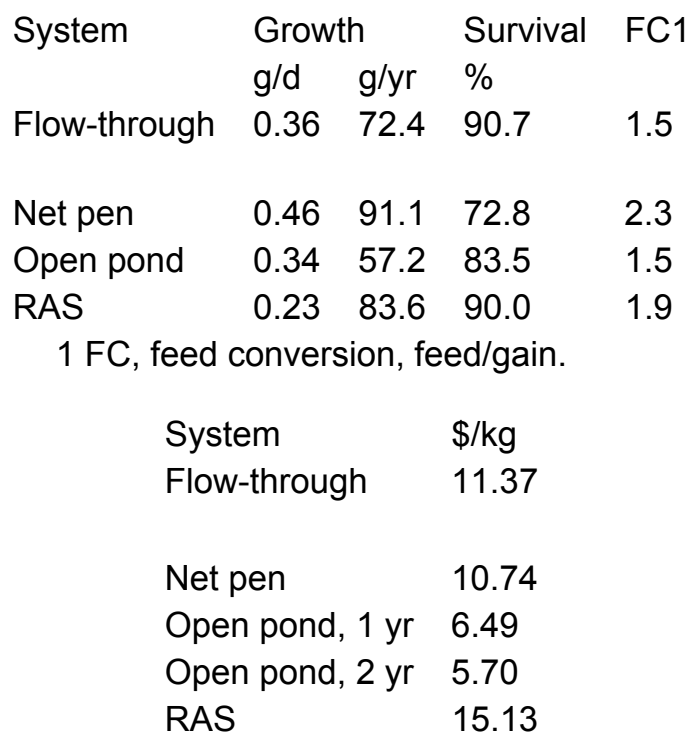

Walleye

Market. Most walleye consumed in the US come from commercial Canadian fisheries, and from fish caught recreationally by fishermen. Until about 1990, the standard "market size" walleye was considered 
to be a fish weighing $800-900 \mathrm{~g}$ and yielding 2 fillets each approximately $230 \mathrm{~g}$. More recently, however, smaller fillets ("baby" walleye fillets $50-150 \mathrm{~g}$ each) have been readily accepted into the market place. Although the consumption of walleye in the US rivals that of yellow perch, the interest of raising walleye to food size in the US is not as high as that of yellow perch. Walleye prices are generally $20-40 \%$ lower than that of yellow perch, and the illegal sale of European zander as walleye is probably acting to keep prices low. At the present time, virtually all aquaculture of walleye in the US is focused on the production of fingerlings for stocking into wild fisheries or private ponds.

There is some commercial production of walleye fingerlings, but the majority of production occurs at public hatcheries, both state and federal. Together, the annual production of walleye fingerlings is normally greater than 10 million fish per year. Although the commercial market may be limited (e.g., to lake associations and private lake owners), walleye fingerlings can bring a premium retail price as high as $\$ 0.40 / \mathrm{cm}$, or $\$ 10.00$ for a single $25-\mathrm{cm}$ fingerling.

\section{Brood Stock Management and Fry Propagation Methods}

Like yellow perch, walleye spawn one each year in the spring. Most public hatcheries rely on the capture of wild brood fish during the spawning season. Most commercial producers overwinter brood fish in ponds and capture them for spawning in the spring. LHRH or hCG can be used to induce spawning in females, and researchers have demonstrated that walleye can be induced to spawn 4-8 weeks before the normal spawning season. Female walleye produce 30,000 to 300,000 eggs, which are normally fertilized using the wet or dry method. Shortly after fertilization, eggs are treated with bentonite, fuller's earth, pond muck or tannic acid to keep the eggs from clumping. Eggs are then normally incubated conventional hatchery jars, and hatch after 8-25 days, depending on temperature. A regular formalin treatment (e.g., $0.01 \%$ for 15 min per day) is normally used to retard the growth of fungus on the eggs.

\section{Fingerling Production}

For reasons of cost, most hatcheries raise walleye fingerlings in fertilized ponds until the fingerlings are approximately $35 \mathrm{~mm}$ in length. A great deal of research has been done on pond management and fertilization regimes, using both organic and inorganic fertilizers. These studies have shown that optimum fertilization regimes are highly site specific, although a high ratio of nitrogen/phosphorus (e.g., $7 / 1-20 / 1)$ is generally advantageous.

After they reach $35 \mathrm{~mm}$ in length, walleye switch from a diet of zooplankton to fish, and further growth in ponds requires the addition 
of forage fish. Some hatcheries attempt to harvest and stock their walleye fingerlings at $35 \mathrm{~mm}$, whereas others produce "extended growth" fingerlings that are normally harvested in the autumn. Wellmanaged ponds can produce upwards of 10,000 fingerlings/ha that range in size from 15 to $35 \mathrm{~cm}$.

Walleye can also be raised entirely in tanks using formulated feeds. Specialty starter diets are needed, but fingerlings can eventually be switched onto trout diets or other diets for carnivorous fish. Problems with swim bladder inflation in tank-reared walleye have largely been resolved by agitating the water or blowing a stream of air across the surface of the water. Problems with cannibalism and skittish, stressrelated behavior have been reduced by increasing water turbidity and using low intensity or internal tank lighting.

\section{Grow-out}

There have been a few (failed) commercial efforts at raising walleye for food, but there is a total lack of information on the costs of raising walleye to food size using different systems. Research in this regard is sorely needed. The temperature and dietary requirements of walleye are similar to that of yellow perch. Walleye are also susceptible to many of the same diseases that affect yellow perch. Several researchers have suggested that a combination of newly developed technologies could be used to produce "baby" walleye fillets in a single year or single growing season. The technologies proposed are: 1) advanced, out-of-season spawning to begin the season in February rather than April; 2) intensive indoor tank culture of fry; and 3) the use of fast growing hybrid walleye (S. vitreus female $\mathrm{x}$ S. glaucum male). An evaluation of this approach seems warranted.

\section{$\underline{\text { References }}$}

Hart, S.D., D.L. Garling, and J.A. Malison. 2006. Yellow perch (Perca flavescens) culture guide. 104 pp. North Central Regional Aquaculture Center Culture series \#103. Ames, IA.

Malison, J.A. 1999 (updated 2003). A white paper on the status and needs of yellow perch aquaculture in the North Central Region. Special publication of the North Central Regional Aquaculture Center, East Lansing, MI, 15 pp. Available at http://www.ncrac.org/Topics/yellowperch112103.htm

Summerfelt, R.C. 1996. Walleye culture manual. 321 pp. North Central Regional Aquaculture Center Culture series \#101. Ames, IA.

Summerfelt, R.C. 2000. Status and Needs of Walleye Aquaculture of the North Central Region. Special publication of the North Central Regional Aquaculture Center, East Lansing, MI, 30 pp. Available at http://www.ncrac.org/Topics/walleye32900.htm 


\section{Posters}


Effects of photothermal kinetic, photoperiod amplitude and duration on the rates of out-of-season spawning and egg fertilization in Eurasian perch Perca fluviatilis.

\author{
ABDULFATAH Abdulbaset, FONTAINE Pascal and MARIE Michel \\ Unité de Recherche Animal et Fonctionnalités des Produits Animaux, \\ Nancy-Université, INRA, 2 avenue de la Forêt de Haye B.P. 172 F- \\ 54505 Vandoeuvre lès Nancy

\section{$\underline{\text { Introduction }}$}

Thermal and photoperiodic variations are necessary for the control of the reproductive cycle in Eurasian perch (Migaud et al., 2003, 2006). However the respective role of these two factors on the induction of out-off-season spawning has never been clearly determined.

\title{
Materials and Methods
}

Broodstock were reared in a recirculated system under constant conditions $\left(21^{\circ} \mathrm{C}, 17 \mathrm{~L} / 7 \mathrm{O}\right)$ until an initial body weight of $114 \mathrm{~g}$. Two initial photothermal decreases were applied for the induction of the gonadogenesis, a rapid (6 weeks) or a slow (16 weeks). For each kinetic, four photoperiod decreases were applied $(0,1,4$ and $8 \mathrm{~h})$. At the end of this induction phase, fish which not responded were eliminated (no photoperiod decrease with the two kinetics and 1 hour in the rapid kinetic). Then two durations for the cooling period $\left(6^{\circ} \mathrm{C}\right)$ were applied, a short (2 months) and a long (4 months). Finally, a same final photothermal program was applied to induce spawning (slow increase of photoperiod until 17L:70, then three weeks later an increase of the temperature up to $14^{\circ} \mathrm{C}$ over three weeks).

\section{$\underline{\text { Results and discussion }}$}

The slow photothermal kinetic with a longer duration (9 months) induced a better rate of spawning and fecundation. This result was closed to those of Migaud et al. (2006) obtained during a natural spawning period (rate of spawning: $100 \%$; rate of fertilization: $57,2 \%$ ). 


\begin{tabular}{|c|c|c|c|c|c|c|c|}
\hline $\begin{array}{c}\text { Kineti } \\
\text { c }\end{array}$ & $\begin{array}{c}\text { Photoperi } \\
\text { od } \\
\text { amplitude }\end{array}$ & $\begin{array}{c}\text { Duration } \\
\text { of cycle }\end{array}$ & $\begin{array}{c}\mathbf{N}^{\circ} \\
\text { femal } \\
\text { es }\end{array}$ & $\begin{array}{c}\mathbf{N}^{\circ} \\
\text { spawni } \\
\text { ng }\end{array}$ & $\begin{array}{c}\text { Rate of } \\
\text { spawni } \\
\text { ng }\end{array}$ & $\begin{array}{c}\text { Rate of } \\
\text { fertilizati } \\
\text { on }\end{array}$ & $\begin{array}{c}\text { Rate of } \\
\text { fertilized } \\
\text { ovocytes }\end{array}$ \\
\hline Rapid & 4 & $7 \mathrm{M}$ & 5 & 5 & $100 \%$ & $0 \%$ & $0 \%$ \\
\hline Rapid & 8 & $7 \mathrm{M}$ & 3 & 3 & $100 \%$ & $33.3 \%$ & $90 \%$ \\
\hline Slow & 1 & $7 \mathrm{M}$ & 7 & 7 & $100 \%$ & $0 \%$ & $0 \%$ \\
\hline Slow & 4 & $7 \mathrm{M}$ & 3 & 3 & $100 \%$ & $0 \%$ & $0 \%$ \\
\hline Slow & 8 & $7 \mathrm{M}$ & 3 & 3 & $100 \%$ & $0 \%$ & $0 \%$ \\
\hline Rapid & 4 & $9 \mathrm{~m}$ & 8 & 6 & $75 \%$ & $0 \%$ & $0 \%$ \\
\hline Rapid & 8 & $9 \mathrm{M}$ & 8 & 5 & $62.5 \%$ & $20 \%$ & $3 \%$ \\
\hline Slow & 1 & $9 \mathrm{M}$ & 9 & 6 & $66.6 \%$ & $50 \%$ & $54.5 \%$ \\
\hline Slow & 4 & $9 \mathrm{M}$ & 3 & 3 & $100 \%$ & $33.33 \%$ & $90 \%$ \\
\hline Slow & 8 & $9 \mathrm{M}$ & 11 & 11 & $100 \%$ & $54.55 \%$ & $76.33 \%$ \\
\hline
\end{tabular}

\section{$\underline{\text { Conclusion }}$}

Environmental manipulations (photoperiod + temperature) permitted to obtain numerous fertilized out-of season spawning (December January) without hormonal manipulations.

\section{$\underline{\text { References }}$}

Migaud, H., Mandiki, R., Gardeur, J.N., Kestemont, P., Bromage, N.R., Fontaine, P., 2003. Influence of photoperiod regimes on the Eurasian perch gonadogenesis and spawning. Fish Physiol. Biochem. 28, 395-397.

Migaud, H., Wang, N., Gardeur, J.-N., Fontaine P., 2006. Influence of photoperiod on reproductive performances in Eurasian perch Perca fluviatilis. Aquaculture 252, 385-393. 
Effects of husbandry and nutritional conditions on lipid metabolism of Eurasian perch, Perca fluviatilis

\author{
BLANCHARD Gersande* and KESTEMONT Patrick
}

Unit of Research in Organismal Biology The University of Namur (FUNDP), 61 rue de Bruxelles, B-5000 Namur, Belgium

${ }^{*}$ Corresponding author. Tel.: +32 (0)81 724287

E-mail address: gersande.blanchard@fundp.ac.be (G. Blanchard).

\title{
$\underline{\text { Introduction }}$
}

Today, important progress were achieved in the overall processes of Eurasian perch production but perch are still fed unspecific feed initially formulated to meet nutritional requirements of Salmonids or European seabass. Main consequences are an inappropriate storage of fat in liver, a decrease of growth performances and stress resistance. Fatty livers have been often observed in fish farming due to an excessive or unbalanced dietary intake of lipids which saturate the physiological capability of the liver to handle them, thus leading to pathological or non-pathological lipid droplet (triglycerides) accumulation. In order to promote sustainable productivity of healthy fish, food is of special importance and comprehension of mechanisms implicated on lipid metabolism are required.

\section{Discrimination of influent factors on hepatic ultrastructure}

Among 12 nutritional and husbandry factors, we discriminated the preponderant factors leading to important modification of hepatic ultrastructure. Rearing temperature, but also lipid and protein sources, distribution frequency and density were factors influencing the most significantly lipid droplet accumulation and RER development.

\section{Lipid levels and antioxidants}

In a next experiment, sensitivity of Eurasian perch to lipid peroxidation was confirmed and antioxidant incorporation partially abrogated the negative effects of high fat diets. The use of astaxanthin as antioxidant in feed formulation appeared as an interesting alternative against lipid peroxidation and subsequent effects on liver metabolism and fish health but more research are still needed to confirm these observations.

\section{Dietary $n-3 / n-6$ ratios}

Dietary fatty acid (FA) composition was assessed using different n$3 / n-6$ ratios. Dietary FA profiles had no effects on growth performances but affected the FA profiles of carcass, liver and fillet 
tissues due to some modifications of the lipid metabolism (stimulation of elongation and desaturation enzymes). Presence of high dietary levels of $18: 2 n-6$ and $18: 3 n-3$ did not induce deterioration of the hepatic ultrastructure, suggesting interesting perspectives on alternative sources of oil to promote sustainable perch aquaculture production.

\section{Conclusions}

Appropriate combination of abiotic, social, feeding and nutritional conditions could be used to control lipid metabolism and liver status in Eurasian perch. Recent advances in the determination of specific nutritional requirements in perch juveniles should help the perch industry to formulate specific diets for perch ongrowing. 
The possibilities of rearing pikeperch fry (Sander lucioperca) in recirculation systems - in different stocking densities and with different starter diets

\section{BÓDIS Márk* and BERCSÉNYI Miklós}

Pannon University, Georgikon Faculty of Agriculture, Department of Animal Science and Husbandry, Deák F. st. 16.

${ }^{*}$ Corresponding author. Tel.: +36 203378128

E-mail address: bodis-m@georgikon.hu

\section{Introduction}

The pikeperch (Sander lucioperca) is a new, promising species for intensive aquaculture. The growing of table size fish is possible using dry feeds in recirculation systems (Hilge 1990). In such systems, pond-nursed pikeperch are weaned to dry feed at a body length of 3-5 $\mathrm{cm}$ and a body weight of 0.5-1.5 g (Zakes 1997, Bódis et al. 2007). However, we currently have little knowledge of the nutritional requirements of the pikeperch larvae. Moreover, at these very small sizes the fish is extremely sensitive, making rearing difficult.

We investigated the possibilities of rearing the first feeding fry with different starter diets and the effect of stocking density on the growth, survival and feed conversion.

The effect of stocking density on the rearing of pikeperch fry with dry feed

We examined the efficiency of weaning pikeperch fry at different stocking densities during a 35 day trial. The fish were originated from artificial propagation. The larvae were fed exclusively with live food for 14 days post-hatch. After that, the fish were selected and stocked to $50 \mathrm{~L}$ tanks in different stocking densities (100, 200 and 300 fish/tank). The initial body weight was $24.5 \pm 4.4 \mathrm{mg}$ and the initial body length was $1.45 \pm 0.07 \mathrm{~cm}$. The water temperature was $19.5 \pm 0.5^{\circ} \mathrm{C}$.

The fish were fed exclusively with trout starter mini pellets of increasing size, according to fish growth.

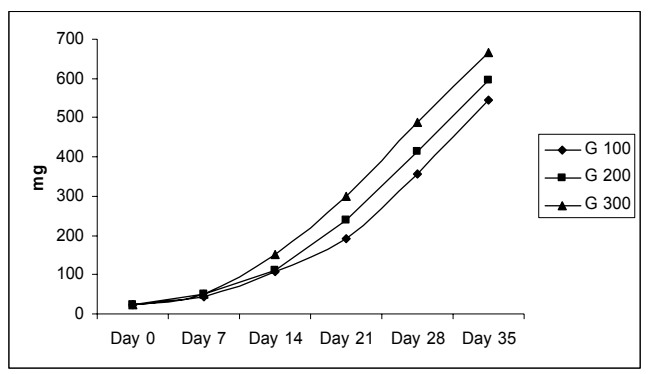

Figure 1. The growth of the experimental fish 


\section{The use of different starter diets}

Newly hatched pikeperch larvae were stocked to $50 \mathrm{~L}$ tanks in a recirculation system. The initial stocking density was 2000 fish/tank (40 larvae/Liter). Five different groups were formed in triplicates. The starter diets were the following: dry feed, Artemia, dry feed + Artemia, enriched Artemia, enriched Artemia + dry feed.

The experimental period was 3 weeks. The growth, survival and body deformities of the fish were measured and determined.

\section{$\underline{\text { Conclusions }}$}

The nutritional components of the starter diet are determining the survival, growth and the development of different organs (swim bladder) of pikeperch larvae.

Juveniles, first fed exclusively with live food can be weaned to dry feed successively. At higher stocking densities, less cannibalism was detected.

\section{$\underline{\text { References }}$}

Bódis M., Kucska B., Bercsényi M. 2007: The effect of different diets on the growth and mortality of juvenile pikeperch (Sander lucioperca) in the transition from live food to formulated feed. Aquaculture International Vol. 15, Number 1, pp 83-90

Hilge,V., 1990. Beobachtungen zur Aufzuht von Zandern (Stizostedion lucioperca) im labor. Arch. Fisch. Wiss. 40, 167-173

Zakes, Z 1997: Converting pond-reared pikeperch fingerlings, Stizostedion lucioperca (L.) to artificial food - effect of water temperature. Archives of Polish Fisheries. Vol. 5. $313-324$ 


\section{Propagation of pikeperch (Sander lucioperca) - Hungarian methods and experiences}

BÓDIS Márk*, ITTZÉS István, CSAPÓ István and BERCSÉNYI Miklós

Pannon University, Georgikon Faculty of Agriculture, Department of Animal Science and Husbandry, Deák F. st. 16.

${ }^{*}$ Corresponding author. Tel.: +36 203378128

E-mail address: bodis-m@georgikon.hu

\section{$\underline{\text { Introduction }}$}

The pikeperch (Sander lucioperca) is one of the most valuable freshwater carnivorous fish species in Europe. The traditional propagation method for this species employs a special spawning material, the spawning nest, made from various natural and/or artificial materials (Bódis \& Csapó, 2004. Artificial propagation with hormone injection is, however, a relatively new method for the pikeperch (Demska- Zakęś \& Zakęś 2005, Müller et al l. 2006).

\section{The traditional way of propagation using spawning nests}

We have compared the effectiveness of different spawning nests made of natural or artificial materials.

The comparison of different incubation techniques

The effectiveness of different incubation techniques, like incubation in a pond, in a mist-chamber or in Zuger glass was compared. The incubation time and efficiency (hatching rate) was compared under pond conditions, in a mist-chamber and in Zuger glasses.

Artificial propagation using hormonal injection

We found, that the ovulation time is changing individually, which makes difficult doing predictable, large scale propagation. A new method was worked out for solving this problem.

\section{$\underline{\text { Reproductional data }}$}

We collected some practical data about pikeperch propagation and we compared it with our experiences, like ovulation time, the egg quantity $/ \mathrm{kg}$ of fish, the diameter of the eggs and the dry and wet egg number $/ \mathrm{kg}$ etc.

\section{$\underline{\text { Conclusions }}$}

Intensive new technologies based on hormone treatment, egg stripping and incubation in hatching jars are efficient and reliable. New methods are advantageous as specially for pikeperch farming in RAS circumstances. 


\section{$\underline{\text { References }}$}

Bódis, M., Csapó, I. 2004 Pikeperch propagation in practice I. Comparing different kinds of spawning nests, and a new method to calculating the number of eggs on a pikeperch spawning nest. Halászat, 97. 132-133 (in Hungarian)

Demska- Zakęś, K., Zakęś, Z., Roszuk J. 2005 The use of tannic acid to remove adhesiveness from pikeperch, Sander lucioperca, eggs. Aquaculture Research, 36 , 1458-1464

Müller, T., Bódis, M., Nyitrai G. 2006. Observations in the artificial propagation of pikeperch. Halászat, 99. 20-22. (in Hungarian) 


\section{Two years observations of Eurasian perch (Perca fluviatilis L.) post-larvae performances in a illuminated floating cage in Lake Varese (N-W Italy).}

\section{CECCUZZI Pietro*, BRAMBILLA Fabio, ANTONINI Micaela, TEROVA Genciana \& SAROGLIA Marco}

University of Insubria, Department of Biotechnology and Molecular Science, Ichthyology \& Aquaculture Unit, Via Dunant 3, 21100, Varese, Italy.

${ }^{*}$ Corresponding author: Tel.: +390332 421423

E-mail address: pietro.ceccuzzi@uninsubria.it

Eurasian perch ( $P$. fluviatilis) is a very important fish species in Lake Varese. During the second half of 20th century, perch catches in the lake have steadily decreased and by the end of 80 s it resulted clearly endangered. The purpose of this study was to investigate an early life of the species. Whit this aim, a study on growth performances, mortality and feeding conditions was afforded by rearing post-larvae stages into an illuminated cage concentrating zooplancton. This method was already applied by other authors studying on carnivorous species (Mamcarz et al., 2001).

The rearing experiment was carried out in Lake Varese (Northern Italy) in the summer season of years 2006 and 2007. Artificial production and incubation of perch eggs were conducted at an experimental hatchery positioned on the bank of the Lake. On July14, 2006 and June 29, 2007, a number of respectively 280 and 300 perch post-larvae, resulting in an average weight of $0.64 \mathrm{~g}( \pm 0.09)$ and 0.25 $\mathrm{g}( \pm 0.082)$, were introduced into a floating cage $(0.8 \times 2 \mathrm{~m}, 2 \mathrm{~mm}$ mesh). The cage was illuminated with a $60 \mathrm{~W}, 24 \mathrm{~V}$ lamp during $10 \mathrm{hrs}$ of the night time. In both all the rearing periods (90 days each) perch were feeding only on zooplankton naturally entering the cage during the day and light-attracted during the night.

For both the years, a sample of 15 fish was taken from the cage every fifteen days, on which total length $( \pm 1 \mathrm{~mm})$ and weigh $( \pm 1 \mathrm{mg})$ was assessed. To evaluate food resources in the lake, zooplankton samples were collected weekly at 1 meter of depth by a Ruttner's bottle, in three sampling points: inside the cage, $10 \mathrm{~cm}$ out of the cage and $15 \mathrm{~m}$ from the cage.

The zooplankton sampling operated during the first week of the experiment, consisted of a sampling each second hour, through 24 hours, while the successive weekly samples were done only at night time from 23:00 to 3:00 a.m.

The plankton density of the samples was determined by counting the zooplankters in 5 sub-samples (100 $\mathrm{ml}$ each). The genus of observed 
zooplankters were determined and corresponded to Daphnia, Leptodora, Cyclops and Chironomidae.

During the night sampling a mean of $322( \pm 136)$ zooplankters I-1 and $945( \pm 600)$ zooplankters $\mathrm{l}-1$ in 2006 and 2007 respectively $(p<0.05)$ were counted in the cage. In 2006 the mean body weight of perch fry at the end of trial $4.65 \mathrm{~g}( \pm 1.47)$ was significantly lower $(p<0.05)$ than that observed 2007 trial $5.9 \mathrm{~g}( \pm 1.88)$. The higher fish growth rate observed in 2007 trial was influenced by a higher zooplankton accumulation in the cage. The final survivor percentage was relatively higher in both the years: 50.7 and $60.7 \%$ in 2006 and 2007 respectively.

The growth in body weight of perch was very fast especially during July and August while a slower growth rate was observed in September, due to the temperature fluctuations. In conclusion, preliminary results indicate the possibility to rear post-larvae of Eurasian perch in Lake conditions with the use of an illuminated cage. Further studies already in progress, will include monitoring of the feeding activity and evaluation of optimal density.

\section{$\underline{\text { References }}$}

Mamcartz A., Kujwa R., Frgala-Seleziniow G.and Kucharczych D., 2001. Preliminary results of larval and fry asp (Aspius aspius) rearing in the illuminated cages. Larvi '01-Fish \& Shellfish larviculture symposium. Europe. Aquaculture Society, Special Publ. No 30, Oostende, Belgium. 


\title{
Endocrine sex control strategies of pikeperch (sander lucioperca (I.))
}

\author{
DEMSKA-ZAKĘŚS Krystyna ${ }^{1 *}$, ZAKĘŚ Zdzisław ${ }^{2}$ \\ ${ }^{1}$ Department of Ichthyology, University of Warmia and Mazury, \\ Oczapowskiego 5, 10-719 Olsztyn, Poland \\ ${ }^{2}$ Department of Aquaculture, The Stanisław Sakowicz Inland Fisheries \\ Institute, Oczapowskiego 10, 10-719 Olsztyn, Poland \\ *Corresponding author, E-mail address: krysiadz@uwm.edu.pl
}

\section{$\underline{\text { Introduction }}$}

Over the past few years there has been extraordinarily dynamic growth in aquaculture, including the farming of percid fish. Among other reasons, this is due to the widespread application of reproductive biotechnology in finfish production (Lee \& Donaldson, 2001). Of particular interest are technologies that permit producing monosex or sterile fish populations. Reproductive potential can be controlled and production profitability increased by favoring the sex with the faster growth rate, the ability to control energy distribution, and the lower feed coefficient. In addition, these technologies can contribute to increasing slaughter value, limiting aggressive behavior, and ensuring greater uniformity of size at harvest. Monosex populations can be obtained through sorting, hybridization, chromosome manipulation, or drug or hormone therapy.

The aim of the research was to determine the possibilities of producing monosex populations of pikeperch (Sander lucioperca (L.)) by adding hormonal preparations to the feed.

\section{Material, Methods, and Results}

Sex manipulation was performed on juvenile pikeperch (initial body weight of about $2 \mathrm{~g}$ ). The hormones applied in this study were 17amethyltestosterone (MT), 11 -hydroxyandrostenedione (OHA), 17 $\beta$ estradiol (E), and diethylstilbestrol (DES). The hormones were delivered with the feed (in doses of $30,60,90 \mathrm{mg} \mathrm{kg}-1$ ) for a period of 21 days. Histological examination confirmed that a substantial increase in the number of males can be obtained with MT at a dose of $30 \mathrm{mg} \mathrm{kg}-1$ feed (about $97 \%$ ) or OHA at a dose of $60 \mathrm{mg} \mathrm{kg}-1$ feed (about 93\%). Increasing or decreasing the hormone dose caused an increase in the percentage of females or bisexual and sterile individuals. Such differentiation was not observed with E or DES; the stock was totally feminized regardless of the dose applied. It should be emphasized that only in the group given the lowest dose of DES was growth rate, condition, and survival similar to the values of the control group. In the other groups these indicators had significantly lower values $(P<0.05)$. 


\section{$\underline{\text { Conclusions }}$}

Pikeperch exhibit sex-linked growth dimorphism; females achieve sexual maturity later, but they grow faster and attain a larger body size than do males. Thus, the production of a monosex female population of this species might have considerable economic advantages. Such a stock can be obtained with the direct method by applying E or DES or also with the indirect method by crossing neomales (following MT or OHA treatment) with females.

\section{$\underline{\text { References }}$}

Lee C.S., Donaldson E.M., 2001. General discussion on "Reproductive biotechnology in finfish aquaculture". Aquaculture 197, 303-320. 
Effect of domestication level on the physiological and immune response of chronically stress-confined Eurasian perch (Perca fluviatilis) juveniles.

DOUXFILS Jessica ${ }^{1 *}$, WANG Neil ${ }^{1}$, MANDIKI S.N.M. ${ }^{1}$, MAROTTE Grégory $^{1}$, SILVESTRE Frédéric ${ }^{1}$, HENROTTE Emilie ${ }^{1}$, ROUGEOT Carole $^{2}$, MÉLARD Charles ${ }^{1}$, KESTEMONT Patrick $^{1}$

${ }^{1}$ Unité de Recherches en Biologie des Organismes (URBO), Facultés Universitaires Notre-Dame de la Paix, Namur, Belgium

${ }^{2}$ Research and Education Center (CEFRA), ULg, Belgium

* Corresponding author. Tel.: +32 (0)81 724284

E-mail address: jessica.douxfils@fundp.ac.be

\section{Introduction}

In aquaculture, chronic stress such as confinement or breeding density, are able to disturb animal welfare by compromising growth, immunity and reproduction. Moreover, mass mortality can result from severe stress and contribute to suboptimal production. However, it seems that domestication process can reduce sensitivity of animals to stressing events. Eurasian perch seems particularly sensitive to stress and recent experimental results pointed out the importance of domestication level on mortality attributed to pathogens. Actually, mortality rates and disease occurrence clearly decreased from F0-F1 to F4-F5 juveniles. The aim of the study is to evaluate the effect of domestication level on stress-affected physiology and immunity of perch juveniles.

\section{Experiment}

During 30 days, F1 and F4 juveniles were confined in 100L tanks while unconfined groups were held in $2000 \mathrm{~L}$ tanks. Samplings were performed on day 5,15 and 30 for confined groups and on day 30 for unconfined fish. Acute stress (netting and anaesthesia) was also applied to juveniles on each sampling date. Serum cortisol, glucose and lysozyme activity were assayed as well as liver HSP60, 70. Fish were infected with Aeromonas hydrophila during 10 days. Serum lysozyme and antibody levels were measured.

\section{$\underline{\text { Results }}$}

Confinement affects HSP70 levels and lysozyme activity in F1 juveniles only. Confined F4 juveniles show higher IGF-1 levels than confined F1 fish. Confinement do not modify cortisol rise in F4 fish submitted to acute stress but induce a higher cortisol elevation in F1 fish. Glucose rise related to acute stress exposure is not modified by confinement for either F1 or F4 fish. Confinement does not affect 
lysozyme activity during bacterial challenge test. However, F4 juveniles show higher lysozyme activity than F1 fish after a 5 days bacteria exposure. Regarding antibody titre during challenge test, F4 values are globally higher than $\mathrm{F} 1$ values. Antibody titre increases in relation to confinement for F4 juveniles, but not for F1 fish.

\section{Conclusion}

Globally, confinement affects immune parameters and increases cortisol response to acute stress in F1 juveniles. Consequently, it seems that $F 1$ juveniles may be more sensitive to confinement than F4 juveniles. This indicates a positive domestication effect on stress responsiveness. During challenge test, F4 juveniles show a higher lysozyme activity and antibody response than F1 fish which may indicate a higher disease resistance of fish related to domestication process. 
The development of genomic tools for selective breeding of yellow perch, Perca flavescens

\author{
GOETZ Frederick ${ }^{1 *}$, ROSAUER Dan ${ }^{1}$, GRZYBOWSKI Mike ${ }^{1}$, \\ SHEPHERD BrianN ${ }^{2}$ \\ ${ }^{1}$ Great Lakes WATER Institute, University of Wisconsin-Milwaukee, \\ 600 E. Greenfield Ave. Milwaukee, WI 53204, USA. \\ ${ }^{2}$ Great Lakes WATER Institute/ARS/USDA 600 E. Greenfield Ave. \\ Milwaukee, WI 53204, USA. \\ ${ }^{*}$ Corresponding author. Tel.: 00-1-414-382-1742 \\ E-mail address: rick@uwm.edu
}

Selective breeding programs require significant amounts of genomic information for determining genetic variation, parentage analysis and as markers for genetic selection. For many intensively aquacultured species such as trout and salmon, there is a considerable amount of genomic data available.

However, for yellow perch (Perca flavescens), there is virtually no gene information. In conjunction with our development of genetically defined perch broodstocks, we have initiated a microsatellite and expressed sequence tag (EST) project. Using a magnetic bead, oligonucleotide trapping approach, we have isolated more than 100 new microsatellites, of which 50 have been analyzed for allelic variation and observed and expected heterozygosity. Six of these new microsatellites were incorporated into our population genetic analysis of perch populations across North America for broodstock selection.

For EST development, we performed an experiment on fingerling perch with estrogens. In the yellow perch, estrogens have been demonstrated to stimulate growth, and while the effect is present in both males and females, the extent is sexually dimorphic. Estradiol was administered to fingerling perch in the diet for 3 months and the effects on body length and weight continually assessed. Estradiol significantly stimulated growth in both females and males and this effect was greater for females as previously demonstrated. At the termination of the experiment, livers, brains and muscle were biopsied and frozen at $-80 \mathrm{C}$.

Separate complimentary DNA (cDNA) libraries were constructed in ZAP Express (Stratagene) of brains and livers from estrogen and control (no steroid) perch and 4,000 ESTs were obtained from each of the 4 libraries (16,000 ESTs total) by sequencing with Big Dye on an $A B I 3730$. In addition, 8,000 ESTs were obtained from ovarian cDNA libraries of perch stimulated with human chorionic gonadotropin to give a total of approximately 24,000 ESTs. 
Comparative analysis of the ESTs from estrogen versus control fish demonstrated distinct differences in gene expression that can be used to understand the effect of estrogens on perch growth.

The genomic tools developed in this project will be submitted to Genbank and are being used in the yellow perch broodstock genetic selection program that is ongoing.

Project funded by NOAA Sea Grant and the USDA/ARS. 
The new concept of salinity stress test for assessment of pikeperch seed quality

\author{
GOMULKA Piotr ${ }^{1 *}$, KUCHARCZYK Dariusz ${ }^{2}$, TARGOŃSKA \\ Katarzyna ${ }^{2}$, KWIATKOWSKI Maciej ${ }^{2}$ \\ ${ }^{1}$ Chair of Ichthyology, University of Warmia and Mazury, Olsztyn \\ Poland \\ ${ }^{2}$ Chair of Lake and River Fisheries, University of Warmia and Mazury, \\ Olsztyn, Poland
}

${ }^{*}$ Corresponding author: +48 $89524 \quad 42$ 25; E-mail address: pgomulka@uwm.edu.pl

\title{
Introduction
}

The quality of fish seed was recognized as an important factor influencing aquaculture development (Bromage, 1995) worldwide. As the resistance to high salinity correlate to overall performance, salinity stress test is used for assessment of the quality of freshwater fish seed. However, currently used procedure (i.e. exposure of a batch of pikeperch fry to $30 \mathrm{~g} \cdot \mathrm{l}-1 \mathrm{NaCl}$ solution for $30 \mathrm{~min}$ ) gives only the two possible answers: good quality or bad quality. As the quality is the most important factor for fish seed price, above procedure is not suitable.

\section{The concept of test modification}

The main idea is that the LC50 value for $\mathrm{NaCl}$ is changing proportionally to fish body performance capacity. We propose to develop LC50 values for weak, mean and very good quality fish seed. Exposure of a batches of fish to above three $\mathrm{NaCl}$ concentrations theoretically can give a range of answers; from "excellent quality" ( no mortality in the highest concentration) to "non acceptable quality" (mortality higher than $50 \%$ in the lowest $\mathrm{NaCl}$ concentration).

\section{Experimental}

Pikeperch fry acclimated to laboratory conditions were divided into 3 groups fed respectively with $10 \%, 2 \%$ and $0 \%$ of body weight daily for 3 days. Than the $\mathrm{LC} 50$ value of $\mathrm{NaCl}$ (for $\mathrm{t}=30 \mathrm{~min}$ ) was developed according to OECD standard No 203 Acute Toxicity Fish Test for each group. Two days later, the batches of 30 fish from each group were exposed for $30 \mathrm{~min}$ to $3 \mathrm{NaCl}$ concentrations equal to earlier calculated LC50 values. A quality assessment was done on the base of fish mortality. 


\section{$\underline{\text { Results }}$}

The calculated LC50 values of $\mathrm{NaCl}$ for pikeperch fry were as 26,6 $\mathrm{g} \cdot \mathrm{l}-1,28,2 \mathrm{~g} \cdot \mathrm{l}-1$ and $29,2 \mathrm{~g} \cdot \mathrm{l}-1$ respectively for fish fed with $0 \%, 2 \%$ and $10 \%$ of body weight daily.

The mortality of starved fish exposed to the lowest LC50 value was $50 \%$ and $100 \%$ in both higher concentrations. The mortality in the group fed with $10 \%$ of body weight was lower then $15 \%$ in all used concentrations.

\section{$\underline{\text { Conclusions }}$}

The proposed method is very simple and easy to perform. Although the range of LC50 values was very narrow, results of laboratory experiments gave expected results. However, the method should be discussed and verified by both scientists and practitioners before implementation.

\section{$\underline{\text { References }}$}

Bromage, N.R., 1995. Broodstock management and seed quality general considerations. In Bromage, N.R. \& Roberts, R.J. eds. Broodstock management and egg and larval quality. Blackwell Science, Oxford. Pages 1-24. 
Comparison of economic effectiveness of pikepersc summer fry production in dependence of reproduction methods

\section{HAKUĆ-BŁAŻOWSKA Anna*, KUCHARCZYK Dariusz, KUPREN Krzysztof, TARGOŃSKA Katarzyna}

Departament of Lake and River Fisheries, Warmia and Mazury University in Olsztyn, ul.Oczapowskiego 5, PL-10-718 OlsztynKortowo, Poland

* Corresponding author. Tel.: +48 8952344 36, E-mail address: aloois@gmail.com (A. Hakuć-Błażowska)

\section{$\underline{\text { Introduction }}$}

In Europe pikeperch are usually reproduced in ponds, mainly with using nests. This method has low effectivity and characterized high fluctuations in obtained results. The aim of this study is comparing the effectiveness of pikeperch summer fry productions using traditional and artificial reproduction methods.

\section{Material and Methods}

The experiment was carried out at Fish Farm Pasłęk Poland. During two following seasons the pikeperch spawners were put on earthen pond for reprodution. On the third year the pikeperch spawners were reproduced artificially using hormonal stimulation. The effectiveness of summer fry production at the same pond was counted and compared. Total costs of methods was taken into consideration (Turkowski 2002).

\section{$\underline{\text { Results }}$}

Table 1.

\begin{tabular}{|c|c|c|c|c|c|c|}
\hline years & $\begin{array}{c}\text { No. of } \\
\text { spawners }\end{array}$ & $\begin{array}{c}\text { spawners } \\
\text { total } \\
\text { value } \\
\text { [Euro] }\end{array}$ & $\begin{array}{c}\text { Survival } \\
{[\%]}\end{array}$ & $\begin{array}{c}\text { No. of } \\
\text { summer } \\
\text { fry }\end{array}$ & $\begin{array}{c}\text { Summer } \\
\text { fry value } \\
\text { [Euro] }\end{array}$ & $\begin{array}{c}\text { Relationship: } \\
\text { no. of } \\
\text { fry/spawners }\end{array}$ \\
\hline 2005 & 23 & 149,35 & 69 & 89400 & 1833,84 & 3886 \\
\hline 2006 & 22 & 150,80 & 68 & 132200 & 2711,79 & 6009 \\
\hline 2007 & 4 & 36,79 & 100 & 169700 & 3481,02 & 42425 \\
\hline
\end{tabular}

The obtained results are showed in table 1 . The highest summer fry production was noted at 2007, when artificial reproduction method was applied. Also the value of summer fry and relationship between number of used spawners and number of produced summer fry were highest at the same year. 


\section{$\underline{\text { Conclusions }}$}

The artificial method of pikeperch reproduction is more effective then traditional in summer fry production in conditions of Fish Farm Pasłęk Poland.

\section{$\underline{\text { References }}$}

Turkowski K., 2002. Conditions for economic efficiency of coregonids stocking in lakes. Disserations and Monographs, University of Warmia and Mazury in Olsztyn, 68: 1-86. 


\section{Effect of dietary phospholipid levels on the development of pikeperch larvae}

HAMZA Neila ${ }^{1,2}$, M'HETLI Mohamed ${ }^{1}$, BEN KHEMIS Ines ${ }^{1}$, CAHU Chantal $^{3}$ and KESTEMONT Patrick ${ }^{2 *}$

${ }^{1}$ Institut National des Sciences et Technologies de la Mer, 28, Rue 2 Mars 1934, 2025 Salammbô Tunisia

${ }^{2}$ University of Namur (FUNDP), Rue de Bruxelles, 61, B-5000 Namur, Belgium

${ }^{3}$ Unité Mixte INRA-IFREMER de Nutrition des Poissons B.P.70 29280 Plouzane France

\section{Introduction}

The production of pikeperch fingerlings still depends on extensive and semi-intensive pond culture. The larval rearing still remains a critical period with some bottlenecks essentially concerning the acceptance and nutritional suitability of artificial diets. Previous studies have shown the capacity of pikeperch larvae to accept inert diets but little is known about the nutritional requirements of this species during its early life stages.

Considering the importance of lipids and phospholipids for the survival and growth of many species, our study aims to investigate the effects of phospholipids levels on survival, growth and enzymatic capacities of pikeperch larvae.

\section{Materials and methods}

From day 10 to day 34 post-hatching (ph), larvae were fed with three isoproteic ( $58 \%$ dry matter) and isolipidic ( $20 \%$ dry matter) formulated diets according to the patent WO0064273 (November 2000) and containing three phospholipid (PL) levels (\% dry matter): 1.5 (PL1), 4.7 (PL5), and 9.5 (PL9).

Growth was monitored by sampling 30 larvae per tank on days 4 and 10 (ph), and 10 larvae per tank on days 16, 22, 28 and 34 (ph). Leucine-alanine peptidase (Leu-ala), alkaline phosphatase (AP) and leucine aminopeptidase N (AN) were assayed according to Nicholson and Kim (1975), Bessey et al. (1946) and Maroux et al. (1973), respectively.

\section{$\underline{\text { Results and discussion }}$}

At the end of the experiment, the survival of larvae varied between 33 and $36 \%$ and was not significantly affected by the dietary PL level. However, the increase in dietary PL level from 1.5 to $9.5 \%$ led to a $50 \%$ increase in mean body weight (from $160 \mathrm{mg}$ in group PL1 to 238 
$\mathrm{mg}$ in group PL9), suggesting that high PL levels are needed during early life stages of pikeperch.

While specific activity of Leu-ala did not differ significantly between dietary treatment, AP and AN specific activities were significantly higher in PL5 and PL9 groups than in PL1 group, suggesting a better development and intestinal maturation process in PL5 and PL9 groups than in PL1 group.

\section{Conclusion}

This study showed that pikeperch can be successfully weaned from day 10 with compound diet, with satisfactory growth and survival. The $\mathrm{PL}$ requirement for pikeperch larvae seems to be at least 9.5\% (dry matter).

\section{$\underline{\text { References }}$}

Bessey, O.A., Lowry, O.H., Brock, M.J., 1946. Rapid coloric method for determination of alkaline phosphatase in five cubic millimetres of serum. J. Biol. Chem. 164, 321-329.

Maroux, S., Louvard, D., Baratti, J., 1973. The aminopeptidase from hog-intestinal brush border. Biochim. Biophys. Acta 321, 282-295.

Nicholson, J.A., Kim, Y.S., 1975. A one-step L-amino acid oxidase assay for intestinal peptide hydrolase activity. Anal. Biochem. 63, 110117. 


\title{
Histological and biochemical analysis of reproductive system in male of Eurasian perch (Perca fluviatilis L.) during spawning and post-spawning period
}

\author{
KROL Jaroslaw* and GLOGOWSKI Jan \\ Department of Ichtiology, University of Warmia and Mazury in Olsztyn, \\ Poland \\ Oczapowskiego 5, 10-719 Olsztyn, Poland \\ corresponding autor - e-mail: krolas@uwm.edu.pl
}

We found, that combination of anatomical and biochemical methods for investigations of physiological processes in reproductive system of male perch, could result in obtaining valuable information. Observation of changes in proteinase and anti-proteinase activities during all spawning periods of perch can be important step in recognition the function of these proteins.

Fishes originated from lake Drwęckie located near Ostróda (northwest Poland). In this study we used methods enabled to show qualitative determinants of perch semen, characterizing basic parameters of perch seminal plasma. Histological methods used in this study enabled to show changes in perch gonads during spawning and post-spawning period.

In both years of investigations essential decline in sperm motility at the end of spawning season was observed. The sperm motility was not influenced by sperm concentrations, because throughout the spawning time, changes in sperm concentration were not observed. No changes in seminal plasma osmolality during the all periods of milt collection were observed.

In contrast to sperm concentrations, protein concentrations in seminal plasma increased in the later part of spawning season. This study confirmed, that protein concentrations in seminal plasma of most fishes are much lower than in other vertebrates. Among fishes which were examined, perch is characterized by one of the highest values of protein concentrations in plasma.

Proteinase activity (measured using azoalbumin as a substrate) has been found in seminal plasma of perch. Means values of proteinase activities did not differ in relation to time of milt collection. Electrophoretic methods allowed to indicate, that gelatinolytic proteinase activity depends on presence of $\mathrm{Ca} 2+$ during incubation. Electrophoretic profiles of gelatinolytic proteinase activities in seminal plasma of perch were characterized by four molecular forms. This study showed that, gelatinolytic proteinase activities were characteristic for metaloproteinases, depended on calcium. Electrophoretic profiles of caseinolytic proteinase activities of perch 
seminal plasma showed two forms of proteinase activities with low molecular masses, which were not detected in profiles of gelatinolytic proteinase activities. Caseinolytic proteinase activities, were independent on calcium and were fully inhibited after incubation with metaloproteinases inhibitor (EDTA).

Anti-proteinase activity in seminal plasma of perch was measured spectrophotometrically using $\mathrm{N}$-benzoyl-DL-arginine p-nitroanilide (BAPNA) as a substrate. Mean values of this activity slightly increased together at the end of spawning season. This observation suggest, that proteinase inhibitors can break resorption process in perch testes in the later part of spawning season. Results concerning separation of inhibitors by use of electrophoretic methods revealed that there are at least seven forms of anti-proteinases in seminal plasma of perch.

There was lack of correlation between semen quality parameters and protein components in seminal plasma of perch. A positive correlation has been found between protein concentrations and anti-proteinase activity. These results suggest, that proteins with anti-proteinase activity comprise large percentage of all proteins in seminal plasma of perch. We also found positive correlation between sperm concentrations and protein concentrations, and sperm concentrations and anti-proteinase activity in seminal plasma, but only at the end of spawning period of perch.

Histological analysis permitted description of changes in male gonads during spawning period. Our results confirmed that there was an additive period after spawning in the annual reproductive cycle of male Eurasian perch. 


\section{Artificial reproduction of pikeperch (Sander lucioperca L.) under controlled conditions}

KUCHARCZYK Dariusz ${ }^{1 *}$, TARGOŃSKA Katarzyna ${ }^{1}$, SOSIŃSKI Michał $^{1}, \quad$ KWIATKOWSKI Maciej ${ }^{1}$, SZKUDLAREK Maciej ${ }^{3}$, SZCZERBOWSKI Andrzej ${ }^{3}$, ŁUCZYŃSKI Marek ${ }^{3}$, GOMUŁKA Piotr ${ }^{2}$, KUJAWA Roman ${ }^{1}$ \& MAMCARZ Andrzej ${ }^{1}$

${ }^{1}$ Department of Lake \& River Fisheries,

${ }^{2}$ Department of Ichthyology, Warmia and Mazury University in Olsztyn, ul. Oczapowskiego 5, PL-10-718 Olsztyn-Kortowo, Poland

${ }^{3}$ Inland Fisheries Institute, Olsztyn, Poland

${ }^{*}$ Corresponding author. Tel.: + 488952342 15,

E-mail address: darekk@uwm.edu.pl (D. Kucharczyk)

\section{$\underline{\text { Introduction }}$}

Pikeperch are usually reproduced at ponds. Fry (summer or autumn) production using this method is often fluctuated. For this reason the new techniques, which gives the possibility to stabile production are required (Ronyai 2007). The aim of this study was to test different spawning agents in pikeperch artificial reproduction in captivity.

\section{Material and Methods}

The breeders were caught at the "Dead Vistula" - north Poland and transported to the Fish Farm Pasłęk. Later, selected fish were moved to the university hatchery, where they were kept at $1000 \mathrm{dm} 3$ tanks under controlled conditions. Fish were divided into few groups and obtained different spawning agents at single dose (Table 1).

\section{$\underline{\text { Results }}$}

Table1. The results of artificial reproduction of pikeperch.

\begin{tabular}{|l|l|l|l|l|}
\hline & $\begin{array}{l}\text { Control } \\
\text { group }\end{array}$ & CPE & hCG & Ovopel \\
\hline Hormone dose/kg & $0.9 \% \mathrm{NaCl}$ & $4 \mathrm{mg}$ & $700 \mathrm{IU}$ & 1 pellet \\
\hline No. of females & 15 & 15 & 15 & 15 \\
\hline Ovulation (\%) & 20 & 47 & 93 & 73 \\
\hline $\begin{array}{l}\text { Embryo survival } \\
(\%)\end{array}$ & $49.1+4.2 \mathrm{~b}$ & $25.9+$ & $81.4+$ & $78.9+4.2$ \\
& $4.5 \mathrm{c}$ & $2.5 \mathrm{a}$ & $\mathrm{a}$ \\
\hline $\begin{array}{l}\text { Females survival } \\
(\%)\end{array}$ & 60 & 40 & 87 & 80 \\
\hline
\end{tabular}

* - data marked with the same letter did not differ statistically (post hoc Tuckey test, $\alpha=0.05$ ) 
The obtained showed that it is possible to apply many different spawning agents in controlled reproduction of pikeperch. The highest percentage of ovulation, 3-days old embryo survival, as well as females' survival was observed after application of hCG (Table 1).

\section{$\underline{\text { Conclusions }}$}

The application of spawning agents usually influenced on spawning synchronization, percentage of fish which ready to spawn and quality and quantity of gametes. The best results are obtained after using hCG.

\section{$\underline{\text { References }}$}

Ronyai, A., 2007. Induced out-of-season and seasonal tank spawning and stripping of pike perch (Sander lucioperca L.). Aquaculture Research, 1-8 (OnlineEarly Articles doi:10.1111/j.13652109.2007.01778.x). 
Relationship between oocyte maturity stages in pikeperch (Sander lucioperca L.) and time of ovulation in captivity

KUCHARCZYK Dariusz ${ }^{1 *}$, TARGOŃSKA Katarzyna ${ }^{1}$, KREJSZEFF Sławomir ${ }^{1}$, SZKUDLAREK Maciej ${ }^{2}$, SZCZERBOWSKI Andrzej ${ }^{2}$ \& ŁUCZYŃSKI Marek ${ }^{2}$

1 Department of Lake \& River Fisheries, Warmia and Mazury University in Olsztyn, ul. Oczapowskiego 5, PL-10-718 OlsztynKortowo, Poland

${ }^{2}$ Inland Fisheries Institute, Olsztyn, Poland

${ }^{*}$ Corresponding author. Tel.: + 48895234215

E-mail address: darekk@uwm.edu.pl (D. Kucharczyk)

\section{Introduction}

The maturity of oocytes can be determined by using biopsy techniques. In this technique eggs (oocytes) are removed from the ovary with the use of catheter, cleared with a prepared solution (Serra's solution), and viewed under a microscope. The main evaluation criteria of pikeperch oocytes maturity stages like other Teleostei fishes are the location of germinal vesicle (GV) and additionally coalescence of the oil droplets.

Oocytes in I maturity stage have GV in a central position and many small oil droplets.

Oocytes classified as II maturity stage have shifted GV less than a half radius, in addition the oil droplets are less numerous and have bigger dimensions.

Oocytes classified as III maturity stage have positioned GV on the periphery, near the oocyte membrane, and oil coalesced in one big droplet (Fig. 1).

Oocytes without visible GV, i.e. in which the process of GV breakdown (GVBD) had begun or GV is present near the zone, should be classified as IV maturity stage In this stage oocytes freshly sampled from ovary have light yellow coloration and clear transparency.

\section{$\underline{\text { Results }}$}

The relationship between oocyte maturity stage and latency time (time between injection from hCG and ovulation) was analyzed (Fig. 2). 


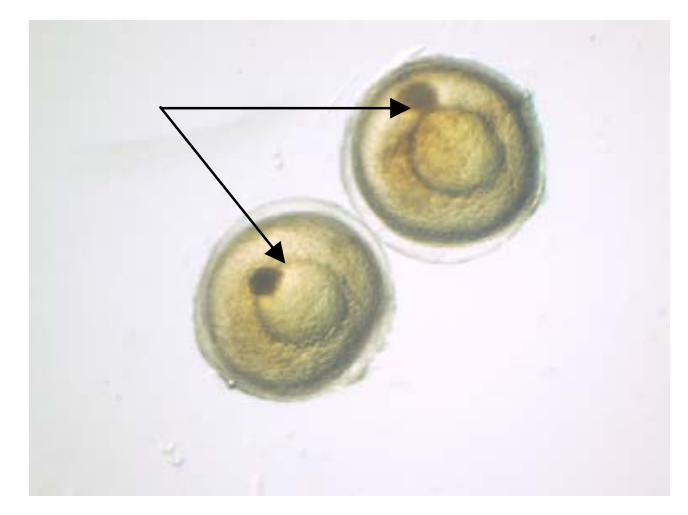

Fig. 1. The oocytes in maturity stage III. The arrows indicate GV

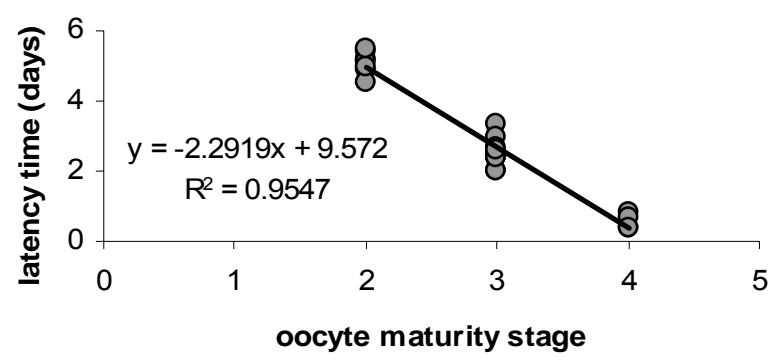

Fig. 2. Relationship between oocyte maturity stage and ovulation time

If fish were kept at constant temperature $\left(15^{\circ} \mathrm{C}\right)$ it is possible to calculate ovulation time.

\section{$\underline{\text { References }}$}

Ronyai, A., 2007. Induced out-of-season and seasonal tank spawning and stripping of pike perch (Sander lucioperca L.). Aquaculture Research, 1-8 (OnlineEarly Articles doi:10.1111/j.13652109.2007.01778.x). 


\section{Applications of chosen hormonal agents in pikeperch reproduction under controlled conditions - some economic aspects}

KUPREN Krzysztof*, BŁAŻOWSKA-HAKUĆ Anna, TARGOŃSKA Katarzyn, KUCHARCZYK Dariusz and TURKOWSKI Konrad

Department of Lake and River Fisheries, Warmia and Mazury University in Olsztyn, ul. Oczapowskiego 5, PL-10-718 Olsztyn-

Kortowo, Poland

${ }^{*}$ Corresponding author. Tel.: +48 895234436

E-mail address: krzysztof.kupren@uwm.edu.pl (K. Kupren)

$\underline{\text { Introduction }}$

For stimulation of pikeperch reproduction in controlled conditions a lot of different hormonal agents are applied (Zakes and Szczepkowski 2004). There are characterized different affectivities in depending of used doses and time of their application. This work focused on defined and compared chosen direct unit costs (Turkowski 2002) of production of pikeperch stocking material in depending on used hormonal spawning agents.

\section{Materials and Methods}

Production costs necessary for obtain 1000 fertilized eggs and the same count of 3-days old embryos (live) were assessed based on market prices of spawners and used specifics and results of spawning effectiveness (percentage of ovulation, mortality of embryos and females) of 4 hormonal spawning agents (CPE, hCG, ovopel and ovaprim) tested on pikeperch. Because the conditions and activities of spawners keeping and eggs incubation were always the same, all other costs were not taken under consideration in this work.

\section{$\underline{\text { Results and Conclusions }}$}

Analyzed unit costs of production of stock material (1000 fertilized eggs and the same number of 3-days old embryos) were shown on Fig 1. The lowest costs were noted in groups where ovopel and hCG were used. These costs were over two times lower than noted in controlled group (without hormonal stimulation) and several times that noted in groups where other hormonal agents were applied. The most expensive was stimulation with CPE. 


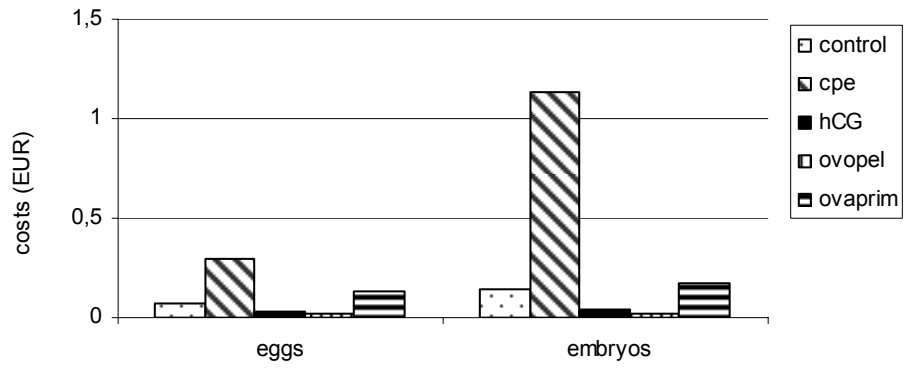

Fig1. Direct costs (in EUR) of production of 1000 fertilized eggs and the same number of 3-days old embryos in depending on applied hormonal agents.

\section{$\underline{\text { References }}$}

Turkowski K., 2002 Conditions for economic efficiency of coregonids stockings in lakes. Dissertations and Monographs, University of Warmia and Mazury in Olsztyn, 68, 1-86. (in Polish with English Summary).

Zakes Z., Szczepkowski M., 2004. Induction of out-of-season spawning of pikeperch, Sander lucioperca (L.). Aquaculture International 12, 11-18. 
Transfer of pahs by trophic way to eurasian perch Perca fluviatilis in controlled environment

\author{
LAZARTIGUES Angélique, THOMAS Marielle*, FEIDT Cyril, BRUN- \\ BELLUT Jean
}

Unité de Recherche Animal et Fonctionnalités des Produits Animaux, Nancy-Université, INRA, 2, avenue de la Forêt de Haye, BP172, F54505 Vandoeuvre-lès-Nancy

${ }^{*}$ Corresponding author. Tel.: +33.(0)3.83.30.28.41.

Email address: marielle.thomas@Isa-man.uhp-nancy.fr

\title{
Introduction
}

Most health risks linked to fish consumption are based on the presence in edible tissues of pollutants, such as Polycyclic Aromatic Hydrocarbons (PAHs), some of them being known to be carcinogenic (Liang et al., 2007). Therefore, our objective consists of studying the transfer of PAHs and metabolites levels, in muscle of Eurasian perch Perca fluviatilis, during low dose exposures by trophic way in a controlled environment.

\section{Experimentation}

After an acclimation period of three months, perch $(\mathrm{N}=75$, mean weight $108 \pm 16 \mathrm{~g}$ ) were randomly distributed into three tanks $(120 \mathrm{~L}$, recirculated water; temperature at $19 \pm 1^{\circ} \mathrm{C}$ ) using three modalities; a control group fed daily with pellets soaked up with acetone only and two experimental groups for which fish were fed daily with pellets, soaked up with acetone and a sub-lethal dose of a phenanthrene (PHE), pyrene (PYR) and benzo(a)pyrene (B(a)P) mixture. Experimental groups 1 and 2 received 10 and $100 \mu \mathrm{g}$ of each PAH / $\mathrm{kg}$ of fish respectively. The experiment lasted 6 weeks. Three perch per group per week were killed. Muscles were frozen $\left(-20^{\circ} \mathrm{C}\right)$ and lyophilized. PHE, PYR, B(a)P and their monohydroxylated metabolites $(1,2,3$ and 4-OH-PHE, 1-OH-PYR, 3-OH-B(a)P) were liquid-liquid extracted, SPE purified and also analyzed by HPLC-Fluorimetry. 


\section{Results}

Fish already displayed concentrations of PYR $(10 \mathrm{ng} / \mathrm{g} \mathrm{dw})$ and PHE (30 ng/g dw) at the beginning of the experimentation (before exposition). PYR and B(a)P were not accumulated in perch muscle during the 6 weeks whatever the doses. Besides, PHE concentration did not vary in the control group and the group 1. However, for the group 2, the level of PHE increased during 3 weeks $(70.7 \mathrm{ng} / \mathrm{g} \mathrm{dw})$ and then levelled off (62 ng/g dw). For metabolites, 3-OH-B(a)P was not detected and 1-OH-PYR increased after 3 weeks $(2 \mathrm{ng} / \mathrm{g} \mathrm{dw})$, only for the group 2. The total of OH-PHE maintained to $8 \mathrm{ng} / \mathrm{g} \mathrm{dw}$ for both control and group 1. For the fish of group 2, the total of OH-PHE increased after 4 weeks of exposure (18 ng/g dw). 1 and 2-OH-PHE were the most important even in the control group. On the other hand, 4 and 3-OH-PHE may be indicators of low PHE pollution, because they appeared only in contamination conditions.

\section{$\underline{\text { Conclusion }}$}

Following a doping of pellets by PHE, PYR and $\mathrm{B}(\mathrm{a}) \mathrm{P}$ mixtures at 2 levels (10 and $100 \mu \mathrm{g}$ of each PAH / $\mathrm{kg}$ of fish), both parent PAHs and metabolites transfers by the trophic way stayed low in perch muscle.

\section{$\underline{\text { References }}$}

Liang Y., Tse M.F., Young L., Wong M.H., 2007. Distribution patterns of polycyclic aromatic hydrocarbons (PAHs) in the sediments and fish at Mai Po Marshes Nature Reserve, Hong Kong. Water Research, 41, 1303-1311. 


\title{
Induced artificial and semiartificial spawning by Supergestran IN perch (Perca fluviatilis L.) under different temperature
}

\author{
POLICAR Tomas $\left({ }^{*}\right)$, KOURIL Jan and HAMACKOVA Jitka
}

University of South Bohemia, Research Institute of Fish Culture and Hydrobiology, Zatisi 728/II, 38925 Vodnany, Czech Republic.

${ }^{*}$ Corresponding author. Tel.: +420 383382402

E-mail address: policar@vurh.jcu.cz (T. Policar).

\section{$\underline{\text { Introduction }}$}

Intensive culture of perch requires some mechanism for controlling reproduction. Synchronization of ovulation in females is one possibility for controlled reproduction in perch (Dabrowski et al., 1994). Therefore the artificial inducted ovulation using different hormones were studied in perch (Kouril and Hamackova, 1999; Kucharczyk et al., 1998). Nevertheless, this induction of ovulation is still not a common practice in perch (Kouril and Linhart, 1997).

\section{Material and Methods}

In total, 4 groups of broodstok were used to test of semiartificial and artificial spawning under different temperature $\left(10 \pm 0.2^{\circ} \mathrm{C}\right.$ and $15 \pm 0.2$ ${ }^{\circ} \mathrm{C}$ ) in perch. All females were injected intramuscularly by uniform hormonal treatment (Supergestran preparation, $50 \mu \mathrm{g} \mathrm{GnRHa}$. $\mathrm{kg}-1$ BW). Males were not hormonally treated. After spawning, time of latency, female's fecundity, hatching rates and broodstock survival rates were found in tested groups. All realized values were compared among all groups by ANOVA, Tucky's multiple comparison test $(P<$ $0.05)$.

\section{Results and conclusions}

Longer latency was found in semiartificial compared to artificial spawning under both temperatures (under $10^{\circ} \mathrm{C}$ about $14.5 \pm 1.1 \mathrm{~h}$ and under $15^{\circ} \mathrm{C}$ about $57.6 \pm 5.2 \mathrm{~h}$ ). Very similar fecundity of females was found in all groups. The highest hatching success $(72.9 \pm 12.3 \%)$ was found in semiartificial spawning under $15{ }^{\circ} \mathrm{C}$. The lowest hatching success $(46.1 \pm 9.8 \%)$ was recorded after artificial spawning under 10 ${ }^{\circ} \mathrm{C}$. During semiartificial and artificial spawning, low mortality rates were found in males $(0 \pm 0 \%$ and $10 \pm 2.5 \%)$ and females $(15 \pm 2.5 \%$ and $17 \pm 4 \%$ ). However, very high mortality rates were evident in both sex (females $99 \pm 2.5 \%$ and $95 \pm 2.5 \%$ and males $85 \pm 2.5 \%$ and $92 \pm 2.5$ \%) 90 days after artificial and semiartificial spawning. 


\section{Acknowledgements}

This study was supported by projects: COOP-CT-2004, 512629; MSM6007665809; NAZV QF 4118 and QH 71305.

\section{$\underline{\text { References }}$}

Dabrowski K., Ciereszko A., Ramseyer L., Culver D., Kestemont P., 1994. Effect of hormonal treatment on induced spermiation and ovulation in the yellow perch (Perca flavescens). Aquaculture, 120, 171-180.

Kouril J., Linhart O., 1997. Temperature effect on hormonally induced spawning in perch (Perca fluviatilis). Pol. Arch. Hydrobiol., 44, 197202.

Kouril J., Hamackova J., 1999. Artificial propagation of european perch (Perca fluviatilis) by means of a $\mathrm{GnRH}$ analogue. Czech J. Anim. Sci., 44, 309-316.

Kucharczyk D., Kujawa R., Mamcarz A., Skrzypczak A., 1998. Induced spawning in perch, Perca fluviatilis L., using FSH + LH with pimozide or metoclopramide. Aquaculture Res. 29, 131-136. 


\title{
Deadhesion of the eggs of pikeperch (Sander lucioperca L.)
}

\author{
RÓNYAI András and GÁL Dénes
}

Research Institute for Fisheries, Aquaculture and Irrigation, Anna-liget 8., Szarvas, H-5541, Hungary. Tel.: +36 66515 320; E-mail address: ronyaia@haki.hu

\section{Introduction}

The fertilised eggs of pikeperch are rapidly sticking; therefore the elimination of "egg sticking" is an important factor for its artificial reproduction and the successful incubation of eggs. Our objective was to compare the effectiveness of different deadhesion treatments.

\section{Material and methods}

Eggs were stripped from four females and were divided into five portions immediately after the fertilisation. The first lot of the eggs was treated with the Woynarovich-solution $(40 \mathrm{~g}$ salt and $30 \mathrm{~g}$ urea $/ 10 \mathrm{~L}$ of water) for $60-80 \mathrm{~min}$. The second lot was treated similarly, but at the end tannic-acid treatment ( $5 \mathrm{~g} / 10 \mathrm{~L}$ of water) for 20 seconds was applied. The third lot was treated with the above salt-urea solutions for 10 minutes then the modified Woynarovich-solution $(40 \mathrm{~g} \mathrm{NaCl}+150 \mathrm{~g}$ urea/10 $\mathrm{L}$ of water) was gradually added and stirred by 10 minutes intervals for 2 minutes/case. The fourth lot was treated by the same way but tannic-acid treatment also was applied. The fifth lot were treated with starch solution (500 g starch per $1 \mathrm{~L}$ of water). After treatments the eggs were incubated in $8 \mathrm{~L}$ Zuger-jars.

\section{$\underline{\text { Results and discussion }}$}

Results are summarised in Table 1. Significant percent from the tannic-acid group hatched with the egg shell over the head and they began to die from the third day. For deadhesion both starch and saltcarbamide solutions can be succesfully used. The modified Woynarovich-solution proved advantageous because handling time can be reduced; shorter stirring time was necessary in this treatment. The tannic-acid treatment produced fewer pike-perch larvae and these eggs required more time to hatch. Such delayed hatching period could result in a significant size difference after few days of hatching (Krise et al., 1986). 
Table 1. Results of different egg deadhesion treatments on pikeperch hatching

\begin{tabular}{|l|l|l|l|l|}
\hline Treatment & \multicolumn{2}{|l|}{ Hatching time (hours) } & $\begin{array}{l}\text { Hatching } \\
\text { rate } \%\end{array}$ \\
\hline & Beginning & End & Duration & \\
\hline Woynarovich & $73 \pm 7 \mathrm{~b}$ & $124 \pm 12 \mathrm{~b}$ & $49 \pm 9 \mathrm{~b}$ & $84 \pm 5 \mathrm{~b}$ \\
\hline Woynarovich + tannin & $98 \pm 3 \mathrm{a}$ & $173 \pm 20 \mathrm{a}$ & $75 \pm 15 \mathrm{a}$ & $66 \pm 12 \mathrm{a}$ \\
\hline Modified Woynarovich & $76 \pm 9 \mathrm{~b}$ & $139 \pm 11 \mathrm{~b}$ & $53 \pm 7 \mathrm{~b}$ & $89 \pm 7 \mathrm{~b}$ \\
\hline $\begin{array}{l}\text { Mod. Woynarovich + } \\
\text { tannin }\end{array}$ & $93 \pm 5 \mathrm{a}$ & $163 \pm 8 \mathrm{a}$ & $70 \pm 9 \mathrm{a}$ & $70 \pm 11 \mathrm{a}$ \\
\hline Starch & $68 \pm 3 \mathrm{~b}$ & $118 \pm 5 \mathrm{~b}$ & $50 \pm 5 \mathrm{~b}$ & $91 \pm 7 \mathrm{~b}$ \\
\hline $\begin{array}{l}\text { No treatment (incubation } \\
\text { in nest) }\end{array}$ & $70 \pm 10 \mathrm{~b}$ & $120 \pm 10 \mathrm{~b}$ & $50 \pm 9 \mathrm{~b}$ & $90 \pm 10 \mathrm{~b}$ \\
\hline
\end{tabular}

1 Values within the columns with different superscripts are significantly different $(P<0.05)$.

\section{$\underline{\text { Conclusions }}$}

Despite the successful elimination of the egg adhesiveness by the applied substances more studies are needed to increase the effectiveness of this process. Other chemicals (i.e. protease enzymes) and methods (i.e. air-stirring) should be tested in order to reduce the handling time and increase the hatching and survival rates of the fries.

\section{$\underline{\text { References }}$}

Krise, W. F., Cummings, L. B., Shellman, A. D., Kraus, K. A. and Gould, R. W., 1986. Increased walleye egg hatch and larval survival after protease treatment of eggs. The Progressive Fish-Culturist 48, 95-100. 


\section{Developing Genetically Defined Yellow Perch (Perca flavescens) Broodstocks}

ROSAUER D. ${ }^{1 *}$, GRZYBOWSKI M. ${ }^{1}$, BINKOWSKI F. ${ }^{1}$, SHEPHERD B. $^{2}$, GOETZ F. ${ }^{1 *}$

${ }^{1}$ Great Lakes WATER Institute, University of Wisconsin-Milwaukee, 600 E. Greenfield Ave. Milwaukee, WI 53204, USA.

${ }^{2}$ Great Lakes WATER Institute/ARS/USDA, 600 E. Greenfield Ave. Milwaukee, WI 53204, USA.

* Corresponding author. Tel.: 00-1-414-382-1751

E-mail address: drosauer@uwm.edu (D. Rosauer)

Yellow Perch are an ecologically and economically important species common in Midwest commercial aquaculture. Broodstocks are traditionally derived from wild populations locally accessible to the producer. This can lead to inconsistencies in the success of producers within and between regions. Successful aquaculture depends on local stocks possessing multiple desirable traits including: fast growth, resistance to disease, and high fecundity. To breed for these traits, it is necessary to have a genetically defined broodstock in which the genetic variability is known. We have initiated a program to establish genetically defined yellow perch broodstocks for commercial perch aquaculture.

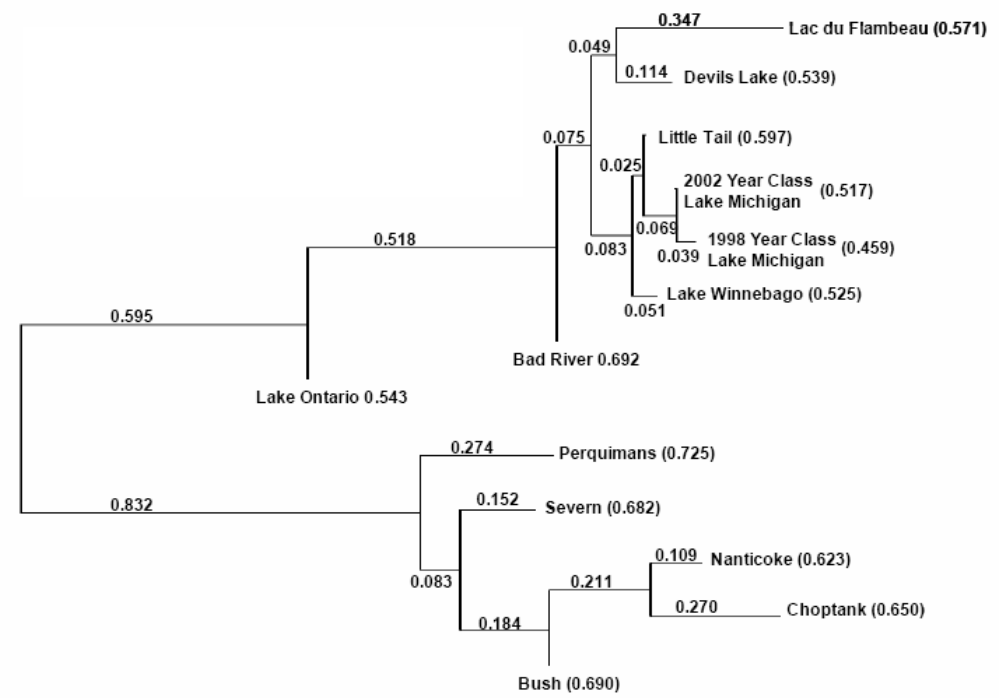

Figure 1. Phylogenetic tree of perch populations indicating genetic distances (on lines). Numbers in parentheses following population names are average observed 
To establish these broodstocks, several steps are being taken including 1) genetic analysis of various wild perch populations throughout North America; 2) spawning from desirable populations to obtain F1 broodstocks; 3) performance trials; and 4) selective breeding.

1. Genetic Analysis: Fin clips were obtained from 12 wild populations ranging from the upper Midwest to the Atlantic Coast. Analysis was completed using published and newly derived microsatellite markers (Figure 1).

2. Spawning to produce $\mathrm{F} 1$ generations: From the microsatellite results we chose the Perquimans River (North Carolina, Atlantic Coast), Choptank River (Maryland, Chesapeake Bay), and Lake Winnebago (Wisconsin, upper Midwest) to obtain gametes for F1 generations (14-34 pairwise crosses of wild adults/population).

3. Performance trial: The performance trial consists of 4 replicate tanks of 650 juveniles/tank from each population raised under identical conditions in flow-through tanks until market size ( 14 months). After obtaining market size, the top performers $(20 \%)$ within each population will be crossed to produce a F2 generation for future selection.

Supported by NOAA Sea Grant and ARS/USDA 


\title{
Dry Feed Adaption and Rearing of one-year old Eurasian Perch (Perca fluviatilis) fed with dry feed with varying oil supplementation
}

\author{
SCHMIDT Gregor(*) and WEDEKIND Helmut
}

Bavarian Federal State Centre for Agriculture, Institute for Fisheries, Weilheimer Str. 8, 82319 Starnberg, Deutschland corresponding author. Tel.: +49 (0)8151 2692142

E-mail address: gregor.schmidt@|fl.bayern,de

\section{$\underline{\text { Introduction }}$}

The conventional fisheries of Eurasian Perch possesses only small available capacities in Western Europe and can not saturate the demand. Due to this bottleneck Eurasian Perch has become a promising candidate for intensive culture in the last years. The supply of fingerlings adapted to dry feed is essential to establishing the production of Eurasian Perch under intensive rearing conditions. Today the artificial reproduction is basically possible, but success can not be assured every time. Another possibility to get adequate fingerlings is the adaption of pond raised juvenile perch to dry feed.

\section{Rearing}

One-year old perch with an individual weight of $3.2 \mathrm{~g}$ were caught in a carp pond and transferred into aquaculture facilities (flow-through system, $21^{\circ} \mathrm{C}$ ). After two days of acclimation fish were fed frozen Chaoborus spp. larvae combined with a artificial dry feed diet. The dry feed fraction of the diet was increased daily. After six days of adaption fish were transfered into grow-out tanks and were fed different diets for 115 days (in triplicates). One group (B) received a basal diet, composed from a fishmeal dominated, basal diet (64\% crude protein, $10 \%$ crude fat, containing mainly fish oil), three groups received the experimental diet supplemented with $8 \%$ sunflower oil (SFO), cod liver oil (CLO) and tuna oil (TO), respectively. A reference group was fed natural food $(\mathrm{N})$ consisting of Chaoborus spp. larvae. Growth, survival, food conversion ratio, body composition and fatty acid composition were determined.

\section{$\underline{\text { Results }}$}

Perch endured the transfer into the tanks without severe impairment. After acclimation perch learned to take up dry feed within one week and approximately $95 \%$ of the fish accepted the new diet. The Ngroup showed low growth and survival was poor. Feeding the fish with higher fat content improved growth, lowered the feed conversion ratios, and resulted in a lower mortality compared to group B. However, due to the different individual growth, no significant 
differences between the groups receiving dry feeds could be observed.

\section{Conclusions}

The investigation confirmed the high growth potential of Eurasian Perch under intensive conditions. Dry feed adaption is an alternative way for intensive perch culture. However, further research is needed concerning the rearing of pond raised perch fingerlings in intensive systems to protect fish from infections, and protective therapies need to be developed. It also can be concluded, that in the case of Eurasian Perch the substitution of rather expensive fish oils by plant oil is possible to some extent. 
The influence of environmental conditions of spawning success of pikeperch (Sander lucioperca I.)

TARGOŃSKA Katarzyna ${ }^{1 *}$ KUCHARCZYK Dariusz 1, SZCZERBOWSKI Andrzej ${ }^{2}$, ŁUCZYŃSKI Marek $^{2}$, SZKUDLAREK Maciej $^{1}$, KWIATKOWSKI Maciej $^{1}$

1 Department of Lake \& River Fisheries, Warmia and Mazury University in Olsztyn, ul. Oczapowskiego 5, PL-10-718 OlsztynKortowo, Poland

${ }^{2}$ Inland Fisheries Institute, Olsztyn, Poland

${ }^{*}$ Corresponding author. Tel.: + 488952344 36, E-mail address: targonska.k@gmail.com (K. Targońska)

\section{Introduction}

Pikeperch are usually spawned naturally in earthen ponds on the ground (bottom) or on the nests. This fish species are very sensitive, mainly for the stress. The aim of this study was investigate on influence on environmental conditions of pikeperch spawning success.

\section{$\underline{\text { Different Environments }}$}

Experiments were conducted with wild breeders held during a whole annual cycle in three different conditions (small ponds, cages or tanks) and, in each stocking conditions, fed with prey fish. On the spring the nest from artificial grass were placed to the ponds, cages or tanks as a substrate for laying eggs. All fish from both sexes before spawning were stimulated using hCG (Zakes and Szczepkowski 2004) at dose $750 \mathrm{IU} / \mathrm{kg}$.

\section{$\underline{\text { Results }}$}

The highest percentage on ovulated females was noted at tanks, where all live fish spawned (Fig. 1). Also, the highest embryo survival was noted at the same group.

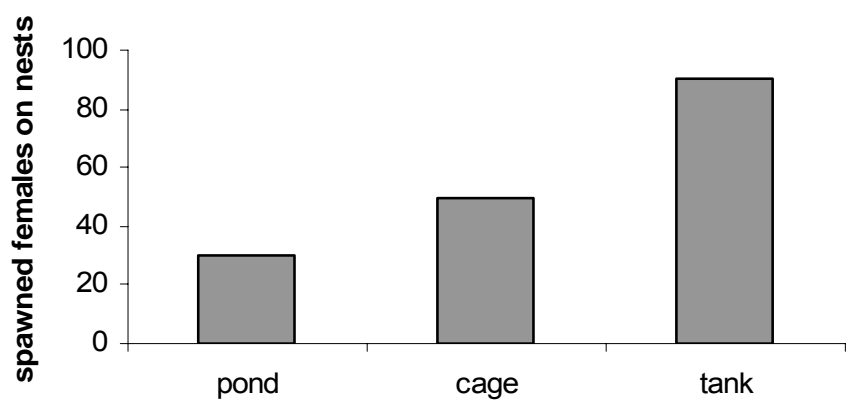

Fig. 1. The percentage on spawned pikeperch in different conditions. 
The highest spawners mortality was noted in fish kept at cages, the lowest at tanks.

\section{$\underline{\text { Conclusions }}$}

The best results were obtained at fish group kept at tanks. Probably, the stress during spawning time was lower for fish from this group.

\section{$\underline{\text { References }}$}

Zakes Z., Szczepkowski M., 2004. Induction of out-of-season spawning of pikeperch, Sander lucioperca (L.). Aquaculture International 12, 11-18. 
Application of new spawning agents in artificial reproduction of pikeperch (Sander lucioperca I.)

TARGOŃSKA Katarzyna ${ }^{1 *}$ KUCHARCZYK Dariusz ${ }^{1}$, KREJSZEFF Sławomir ${ }^{1}$, KWIATKOWSKI Maciej ${ }^{1}$, SZCZERBOWSKI Andrzej ${ }^{2}$, ŁUCZYŃSKI Marek ${ }^{2}$, SZKUDLAREK Maciej ${ }^{2}$

1 Department of Lake \& River Fisheries, Warmia and Mazury University in Olsztyn, ul. Oczapowskiego 5, PL-10-718 OlsztynKortowo, Poland

${ }_{2}^{2}$ Inland Fisheries Institute, Olsztyn, Poland

*Corresponding author. Tel.: + 48895234436

E-mail address: targonska.k@gmail.com (K. Targońska)

\section{Introduction}

In fish artificial reproduction, the obtaining high quality gametes, is one of the most important problem. For this reason different new techniques and new spawning agents are tested for many fish species (Ronyai 2007). The aim of this study was to test two spawning agents: Ovaprim and PG- 600 in artificial pikeperch reproduction in comparison to hCG, the spawning agent which worked very well in this species (Zakes and Szczepkowski 2004).

\section{Material and Methods}

The pikeperch spawners were collected from open waters near Olsztyn (north Poland). After catching the selected fish were transported to the university hatchery, when fish obtain spawning agents: Ovaprim at dose $0.5 \mathrm{ml} / \mathrm{kg}$, at PG-600 at dose $600 \mathrm{lU} / \mathrm{kg}$. As a control group was treated fish stimulated by hCG at dose $500 \mathrm{IU} / \mathrm{kg}$. Eggs and milt were stripped manually. The water temperature at the hatchery was $14.8+0.1^{\circ} \mathrm{C}$.

\section{$\underline{\text { Results }}$}

The obtained results are presented in Table 1. The best noted parameters, such as percentage of ovulated females, females survival and embryo survival on the 3rd day of incubation were observed in control group, where hCG was applied. 
Table 1. Results from testing new spawning agents in pikeperch artificial reproduction.

\begin{tabular}{|l|l|l|l|}
\hline & Ovaprim & PG-600 & hCG \\
\hline No. of females & 10 & 10 & 10 \\
\hline Ovulation (\%) & 60 & 80 & 90 \\
\hline $\begin{array}{l}\text { Embryo survival } \\
(\%)^{*}\end{array}$ & $56.1+7.8 \mathrm{a}$ & $60.1+9.7 \mathrm{a}$ & $80.5+5.7 \mathrm{~b}$ \\
\hline $\begin{array}{l}\text { Females survival } \\
(\%)\end{array}$ & 60 & 60 & 80 \\
\hline
\end{tabular}

* - data marked with the same letter did not differ statistically (post hoc Tuckey test, $\alpha=0.05$ )

\section{Conclusions}

The tested spawning agents: Ovaprim and PG-600 might be used in pikeperch artificial reproduction, but after application hCG the better results were noted.

\section{$\underline{\text { References }}$}

Ronyai, A., 2007. Induced out-of-season and seasonal tank spawning and stripping of pike perch (Sander lucioperca L.). Aquaculture Research, 1-8 (OnlineEarly Articles doi:10.1111/j.13652109.2007.01778.x).

Zakes Z., Szczepkowski M., 2004. Induction of out-of-season spawning of pikeperch, Sander lucioperca (L.). Aquaculture International 12, 11-18. 


\title{
Effects of four factors on the quality of the male reproductive cycle in pikeperch Sander lucioperca.
}

\author{
TELETCHEA Fabrice ${ }^{1}$, PSENICKA Martin ${ }^{2}$, KASPAR Vojtich ${ }^{2}$, LE \\ DORE Yannick ${ }^{1}$, GARDEUR Jean-Noël ${ }^{1}$, LINHART Otomar $^{2}$, and \\ FONTAINE Pascal ${ }^{1}$ \\ ${ }^{1}$ nité de Recherche Animal et Fonctionnalités des Produits Animaux, \\ Nancy-Université, INRA, 2 avenue de la Forêt de Haye B.P. 172 F- \\ 54505 Vandoeuvre lès nancy \\ ${ }^{2}$ University of South Bohemia České Budějovice, Research Institute of \\ Fish Culture and Hydrobiology, Zátiší 728/ll, 38925 Vodňany, Czech \\ Republic
}

\section{Introduction}

A multiplicity of factors could modulate the quality of gonadogenesis (Wang et al., 2006). The main objective of this study was thus to improve the broodstock management of pikeperch Sander lucioperca during an entire reproductive cycle using a fractional factorial design, which allows testing several factors simultaneously.

\section{Materials and Methods}

A batch of 136 fish coming from Excellence Fish (The Netherlands) were equally distributed on October $18^{\text {th }}$ into eight $3 \mathrm{~m}^{3}$ outdoor tanks (16-18 fish per tank, age: $2^{+}$) in an isolated $40 \mathrm{~m}^{3}$ recirculating system and reared over 10 months. Four factors with two modalities were tested, namely the initial nutritional status of breeders prior to the beginning of the gametogenesis cycle, i.e. applied from July until midOctober (low or high reserves), the photoperiodic treatment (natural or natural simulated), the food type (pellets or forage fish) and the feeding rate (ad libitum or restricted). The last three factors were applied on October $23^{\text {rd }}$. Three samplings were realized on all fish on April $4^{\text {th }}, 16^{\text {th }}$ and $24^{\text {th }}$.

\section{$\underline{\text { Results and discussion }}$}

The influence of the four tested factors on the quality of gametogenesis in males was determined. Among the 16 variables analyzed for five males per tank, eight appeared significantly influenced by the four tested factors, i.e., variation of weight, variation of condition factor $(\mathrm{k})$, the frequency (\%) of non spermiating males on April $4^{\text {th }}$, the frequency (\%) of slightly spermiating males on April $4^{\text {th }}$, the frequency $(\%)$ of spermiating males on April $4^{\text {th }}$, the concentration of spermatozoa, the motility at $15 \mathrm{~s}$ and $45 \mathrm{~s}$. The initial reserves appeared to be the most influential factor on the quality of the sperm, in term of both the concentration of spermatozoa and the motility at 15 $\mathrm{s}$, and also on the timing of spermiation (those having lots of reserves, being spermiating earlier in the season). The other three factors have 
less influence on the quality of sperm, usually in interaction with the initial nutritional status. Interestingly, a significant interaction was found between the initial amount of reserves and the food availability during autumn and winter on the difference between initial and final weight (variation of weight), i.e., pikeperch seems to change its feeding behaviour according to the modalities of these two factors.

\section{$\underline{\text { Conclusion }}$}

This study shows that the initial nutritional status highly influenced both the male condition during the spawning season and the sperm quality, whereas the type of food given during the wintering period appears less important.

\section{$\underline{\text { References }}$}

Wang, N., Gardeur, J.-N., Henrotte, E., Marie, M., Kestemont, P. and Fontaine P., 2006. Determinism of the induction of the reproductive cycle in female Eurasian perch, Perca fluviatilis: Identification of environmental cues and permissive factors. Aquaculture 261, 706714. 


\section{Ammonia toxicity in percids}

VANDECAN Michaël* , GBAMOU Pépé and MELARD Charles

CEFRA- Centre de Formation et de Recherches en Aquaculture Université de Liège, 10 Chemin de la Justice, B-4500 Tihange, Belgium

${ }^{*}$ Corresponding author. Tel.: +32 (0)85 274156

E-mail address: cefra@ulg.ac.be .

\section{$\underline{\text { Introduction }}$}

Due to the control of water quality and temperature, intensive culture of Percids in intensive recirculating system is more productive than in flowthrought one. The sizing of the recirculating system, mainly the biofilter, depend of sensitivity of the species to ammonia and nitrites. Therefore it is important to assess the effect of ammonia on the survival rate and growth performances of Percids to determine their tolerance level.

\section{Perch}

For adult perch $(140 \mathrm{~g})$, acute exposure gave an LC5096h (median lethal concentration after $96 \mathrm{~h}$ exposure) of $0.80 \mathrm{mg} / \mathrm{l} \mathrm{N}-\mathrm{NH} 3$, and chronic exposure show decrease of growth $(50 \%$ lesser than the control) from $0.03 \mathrm{mg} / \mathrm{l} \mathrm{N}-\mathrm{NH} 3\left(\mathrm{~T}^{\circ} \mathrm{C}=23.1 ; \mathrm{O} 2 \mathrm{sat}=100 \% ; \mathrm{pH}=8.1\right)$.

\section{$\underline{\text { Pike-Perch }}$}

Experimental acute exposure to ammonia of juvenile pike-perch (100 g) gave an LC5096h of $2.00 \mathrm{mg} / \mathrm{l} \mathrm{N}-\mathrm{NH} 3 .\left(\mathrm{T}^{\circ} \mathrm{C}=23.1\right.$; O2 sat $=100 \%$; $\mathrm{pH}=7.4)$.

\section{$\underline{\text { Conclusions }}$}

Percids are very sensitive to ammonia compared to others species. Perch is more sensitive than pike-perch. Growth of perch is affected by low concentrations of ammonia (27-fold lesser than the LC5096h). Maintain ammonia concentration under $0.03 \mathrm{mg} / \mathrm{l} \mathrm{N}-\mathrm{NH} 3$ during all the phases of Percids production is thus a priority, as well for survival than for growth.

\section{$\underline{\text { References }}$}

Arillo, A., Margiocco, C., Melodia, F., Mensi, P., Schenone, G., 1981. Ammonia toxicity mechanisms in fish: studies on rainbow trout (Salmo gairdneri Rich). Ecotoxicol. Environ. Saf. 5: 316-325. 
Das, P.C., Ayyapann, S., Jena J.K., Das, B.K., 2004. Acute toxicity of ammonia and its sub-lethal effects on selected haematological and enzymatic parameters of mrigal, Cirrhinus mrigala (Hamilton). Aquaculture Research 35: 134-143.

Frances, J., Nowak, B.F., Allan, G.L., 2000. Effects of ammonia on juvenile silver perch (Bidyanus bidyanus). Aquaculture 183: 95-103.

Sampath, K., Sivakumar V., Sakthivel, M., James, R., 1991. Lethal and sublethal effects of ammonia on survival and food utilization in Oreochromis mossambicus (Pisces, Cichlidae). Journal of Aquaculture in the Tropics 6: 223-230. 


\title{
Variations of the spawning quality over a spawning period in Eurasian perch Perca fluviatilis.
}

\author{
VUILLARD Jean-Thomas, WANG Neil and FONTAINE Pascal ${ }^{*}$ \\ Unité de Recherche Animal et Fonctionnalités des Produits Animaux, \\ Nancy-Université, INRA, 2 avenue de la Forêt de Haye B.P. 172 F- \\ 54505 Vandoeuvre lès Nancy
}

${ }^{*}$ Corresponding author. Tel.: +33.(0)3.83.30.28.41., Email address: pascal.fontaine@Isa-man.uhp-nancy.fr

\section{$\underline{\text { Introduction }}$}

The high variability in eggs and/or larvae quality is one of the major current bottlenecks for the development of the Eurasian perch culture. This problem is observed when you compare the egg quality of successive spawning period, but also between eggs collected into a same spawning period (Migaud et al., 2001). The regulation of the egg and initial larvae quality must be better understood. This problem appears more important when you start the domestication of a new species like perch.

\section{Materials and Methods}

Wild broodstock (106 females, 108 males, Bouzule pond) were harvested in March 2006 and transferred in an outdoor recirculated system. Fish were fed with forage fish. Fish reproduction has been either natural or artificial (by stripping, without hormonal injection, dry method). The spawning season started on April $16^{\text {th }}$. For each spawning, fecundation and hatching rates, larvae size, starvation and osmotic stress $(30,60$ and $90 \mathrm{~min}$.) resistances were calculated with triplicate trials using experimental hatcheries $\left(t=13^{\circ} \mathrm{C}\right)$. Data analysis with PCA method has been used to correlate the spawning quality to biological parameters.

\section{$\underline{\text { Results and discussion }}$}

90 egg ribbons were obtained (52 with normal eggs and 38 with white eggs) over a 2 week period. White eggs were mainly obtained during the second week of the spawning period. For the first time, we have obtained eggs without their gelatinous coat $(n=10)$, by stripping only. Due to technical problems, only 45 ribbons have been used for the PCA analysis (23 from artificial reproduction method and 22 from natural spawning). The analysis of the correlation circle showed positive correlations (i) between the rates of fertilization, hatching and larvae survival at day 7 , and (ii) between parameters measured to evaluate larvae resistance. A negative correlation was observed between the spawning time and the incubation duration. The incubation duration was more and more short (shorter and shorter) as 
the females spawn belatedly. Finally the study demonstrated clearly that the free eggs (without gelatinous coat) were associated with a lower quality (fertilization rate: 63.6 vs $94.7 \%$, hatching rate: 25.7 vs $87.9 \%)$. However, considering the quality of larvae hatched, no difference was observed, except a smaller size $(5.7$ vs $6.0 \mathrm{~mm})$. No difference in quality was recorded according to the reproduction method used (natural or artificial).

\section{Conclusion}

The study confirms that spawning obtained at the beginning of the spawning season are of higher quality. Eggs without gelatinous coat also display a bad quality, even though it does not seem to be the case for the larvae.

\section{$\underline{\text { References }}$}

Migaud H., Gardeur J.N., Fordoxcel L., Fontaine P. and J. Brun-Bellut, 2001. Influence of the spawing time during the reproductive period on the larval quality of Eurasian perch Perca fluviatilis In: E.A.S. (Ed.), Larvi 2001, September 3-6, 2001, Ghent, Belgium. E.A.S. spe. pub. 30: 371-374. 
Rates of oxygen consumption and ammonia excretion of pikeperch (Sander lucioperca (I.)) reared in a water recirculation system

\section{ZAKĘŚ Zdzisław}

Department of Aquaculture, The Stanisław Sakowicz Inland Fisheries Institute, Oczapowskiego 10, 10-719 Olsztyn, Poland

E-mail address: zakes@infish.com.pl

\section{$\underline{\text { Introduction }}$}

The production of percid fishes (stocking material and commercialsized fish) in recirculation systems is of increasing practical importance (review in Kestemont \& Mélard, 2000).

In order to stimulate the development of fish production methods, especially in recirculation systems, it is important to know a given species oxygen requirements and ammonia excretion rate. Concentrations of oxygen and ammonia are the primary limiting factors for fish stock size (production), which effectively determines profitability (e.g., Wedemeyer, 1996).

The aim of the present study was to determine the rates of oxygen consumption and ammonia production by juvenile pikeperch (Sander lucioperca (L.)) reared in a recirculation system. The study was conducted during 15 weeks of intensive pikeperch rearing on formulated feed (water temperature of $22^{\circ} \mathrm{C}$ ).

\section{Material, Methods, and Results}

Metabolic rate measurements of oxygen consumption (OC, $\mathrm{mg} \mathrm{O} 2 \mathrm{~kg}-$ $1 \mathrm{~h}-1$ ) and ammonia production (AE, mg TAN kg-1 h-1; TAN $=\mathrm{NH} 4+-$ $\mathrm{N}+\mathrm{NH} 3-\mathrm{N}$ ) were taken hourly around the clock for five size groups of pikeperch (mean body weight (BW) in groups was 1.6, 7.1, 17.3, 38.1, and $55.7 \mathrm{~g}$ ). In the fish size groups studied the mean daily values of $\mathrm{OC}$ and $\mathrm{AE}$ decreased from $701.0 \mathrm{mg} \mathrm{O} 2 \mathrm{~kg}-1 \mathrm{~h}-1$ and $38.7 \mathrm{mg}$ TAN kg-1 h-1 (BW 1.6 g) to $205.4 \mathrm{mg} \mathrm{O} 2 \mathrm{~kg}-1 \mathrm{~h}-1$ and $7.3 \mathrm{mg}$ TAN kg-1 h1 (BW $55.7 \mathrm{~g})(\mathrm{P}<0.05)$.

By analyzing the oxygen consumption and ammonia excretion of all the pikeperch size groups held at $22^{\circ} \mathrm{C}$, it was determined that the logarithmic dependence between $\mathrm{OC}, \mathrm{AE}$, and the mean body weight (BW) could be described with the following equations: $\log 10(\mathrm{OC} / \mathrm{BW})=2.92-0.35 \log 10 \mathrm{BW} ;(\mathrm{R} 2=0.98)$ $\log 10(A E / B W)=1.70-0.43 \log 10 B W ;(R 2=0.95)$. 


\section{$\underline{\text { Conclusions }}$}

Knowing the $\mathrm{OC}$ and $\mathrm{AE}$ rates permits modeling the quantity of fish production and monitoring water quality parameters appropriately. Knowledge of the course of daily oxygen consumption and ammonia excretion is also of measurable practical importance. It allows identifying when the maximum values of $O C$ and $A E$ occur; and these parameters determine the quantity of production. With the preceding information, certain situations can be foreseen which renders the entire rearing process safer and more predictable.

\section{$\underline{\text { References }}$}

Kestemont P., Mélard C., 2000. Aquaculture. In: Percid fishes systematics, ecology and exploitation (Ed.) J.F. Craig, Blackwell Science, Oxford, 191-224.

Wedemeyer G.A., 1996. Physiology of fish in intensive culture systems. Chapman \& Hall, London, 232 p. 
Slaughter value and flesh characteristics of wild and cultured pikeperch (Sander lucioperca (I.))

\author{
ZAKĘŚ Zdzisław ${ }^{1 *}$, JANKOWSKA Barbara ${ }^{2}$ \\ ${ }^{1}$ Department of Aquaculture, The Stanisław Sakowicz Inland Fisheries \\ Institute, Oczapowskiego 10, 10-719 Olsztyn, Poland \\ ${ }^{2}$ Chair of Meat Technology and Chemistry, University of Warmia and \\ Mazury in Olsztyn, Plac Cieszyński, 10-718 Olsztyn-Kortowo, Poland \\ *Corresponding author - E-mail address: zakes@infish.com.pl

\section{Introduction}

The fundamental criterion for deciding whether or not a given species is introduced into aquaculture is the quality of the final product (e.g., organoleptic qualities and chemical composition of the meat). It is known that the quality indicators of meat are determined mainly by feed (e.g., Jobling, 2001). Pikeperch (Sander lucioperca (L.)) is a species that might be suitable for production under intense rearing on commercial feed. Under natural conditions they are piscivorous, and replacing this diet with commercial feed (e.g., trout pellets) may modify meat quality and slaughter value.

The current study compares the slaughter value and chemical composition of wild fish (from lakes) with individuals reared in recirculating systems and fed exclusively on commercial feed.

\title{
Material, Methods, and Results
}

The mean body weights (BW) of the wild (group W) and reared (group C) fish was similar ( $>$ > 0.05; group $\mathrm{W}-1.19 \mathrm{~kg}$, group $\mathrm{C}-1.10 \mathrm{~kg}$ ). The fish from group $\mathrm{C}$ were fed feed containing $46 \%$ protein and $11 \%$ fat with a digestible energy of $17.0 \mathrm{MJ} \mathrm{kg}-1$. The slaughter values (skinless fillets) of fish C and W were similar at 48.1 and $51.3 \%$ BW, respectively $(P>0.05)$. The proximate composition of the fillets from the two fish groups differed significantly with regard to fat content (group C $-2.9 \%$, group $\mathrm{W}-1.0 \%$; $\mathrm{P}<0.05$ ). This is also why differences in the caloric value between the groups were noted $(P<$ 0.05 ; groups $\mathrm{C}$ and $\mathrm{W} 424$ and $338 \mathrm{~kJ} 100 \mathrm{~g}-1$ of fillet, respectively; Jankowska et al., 2003). The meat of pikeperch from the two groups contained similar amounts of saturated fatty acids (SFA). Differences were confirmed when monoenoic (MUFA) and polyenoic (PUFA) acids were compared. The fillets from fish $\mathrm{C}$ contained more MUFA (31.4 vs. $21.4 \%$ of all the fatty acids), and less PUFA (41.1 vs. $50.8 \%$ ). It was not confirmed that the applied diet had a significant impact on the PUFA content, which is particularly important for humans. These are eicosapentaenoic (EPA; 20:5n-3) and docosahexaenoic (DHA; 22:6n3) $(P>0.05)$. 


\section{$\underline{\text { Conclusions }}$}

Feeding pikeperch commercial feed did not have a significant impact on slaughter value or on the contents of PUFA n-3 (EPA and DHA), which are a particularly important group of acids for humans.

\section{$\underline{\text { References }}$}

Jankowska B., Zakęś Z., Żmijewski T., Szczepkowski M., 2003. A comparison of selected quality features of the tissue and slaughter value of wild and cultivated pikeperch Sander lucioperca (L.). European Food Research and Technology 217, 401-405.

Jobling, M., 2001. Nutrient partitioning and influence of feed composition on body composition. In: Food intake in fish (Eds.) D. Houlihan, T. Boujard, M. Jobling. Blackwell Science Ltd., 354-375. 
A

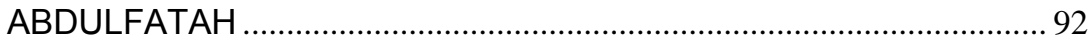

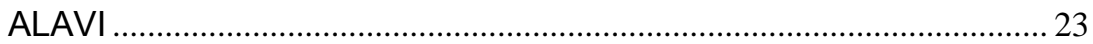

ANTONINI ............................................................................ 100

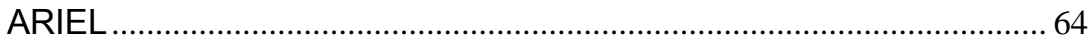

$B$

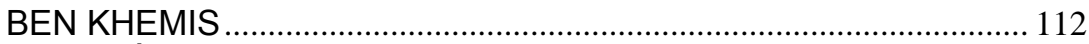

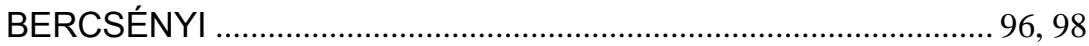

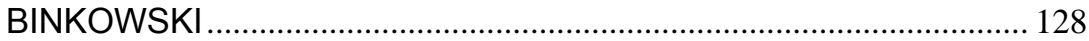

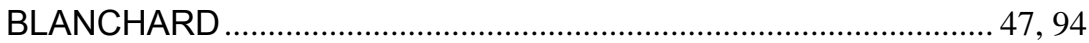

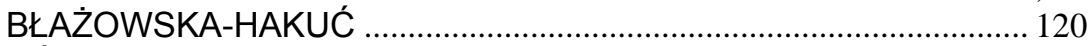

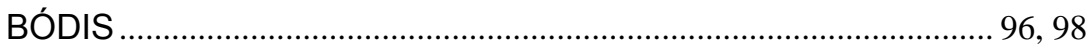

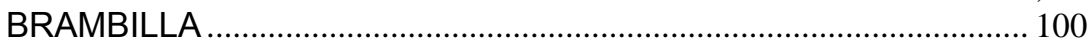

BRUN-BELLUT …………………………………………….... 59, 122

C

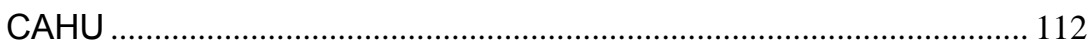

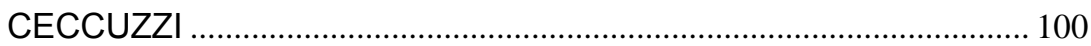

D

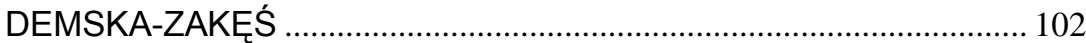

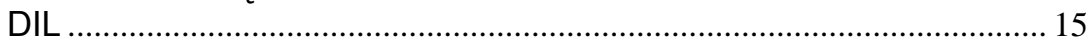

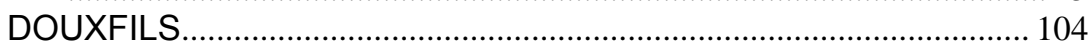

F

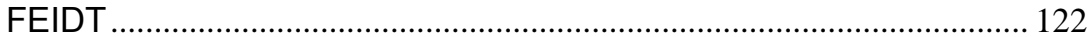

FONTAINE ……………………………………...... 19, 92, 136, 140

G

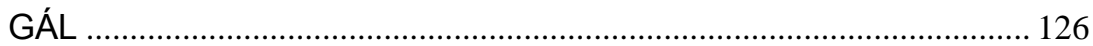

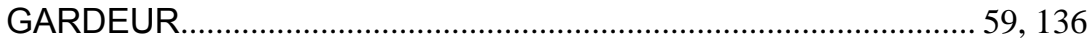

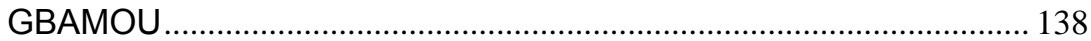

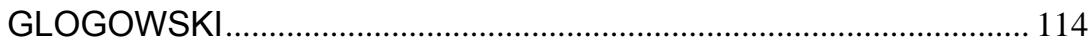

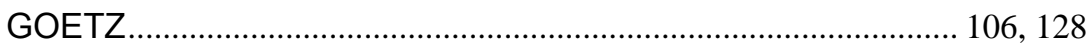

GOMUŁKA..................................................................... 108, 116

GRZYBOWSKI.................................................................. 106, 128

$\boldsymbol{H}$

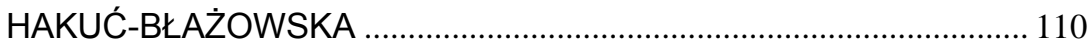

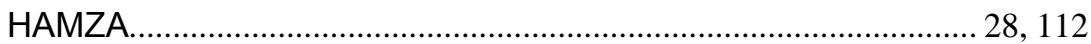

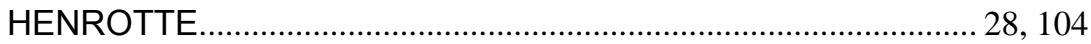

I

ITTZÉS 


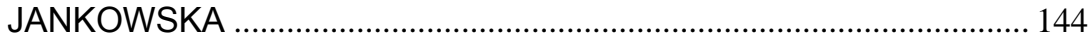

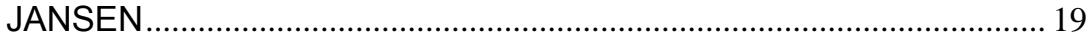

K

KASPAR

KESTEMONT

28, 47, 94, 104, 112

KOURIL

KREJSZEFF

118,134

KROL. 114

KUCHARCZYK $.40,108,110,116,118,120,132,134$

KUJAWA 116

KUPREN 110,120

KWIATKOWSKI $108,116,132,134$

$L$

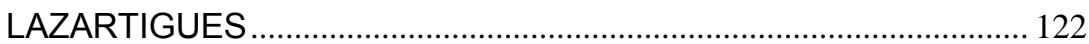

LE DORE.

LINHART

23, 136

ŁUCZYŃSKI $116,118,132,134$

$M$

M'HETLI

MAIRESSE

MALISON

MAMCARZ

MANDIKI

MARIE

MAROTTE

MARTIN

MELARD $35,53,104,138$

$\ddot{O}$

ÖBERG

$O$

OVERTON 28, 40

$P$

PAULSEN 28, 40

PHILIPSEN

POLICAR. 23, 124

PSENICKA

\section{R}

RODINA 
$S$

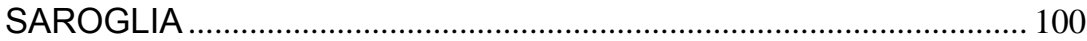

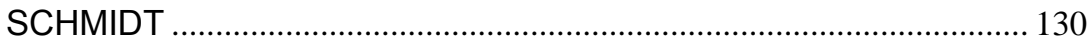

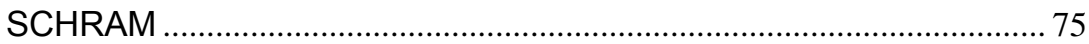

SHEPHERD ……………………………………............ 106, 128

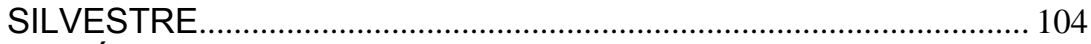

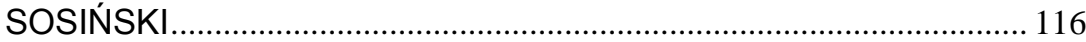

SZCZERBOWSKI................................................... 40, 116, 118, 132, 134

SZKUDLAREK ……………………………………... 116, 118, 132, 134

$T$

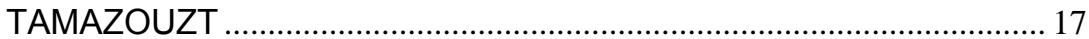

TARGOŃSKA ……………………..........108, 110, 116, 118, 120, 132, 134

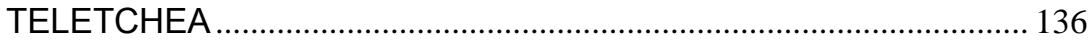

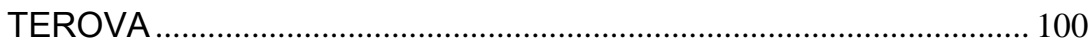

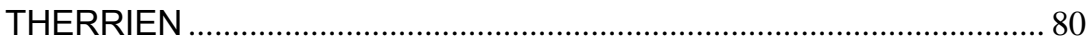

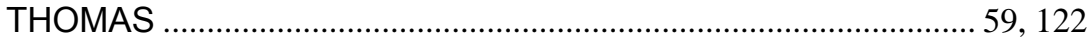

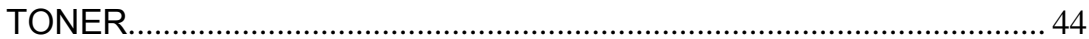

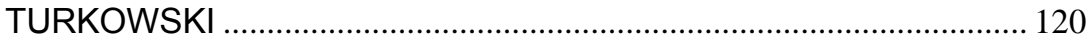

$\checkmark$

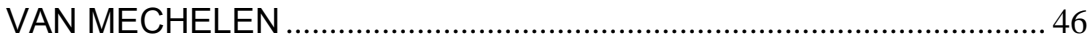

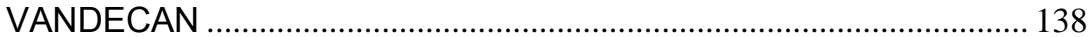

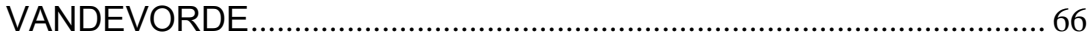

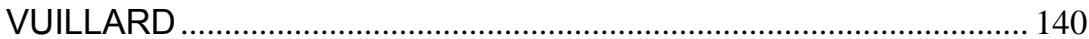

$W$

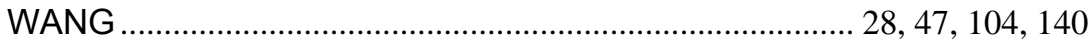

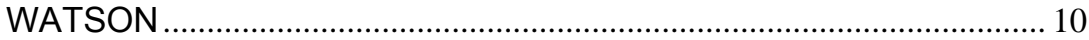

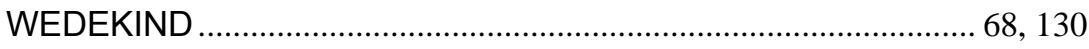

Z

ZAKĘŚ

102, 142, 144 
Notes 
Notes 